Check for updates

Cite this: Phys. Chem. Chem. Phys., 2018, 20, 24263

Received 18th April 2018, Accepted 1st August 2018

DOI: $10.1039 / c 8 c p 02473 a$

rsc.li/pccp

\section{Chemical kinetics in an atmospheric pressure helium plasma containing humidity $\dagger$}

\author{
Sandra Schröter, (D) *a Apiwat Wijaikhum, ID * $^{a}$ Andrew R. Gibson, (D) ab \\ Andrew West, (iD $\S^{a}$ Helen L. Davies, (iD ac Nicolas Minesi, $\boldsymbol{q}^{a}$ James Dedrick, (ID a \\ Erik Wagenaars, iD a Nelson de Oliveira, ' Laurent Nahon, 'Mark J. Kushner, (iD) \\ Jean-Paul Booth, (D) ${ }^{b}$ Kari Niemi, (D) a Timo Gans (D) a and Deborah $\mathrm{O}^{\prime}$ Connell (iD ${ }^{a}$
}

\begin{abstract}
Atmospheric pressure plasmas are sources of biologically active oxygen and nitrogen species, which makes them potentially suitable for the use as biomedical devices. Here, experiments and simulations are combined to investigate the formation of the key reactive oxygen species, atomic oxygen (O) and hydroxyl radicals $(\mathrm{OH})$, in a radio-frequency driven atmospheric pressure plasma jet operated in humidified helium. Vacuum ultra-violet high-resolution Fourier-transform absorption spectroscopy and ultra-violet broad-band absorption spectroscopy are used to measure absolute densities of $\mathrm{O}$ and $\mathrm{OH}$. These densities increase with increasing $\mathrm{H}_{2} \mathrm{O}$ content in the feed gas, and approach saturation values at higher admixtures on the order of $3 \times 10^{14} \mathrm{~cm}^{-3}$ for $\mathrm{OH}$ and $3 \times 10^{13} \mathrm{~cm}^{-3}$ for $\mathrm{O}$. Experimental results are used to benchmark densities obtained from zero-dimensional plasma chemical kinetics simulations, which reveal the dominant formation pathways. At low humidity content, $\mathrm{O}$ is formed from $\mathrm{OH}^{+}$by proton transfer to $\mathrm{H}_{2} \mathrm{O}$, which also initiates the formation of large cluster ions. At higher humidity content, $\mathrm{O}$ is created by reactions between $\mathrm{OH}$ radicals, and lost by recombination with $\mathrm{OH}$. $\mathrm{OH}$ is produced mainly from $\mathrm{H}_{2} \mathrm{O}^{+}$by proton transfer to $\mathrm{H}_{2} \mathrm{O}$ and by electron impact dissociation of $\mathrm{H}_{2} \mathrm{O}$. It is lost by reactions with other $\mathrm{OH}$ molecules to form either $\mathrm{H}_{2} \mathrm{O}+\mathrm{O}$ or $\mathrm{H}_{2} \mathrm{O}_{2}$. Formation pathways change as a function of humidity content and position in the plasma channel. The understanding of the chemical kinetics of $\mathrm{O}$ and $\mathrm{OH}$ gained in this work will help in the development of plasma tailoring strategies to optimise their densities in applications.
\end{abstract}

\section{Introduction}

The interaction of non-thermal atmospheric pressure plasmas (APPs) with biological matter and their potential applications

\footnotetext{
${ }^{a}$ York Plasma Institute, Department of Physics, University of York, Heslington, York YO10 5DD, UK. E-mail: sandra.schroeter@york.ac.uk

${ }^{b}$ LPP, CNRS, Ecole Polytechnique, UPMC Univ. Paris-Sud, Observatoire de Paris, Université Paris-Saclay, Sorbonne Universités, PSL Research University, 91128 Palaiseau, France

${ }^{c}$ Centre of Immunology and Infection, Department of Biology and Hull York Medical School, University of York, Heslington, York YO10 5DD, UK

${ }^{d}$ Synchrotron Soleil, l'Orme des Merisiers, St. Aubin BP 48, 91192 Gif sur Yvette Cedex, France

${ }^{e}$ Department of Electrical Engineering and Computer Science,

University of Michigan, 1301 Beal Ave., Ann Arbor, Michigan 48109-2122, USA

$\dagger$ Data underpinning the figures in this manuscript can be found at DOI: 10 . 15124/1a186859-ad12-4e33-bf17-ccfcbad48ba0.

¥ Current address: Plasma and Beam Physics Research Facility, Faculty of Science, Chiang Mai University, Chiang Mai 50200, Thailand.

$\S$ Current address: School of Electrical and Electronic Engineering, The University of Manchester, Manchester M13 9PL, UK.

ๆ Current address: Laboratoire EM2C, CNRS, CentraleSupélec, Université ParisSaclay, 3, rue Joliot Curie, 91192 Gif-sur-Yvette Cedex, France.
}

as biomedical devices ${ }^{1-4}$ are currently a topic of significant interest. APPs have been shown to be effective in many different areas of biomedicine, such as sterilization, ${ }^{5-7}$ cancer treatment, ${ }^{8-12}$ and wound healing, ${ }^{13-15}$ and have recently been identified as potential triggers of beneficial immune responses. ${ }^{16}$ First trials on patients confirm the effectiveness of APPs. ${ }^{13,17,18}$ APPs may offer advantages compared to conventional therapeutics due to their typically small dimensions, offering the possibility of locally confined treatment, low production cost, and the potential to tailor sources for specific applications.

A key question in plasma interactions with biological matter is the role played by plasma produced reactive species (RS). RS are known to interact with cells and their membranes, and often serve as signaling agents in cell metabolism. ${ }^{19,20}$ They can also cause severe damage to cells at high concentrations. ${ }^{19,21}$

For APPs to fulfil their potential in any biomedical application, a full characterization of the sources used to produce them is necessary, including the quantification of RS produced. Reactive oxygen and nitrogen species (RONS), such as atomic oxygen and nitrogen (O and $\mathrm{N})$, ozone $\left(\mathrm{O}_{3}\right)$, excited states of molecular oxygen (e.g. $\mathrm{O}_{2}\left(\mathrm{a}^{1} \Delta\right)$ ), or nitric oxides, have previously been quantified both 
experimentally and numerically in $\mathrm{O}_{2}$ and $\mathrm{N}_{2}$ containing plasmas. $^{22-28}$ Here, the production of RS in an enclosed APP operating in helium with small contents of humidity is investigated. Water is typically present in the direct vicinity of biological material, and can easily enter the gas phase via evaporation. Therefore, RS produced from water vapor can be created during the treatment of the material when plasmas are applied. Water is also usually present as a feed gas impurity. ${ }^{29}$ Therefore, the investigation of RS directly produced from water vapor, such as $\mathrm{O}$ and the hydroxyl radical $\mathrm{OH}$, is of interest for biomedical applications. These species can act as precursors for longer-lived species such as hydrogen peroxide $\left(\mathrm{H}_{2} \mathrm{O}_{2}\right)$, an important signaling agent in cells, ${ }^{19,30}$ and $\mathrm{O}_{3}$. In high concentrations both of these species can have toxic effects on biological material.

The quantification of RS in APPs represents a challenge for diagnostics based on optical emission from excited states, since the plasma emission is strongly quenched by the ambient gas due to the high pressure. Laser Induced Fluorescence (LIF) and Two-photon Absorption LIF (TALIF) have been previously used to detect species such as $\mathrm{O}$ and $\mathrm{OH}$ produced from water vapor. ${ }^{31-34}$ However, in order to accurately predict the effect of quenching using these techniques at atmospheric pressure, the densities of all potential quenching particles are needed. This is increasingly challenging in complex gas mixtures and in regions with gradual gas mixing, like the plasma effluent. These techniques also rely on quenching rate coefficients for investigated species with all possible quenchers, which for some cases, particularly quenching involving water molecules, are only poorly known. The implementation of faster laser systems such as picosecond or femtosecond lasers ${ }^{35-37}$ can help to quantify the effect of these quenching processes. In addition to accounting for the effects of quenching to obtain absolute density measurements using TALIF, an additional calibration measurement involving a gas with a known quantity is typically needed. An alternative diagnostic technique, which is independent of collisional quenching, is mass spectrometry. This technique has recently been used to detect RS such as $\mathrm{OH}$ and $\mathrm{H}_{2} \mathrm{O}_{2}$ produced from water vapor in the plasma effluent. ${ }^{38}$ Similar to LIF and TALIF, this technique requires a calibration measurement to obtain absolute species densities. Mass spectrometry has also been used to detect high order protonated water clusters $^{39,40}$ produced in APPs. Species deposited in a liquid by plasma treatment are sometimes investigated by means of absorption spectroscopy in the liquid phase, and electron paramagnetic resonance spectroscopy. ${ }^{41,42}$ However, to calculate gas-phase densities from liquid-phase densities, usually a calibration is required.

An established optical diagnostic technique for the quantification of $\mathrm{OH}$ in the gas-phase is ultra-violet (UV) Absorption Spectroscopy (AS), ${ }^{34,43-45}$ which is independent of collisional quenching and does not require an additional calibration measurement. However, measuring ground state densities of atomic species produced in water-containing plasmas, such as $\mathrm{O}$, is challenging using AS since the energy gaps between the ground and excited states of the atoms are large. Therefore, the required excitation wavelengths typically lie in the vacuum ultra-violet (VUV) spectral range, which is strongly absorbed by air. However, atomic species, in particular $\mathrm{O}$ and $\mathrm{N}$, have previously been quantified in an APP using synchrotron radiation and a spectrometer with an ultra-high spectral resolution, so-called VUV high-resolution Fourier-Transform Absorption Spectroscopy (VUV-FTAS). ${ }^{22,23}$

In this work, we combine VUV-FTAS and UV broad-band AS (UV-BBAS) to determine absolute densities of gas-phase $\mathrm{O}$ and $\mathrm{OH}$ in a radio-frequency APP jet operated in helium (He) for different values of humidity up to $1.3 \%$. We combine the experimental investigations with zero-dimensional, plug-flow plasma simulations to model the chemical kinetics in the source. These models are commonly used to study properties of atmospheric pressure plasmas. ${ }^{46-51}$ The role of humidity on the plasma chemistry in APPs has been subject of numerical investigations in the past, ${ }^{48,52-54}$ that have established the baseline understanding of these systems. We build upon these prior works by comparison of modeling results to experiments performed for the same conditions. Species densities are measured and simulated mainly in the plasma bulk, to validate the reaction mechanism. The resulting reaction mechanism can then be used to investigate important formation pathways for different RS, and to predict additional species densities that are difficult to measure. In many applications, reactive species exit the plasma source into ambient air where the chemical kinetics will differ from the active plasma region. This transition is not investigated here, but the validated reaction mechanism constructed in this work will act as a base to be built upon for future studies in this area.

\section{Experimental setup}

\subsection{Atmospheric pressure plasma jet}

The production of atomic oxygen $(\mathrm{O})$, and hydroxyl radicals $(\mathrm{OH})$, in an atmospheric pressure plasma jet (APPJ) operating in 5 slm helium (either grade 4.6 with 25 ppm $\mathrm{N}_{2}$ and $7 \mathrm{ppm} \mathrm{O}_{2}$ impurities, or grade 5 with 3 ppm $\mathrm{H}_{2} \mathrm{O}$ and 2 ppm $\mathrm{O}_{2}$ impurities) with water vapor $\left(\mathrm{H}_{2} \mathrm{O}\right)$ admixtures is investigated. The plasma jet used in this work is shown in Fig. 1 and is the same as described by Dedrick et $a .^{23}$ The jet has a plane-parallel electrode configuration. One electrode with an area of $2.4 \times 0.86 \mathrm{~cm}^{2}$ is powered by a sinusoidal voltage at a frequency of $13.56 \mathrm{MHz}$ while the other electrode, which is the housing of the source, is grounded. (a)

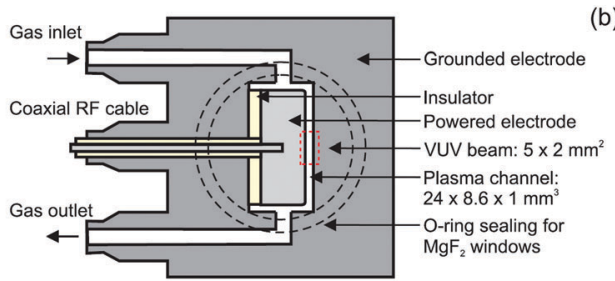

(b)

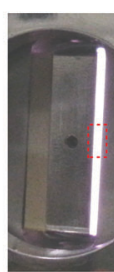

Fig. 1 (a) Schematic cross-section and (b) photograph of the plasma source. The perpendicular orientation of the synchrotron vacuum ultraviolet (VUV) beam with respect to the plasma channel is indicated by the dashed rectangle. Images taken from Dedrick et al., ${ }^{23}$ under a Creative Commons Attribution 3.0 licence (https://creativecommons.org/licenses/ by/3.0/). 
Powered and grounded electrodes are separated by $0.1 \mathrm{~cm}$, keeping the critical dimensions and operating parameters close to the 'COST Reference Microplasma Jet' ${ }^{55}$ but with a smaller surfaceto-volume ratio $\left(22 \mathrm{~cm}^{-1}\right.$ here instead of $40 \mathrm{~cm}^{-1}$ for the 'COST Reference Microplasma Jet'). An impedance matching network unit (L-configuration) is used to optimise the power coupled into the plasma. The applied voltage across the gap is monitored using a high-voltage probe. A list with the equipment for the power coupling and voltage monitoring can be found in Appendix B.

We generally conduct experiments at a fixed generator power. For measurements of $\mathrm{OH}$, we set the generator power close to the arcing point of the plasma in pure helium, which is independent of the generator power when using different generators and which typically occurs around $520 \pm 10 \mathrm{~V}_{\mathrm{pp}}$. Starting at this point also maximises the measurement range with respect to water content. The water content is varied while keeping the settings on the generator constant. The implications of this on the coupled power to the plasma will be further discussed in Section 2.4. At higher voltages, the plasma tends to extend around the powered electrode when operated in pure $\mathrm{He}$, and transitions from a homogeneous glow-like discharge into a constricted "arc" mode at the electrode edges, which can damage the source.

For the O measurements, the source is operated in a vacuum vessel, with limited options for visually identifying the plasma mode through a transparent vacuum flange. In this case measurements are carried out at a lower voltage of $470 \mathrm{~V}_{\mathrm{pp}}$ to avoid the 'constricted mode' and related damage of the electrodes.

For the spatially resolved measurement of $\mathrm{OH}$ (presented in Section 4.1), a different plasma source, as described elsewhere, ${ }^{22}$ has been used. It utilises the same design concept, i.e. the same gap size of $1 \mathrm{~mm}$, but a slightly larger electrode area of $(1.1 \times 3) \mathrm{cm}^{2}$, compared to the source described earlier. Since the surface-to-volume ratios for both designs are very similar, we assume the RS production to be comparable under similar operating conditions (gas flow, power density).

Water vapor is admixed into the He flow using two mass flow controllers and a homemade bubbler, which consists of a domed glass adapter (Biallec $\mathrm{GmbH}$ ) clamped to a KF40 flange. Two stainless steel pipes welded to the flange provide gas in- and out-lets. Both mass flow controllers are fed with dry $\mathrm{He}$, while the outlet flow of one controller passes through the bubbler before being mixed with the other. By changing the ratio of the humidified to the dry He flow, the water vapor content of the total gas flow can be regulated. ${ }^{34,43,45}$ With the humidity level in the He flow leaving the bubbler being saturated (see below), the vapor pressure $p_{\mathrm{H}_{2} \mathrm{O}}^{\mathrm{vap}}$ can be calculated using the semi-empirical expression given below. ${ }^{56}$ The total amount of water in the vapor phase can then be calculated using the vapor pressure of $\mathrm{H}_{2} \mathrm{O}$ (in bar) and the flow rate of the He through the bubbler $F_{\mathrm{He}}^{\text {bubbler }}$, as described in ref. 34:

$$
\begin{gathered}
p_{\mathrm{H}_{2} \mathrm{O}}^{\mathrm{vap}}=6.112 \times 10^{-3} \exp \left(\frac{17.62 T_{\mathrm{w}}}{243.04+T_{\mathrm{w}}}\right) \\
F_{\mathrm{H}_{2} \mathrm{O}}=F_{\mathrm{He}}^{\text {bubbler }} \frac{p_{\mathrm{H}_{2} \mathrm{O}}^{\text {vap }}}{p_{\mathrm{atm}}-p_{\mathrm{H}_{2} \mathrm{O}}^{\mathrm{vap}}}
\end{gathered}
$$

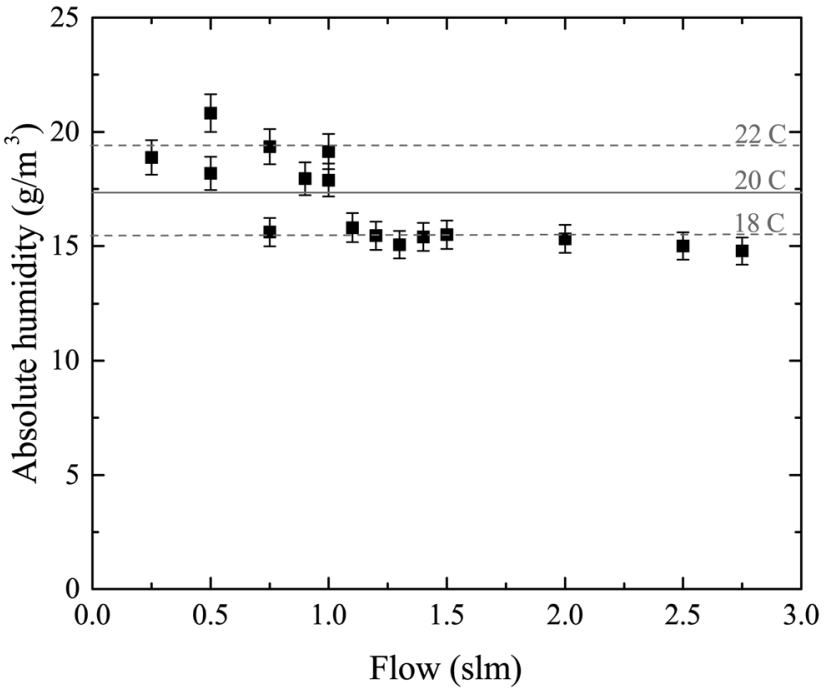

Fig. 2 Measured absolute humidity in the gas phase as a function of the He flow through the bubbler. Horizontal lines represent different theoretical values for the water temperature. For calculations of the water content in later experiments a temperature of $(20 \pm 2){ }^{\circ} \mathrm{C}$ is assumed, as indicated as solid and dashed lines.

where $T_{\mathrm{w}}$ is the water temperature in ${ }^{\circ} \mathrm{C}$. To check that the He flow exiting the bubbler is saturated with $\mathrm{H}_{2} \mathrm{O}$, the weight loss of the bubbler due to evaporation of the water is measured for different He flow rates as a function of time. The absolute water concentration in the He flow is given by the ratio of the two former quantities. The results are shown in Fig. 2. A small systematic drop of the measured water concentration with increasing He flow is observed. This may reflect a temperature drop of the water inside the bubbler, which is not temperature controlled, either because of an increased evaporation rate, or fluctuations in the laboratory room temperature, since measurements were taken over several days. The averaged result for the water concentration of $(16.9 \pm 2.0) \mathrm{g} \mathrm{m}^{-3}$ corresponds to a water temperature of $(20 \pm 2.0){ }^{\circ} \mathrm{C}$ assuming full saturation. Since this temperature represents the typical 'room temperature' at which the measurements were taken, we can confirm that the He flow out of the bubbler is saturated with water vapor. The uncertainty of $2{ }^{\circ} \mathrm{C}$ would lead to an uncertainty of approximately $14 \%$ in the calculation of the water vapor content in the gas.

\subsection{VUV high-resolution Fourier-transform absorption spectroscopy}

Absolute line-averaged $\mathrm{O}$ atom ground state densities are measured at the DESIRS beamline at the synchrotron SOLEIL, ${ }^{57}$ with its unique ultra-high resolution VUV Fourier-Transform spectrometer ${ }^{58}$ able to cover the complete VUV spectral range down to $40 \mathrm{~nm}$ with a resolving power $(\lambda / \Delta \lambda)$ of up to $10^{6}$. The atomic oxygen transition $\mathrm{O}\left(2 \mathrm{p}^{4}{ }^{3} \mathrm{P}_{J=2} \rightarrow 3 \mathrm{~s}{ }^{3} \mathrm{~S}_{1}\right)$ is investigated in this work.

The measurement and analysis procedure is described in detail elsewhere. ${ }^{22}$ The spectrometer yields a transmission spectrum $S_{\mathrm{T}}$, which includes the convolution of the plasma transmission $T$ (accounting for Doppler and pressure broadening 
of the corresponding spectral line profile) with the sinc-shaped instrumental function $\Phi\left(\sigma^{\prime}\right)=\frac{\sin \left(\pi\left(\sigma^{\prime}-\sigma\right)\right)}{\pi\left(\sigma^{\prime}-\sigma\right)}$ of the FT spectrometer

$$
S_{\mathrm{T}}\left(\sigma^{\prime}\right)=S_{0}\left(\sigma^{\prime}\right)\left[\Phi\left(\sigma^{\prime}-\sigma\right) \times T(\sigma)\right] .
$$

where $\sigma$ is the wavenumber of the transition and $S_{0}$ the reference spectrum without absorber. Absolute densities are obtained from the transmission spectra using Beer-Lambert's law

$$
T(\sigma)=\exp (-A(\sigma))=\exp (-k(\sigma) \cdot l),
$$

where $A(\sigma)$ is the absorbance, $l$ the length of the absorbing medium (here defined by the width of the electrode as $8.6 \mathrm{~mm}$ ), and $k$ the absorption coefficient, which includes the ground state density, the spectral line "Voigt" profile, which takes into account the Doppler and pressure broadening of the spectral line, the statistical weights $g_{J}$ for the different states and the transition probabilities. For the evaluation of these transmission spectra, the different broadening mechanisms are taken into account as fixed values during the fitting process. The instrumental broadening is set to $\Delta \sigma_{\mathrm{I}}=0.87 \mathrm{~cm}^{-1}$ as described elsewhere. ${ }^{22}$ The Doppler width $\Delta \sigma_{\mathrm{D}}=0.24 \mathrm{~cm}^{-1}$ is calculated for a gas temperature $T_{\mathrm{g}}=304 \mathrm{~K}$. This value is determined as the $\mathrm{OH}$ rotational temperature from the absorption measurements by fitting the $\mathrm{OH}\left(\mathrm{X}^{2} \Pi_{i}, v^{\prime}=0\right) \rightarrow \mathrm{OH}\left(\mathrm{A}^{2} \Sigma^{+}, v^{\prime \prime}=0\right)$ rotational transitions using a spectral simulation (see results discussed in Section 4.2 and shown in Fig. 9). The detailed working principle of the simulation will be described in the next section. Rotational temperatures were obtained for different water contents ranging from 0.1 to $1.3 \%$. A standard deviation of $2.2 \mathrm{~K}$ shows that the gas temperature stays fairly constant within the investigated range of $\mathrm{H}_{2} \mathrm{O}$ admixtures. Finally, the pressure broadening is determined as $\Delta \sigma_{\mathrm{L}}=0.37 \mathrm{~cm}^{-1}$ from an average of several automated fits to the data using the previously specified values for $\Delta \sigma_{\mathrm{D}}$ and $\Delta \sigma_{\mathrm{I}}$. This value is in reasonable agreement with $\Delta \sigma_{\mathrm{L}}=(0.46 \pm 0.03) \mathrm{cm}^{-1}$ for He measured by Marinov et al. ${ }^{59}$ in the 'COST Reference Microplasma Jet' using Doppler-free TALIF, albeit for a different optical transition.

A typical transmission spectrum is presented in Fig. 3. We only evaluate the strongest $J=2$ transition of the $\mathrm{O}\left(2 \mathrm{p}^{4}{ }^{3} \mathrm{P}_{J=2}\right)$ triplet from the fine structure split ground state to the first electronically excited state because of the low signal-to-noise ratio of the weaker $J=0,1$ transitions. In order to estimate the total ground state density $n_{\mathrm{O}}=\sum_{J=0-2} n_{J}$, the Boltzmann factor

$$
\frac{n_{2}}{n_{\mathrm{O}}}=\frac{g_{2}}{\sum_{J=0-2} g_{J} \exp \left(-E_{J} / k_{\mathrm{B}} T_{\mathrm{g}}\right)}
$$

is applied, where $E_{J}$ is the energy of the state and $k_{\mathrm{B}}$ is the Boltzmann constant.

The main uncertainties in this technique lie in the estimated absorption length (uncertainty of $5 \%$ ), and the accuracy of the transition probability $A_{i k}\left(\leq 3 \%{ }^{60}\right)$, which are included in the expression for the absorption coefficient in eqn (4). A change of the gas temperature within $10 \mathrm{~K}$ influences the Boltzmann factor calculated using eqn (5) by less than $2 \%$. We therefore estimate

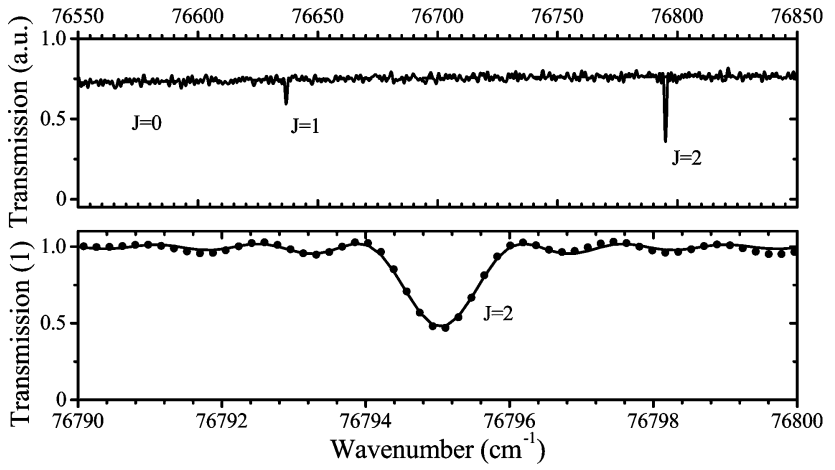

Fig. 3 Example measured (points) and fitted spectrum (solid line) for the measured transition $\mathrm{O}\left(2 \mathrm{p}^{4}{ }^{3} \mathrm{P}_{J}\right) \rightarrow \mathrm{O}\left(3 \mathrm{~s}^{3} \mathrm{~S}_{1}\right)$ using VUV-FTAS. Top: Broad spectral range. The transition from the ground $J=0$ sub-level is at $\sigma=$ $76568 \mathrm{~cm}^{-1}$ (not visible). Bottom: Zoom into the transition from the $J=2$ sub-level of the ground state. The spectrum was taken with $4.6 \mathrm{slm}$ dry He and $0.4 \mathrm{slm}$ humidified $\mathrm{He}$, equivalent to $1880 \mathrm{ppm}$ of water vapor in the gas phase. The $O$ density obtained from this spectrum is $2.7 \times 10^{13} \mathrm{~cm}^{-3}$.

the systematic error in all VUV-FTAS measurements presented here to be within $10 \%$.

\subsection{UV broad-band absorption spectroscopy}

Absolute $\mathrm{OH}$ densities are measured in the same plasma source using UV-BBAS using two different experimental setups to ensure reproducibility. The experimental setup UV-BBAS I is presented in Fig. 4(a). Light from an ultra-stable broad-band plasma lamp (Energetiq EQ-99) is guided through the middle of the plasma channel and focused on the entrance slit of a $320 \mathrm{~mm}$ spectrograph (Isoplane SCT320) with a 2400 grooves per mm grating. Spectra are recorded using a photodiode array detector (Hamamatsu S-3904). The setup is described in detail elsewhere. ${ }^{61}$

The second setup (UV-BBAS II), which is shown in Fig. 4(b), comprises several different components, mainly a UV LED (UVTOP-305-FW-TO18, Roithner Lasertechnik GmbH) as light source and a CCD camera (Andor Newton 940) in combination with a spectrometer (Andor SR-500i) as detector. For the UV-BBAS II setup, the plasma is mounted on an automated $x-z$ stage, allowing for spatially resolved measurements in the plasma channel. The experimental setup is described in detail elsewhere. $^{24}$

To calculate the absorbance in eqn (4), four signals are required: plasma on and light source on $\left(I_{\mathrm{P}, \mathrm{L}}\right)$, plasma on only $\left(I_{\mathrm{P}}\right)$, light source on only $\left(I_{\mathrm{L}}\right)$ and a background with both plasma and light source off $\left(I_{0}\right)$. Each signal is integrated over a time period of $50 \mathrm{~ms}$, with a plasma stabilisation time of $4 \mathrm{~s}$ beforehand. A schematic showing this sequence is shown in Fig. 5. The plasma transmission $T$ in eqn (4) is calculated as

$$
T(\sigma)=\frac{I_{\mathrm{P}, \mathrm{L}}(\sigma)-I_{\mathrm{P}}(\sigma)}{I_{\mathrm{L}}(\sigma)-I_{0}(\sigma)}
$$

An example spectrum of the $\mathrm{OH}$ absorbance $A$ is shown in Fig. 6. Using two setups, an admixture range of 200-13 $000 \mathrm{ppm}$ humidity content is investigated. 


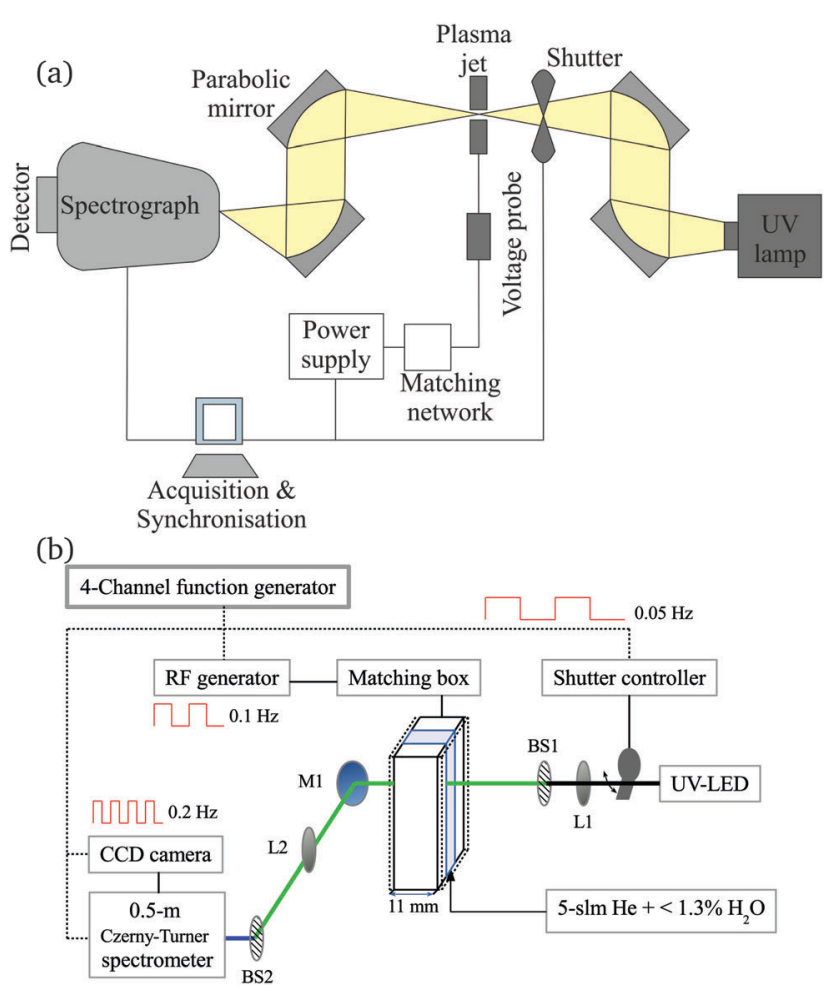

Fig. 4 Schematics of the experimental setups used for the UV-BBAS measurements of OH. UV-BBAS I (a) and UV-BBAS II (b). Figure (b) was adapted from Wijaikhum et al., ${ }^{24}$ under a Creative Commons Attribution 3.0 licence (https://creativecommons.org/licenses/by/3.0/).

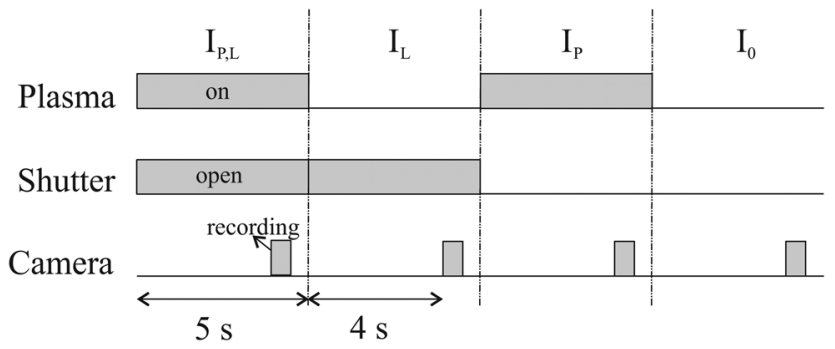

Fig. 5 Trigger scheme for all UV-BBAS absorption measurements.

Measured $\mathrm{OH}$ rotational absorbance spectra of the transition $\mathrm{OH}\left(\mathrm{X}^{2} \Pi_{i}, v^{\prime}=0\right) \rightarrow \mathrm{OH}\left(\mathrm{A}^{2} \Sigma^{+}, v^{\prime \prime}=0\right)$ are fitted using a spectral simulation in order to obtain absolute $\mathrm{OH}\left(\mathrm{X}^{2} \Pi_{i}, v^{\prime}=0\right)$ densities. The fitting programme is based on a calculation of the Einstein coefficients and wavelengths for the individual transitions within the investigated rotation band, as described by Dieke and Crosswhite. ${ }^{62}$ Based on the selection rules for the total angular momentum $J=L \pm S$ and the angular momentum $L$ (without electron spin $S=1 / 2$ for the $\mathrm{OH}$ radical), relative intensities are calculated for 12 possible branches, using expressions derived by Earls. ${ }^{63}$ An experimental value for the radiative lifetime for a rotationless upper state $F_{1}\left(J^{\prime \prime}=0.5\right)$ has been determined as $0.688 \mu \mathrm{s}^{64}$ (here, $F_{1}$ donates the doublet component of the upper state with $J=L+1 / 2$, in accordance with Diecke and Crosswhite ${ }^{62}$ ). Therefore, all calculated relative Einstein coefficients can be normalised to this value.

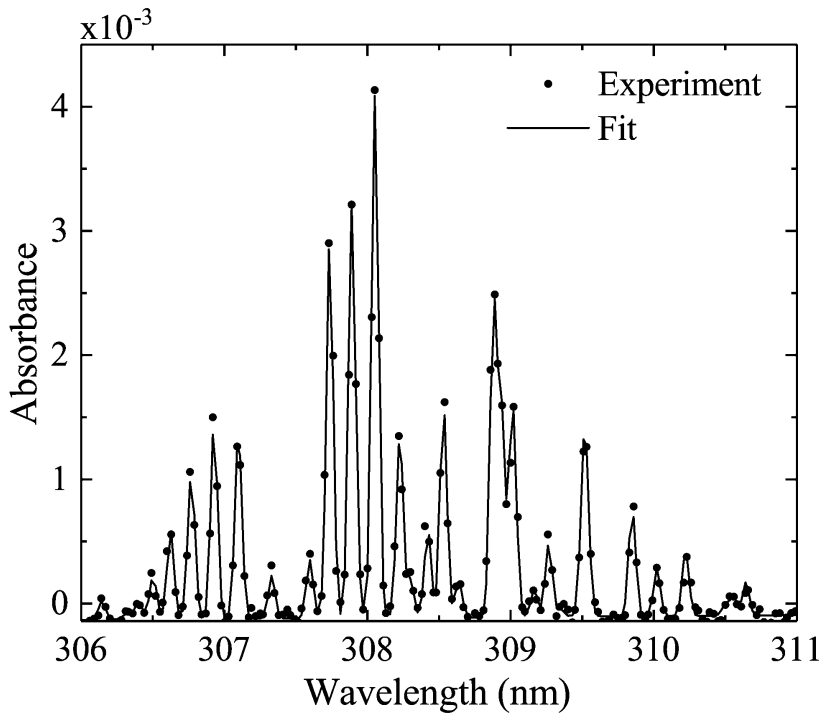

Fig. 6 Example spectrum for the measured and fitted transition $\mathrm{OH}(\mathrm{X}$ $\left.{ }^{2} \Pi_{J}, v^{\prime}=0\right) \rightarrow \mathrm{OH}\left(\mathrm{A}^{2} \Sigma_{J}^{+}, v^{\prime \prime}=0\right)$ using the UV-BBAS I setup, for 4 slm dry and $1 \mathrm{slm}$ humidified $\mathrm{He}, 530 \mathrm{~V}_{\mathrm{pp}}$. The calculated $\mathrm{OH}\left(\mathrm{X}^{2} \Pi_{J}, v^{\prime}=0\right)$ density obtained from this spectrum is $2.6 \times 10^{14} \mathrm{~cm}^{-3}$.

Our calculated values are in good agreement with those from Goldman and Gillis. ${ }^{65}$ As in Dilecce et al. ${ }^{45}$ the spectral fitting includes an instrumental function, whose width represents the spectral resolution of the spectrometer, which depends on the pixel size of the detector array, the optical grating and the width of the spectrograph's entrance slit. We assume the instrumental function to be Gaussian. Examples of measured and simulated absorbance spectra are shown in Fig. 6. Here, the instrumental width is $56 \mathrm{pm}$ (UV-BBAS I) or $34 \mathrm{pm}$ (UV-BBAS II), which is much larger than the Doppler $\left(\Delta \lambda_{\mathrm{D}}(304 \mathrm{~K})=0.098 \mathrm{~cm}^{-1}=\right.$ $0.93 \mathrm{pm})$ and pressure broadening (estimated as $\Delta \lambda_{\mathrm{P}}(1 \mathrm{~atm})=$ $0.07 \mathrm{~cm}^{-1}=0.66 \mathrm{pm}$, as in ref. 66). The fitting programme is also used to calculate $\mathrm{OH}$ rotational temperatures.

The main systematic uncertainties of UV-BBAS lie in the estimation of the absorption length (5\%), and the accuracy of the calculated Einstein coefficients, which we estimate here to be within $10 \%$. For the absorbance measured with the UV-BBAS II setup (featuring the LED), the standard deviation of the noise is in the order of $3 \times 10^{-4}$, which places a lower limit on the measurable $\mathrm{OH}$ density at $3.6 \times 10^{13} \mathrm{~cm}^{-3}$. For the UV-BBAS I setup (featuring the ultra-stable light source), the noise level of the measured absorbance is typically an order of magnitude lower, and therefore disregarded in the uncertainty estimation. The combination of the systematic error and a statistical error of $7 \%$ is shown as error bars in the results that follow.

\subsection{Determination of plasma power}

For accurate comparison between simulation and experiment the rf power dissipated in the plasma is a particularly important. Experimentally, this so-called plasma power is measured by determining current, voltage and phase shift using current (Ion Physics Corp. CM-100-L 1 V/A) and voltage probes (PMK-14KVAC). 
The probes are installed between the impedance matching unit and the plasma source. The time averaged power $P$ is given by

$$
P=\frac{U I}{2} \cos (\varphi)
$$

where $U$ and $I$ are the voltage and current amplitudes, respectively, and $\varphi$ is the phase shift between the two. Parasitic power losses, e.g. into the plasma source or the rf cables, are accounted for by measuring the power deposited in the system without a gas flow, so that the ignition of the plasma is inhibited. The subtraction method is then used ${ }^{67,68}$ for a given current to determine the plasma power

$$
P_{\mathrm{d}}\left(I^{2}\right)=P_{\text {on }}\left(I^{2}\right)-P_{\text {off }}\left(I^{2}\right)
$$

The net power $P_{\mathrm{d}}$ is the difference between the power measured with and without plasma, $P_{\text {on }}$ and $P_{\text {off }}$, respectively. For a given plasma volume $V_{\text {plasma }}$, the corresponding plasma power per unit volume $p_{\mathrm{d}}$ is given by

$$
p_{\mathrm{d}}=\frac{P_{\mathrm{d}}}{V_{\text {plasma }}}
$$

The instrumental phase shift of the measurement system (probes, BNC signaling cables, and digital oscilloscope) is determined using a variable air capacitor with known phase shift (MFJ 282-2018-1). For the calibration measurement, the plasma source with its rf cable to the matching box is replaced by this capacitor.

Current and voltage waveforms are recorded by a fast oscilloscope (LeCroy WaveSurfer10, 10 GS per s sample rate). The voltage and current amplitude as well as the corresponding phase shift are determined by a Fourier analysis of this data. $P_{\mathrm{d}}$ was found to be approximately constant (within 15\%) as a function of feed gas water content at a constant generator power and matching settings. The average of $P_{\mathrm{d}}$ over several different water contents is used as an input for the simulations over the whole range of water content. The average value of $P_{\mathrm{d}}$ was determined as $2.8 \mathrm{~W}\left(\approx 14 \mathrm{~W} \mathrm{~cm}^{-3}\right)$ for the UV-BBAS measurements of $\mathrm{OH}$ (at approximately $510 \mathrm{~V}_{\mathrm{pp}}$ ), and $2.1 \mathrm{~W}$ $\left(\approx 10 \mathrm{~W} \mathrm{~cm}^{-3}\right)$ for the measurement of $\mathrm{O}$ using VUV-FTAS (at approximately $470 \mathrm{~V}_{\mathrm{pp}}$ ). These values are used as the input for the simulations, unless otherwise stated.

Power measurements are carried out separately from the density measurements using two power generators: coaxial RFG-150-13 (150 W maximum output power, same model as used for the $\mathrm{OH}$ measurements using the UV-BBAS II setup), and coaxial RFG-50-13 (50 W maximum output power, smaller range of powers for a better stability). We find a similar average power using these two setups, and that the power stays constant as a function of water content within one measurement set with a standard deviation of all points below $5 \%$. We estimate a total uncertainty of $15 \%$ from repetitive measurements. These variations are small enough to not significantly influence measured species densities, particularly for $\mathrm{OH}$, which we found to be only weakly dependent on applied voltage, and therefore power (increase of about $40 \%$ when the voltage is increased from 490 to $850 \mathrm{~V}_{\mathrm{pp}}$, not shown here).

\section{Plasma simulations}

\subsection{Model description and reaction mechanism}

To better understand the dynamics of reactive species in cold atmospheric pressure plasmas, zero-dimensional plasma chemical kinetics simulations (global models) are often used. ${ }^{51}$ In this work, experimental results are compared to those obtained using the GlobalKin code as described elsewhere. ${ }^{50}$ GlobalKin solves the continuity equation for mass conservation for both charged and neutral species, taking into account particle production and loss through gas phase reactions and interactions with surfaces

$$
\frac{\mathrm{d} N_{i}}{\mathrm{~d} t}=\frac{S}{V}\left(-\frac{D_{i} N_{i} \gamma_{i}}{\gamma_{i} \Lambda_{\mathrm{D}}+\frac{4 D_{i}}{v_{\mathrm{th}, i}}}+\sum_{j} \frac{D_{j} N_{j} \gamma_{j} f_{i j}}{\gamma_{j} \Lambda_{\mathrm{D}}+\frac{4 D_{j}}{v_{\mathrm{th}, j}}}\right)+S_{i}
$$

where $N$ denotes the number density of heavy particles $i, \frac{S}{V}$ the surface to volume ratio, $\Lambda_{\mathrm{D}}$ the diffusion length, $D$ the diffusion coefficient, $\gamma$ the surface sticking coefficient, $f$ the return fraction of species from walls, and $S_{i}$ the source term, which accounts for gas phase production and losses. In addition, the electron energy conservation equation is solved to calculate the electron temperature in the plasma by taking into account the balance of power input and loss of electron energy due to elastic and inelastic collisions with heavy particles

$$
\begin{aligned}
\frac{\mathrm{d}}{\mathrm{d} t}\left(\frac{3}{2} n_{\mathrm{e}} k_{\mathrm{B}} T_{\mathrm{e}}\right)= & p_{\mathrm{d}}-\sum_{i} \frac{3}{2} n_{\mathrm{e}} \nu_{m i}\left(\frac{2 m_{\mathrm{e}}}{M_{i}}\right) k_{\mathrm{B}}\left(T_{\mathrm{e}}-T_{i}\right) \\
& +\sum_{l} n_{\mathrm{e}} k_{l} N_{l} \Delta \varepsilon_{l}
\end{aligned}
$$

where $n_{\mathrm{e}}$ is the number density of electrons, $T_{\mathrm{e}}$ the electron temperature, $m_{\mathrm{e}}$ and $M_{i}$ the electron and heavy particle masses, respectively, $\nu_{m i}$ the electron collision frequency, $k$ the reaction rate coefficient and $\Delta \varepsilon_{l}$ the electron energy gain/loss through inelastic collisions. GlobalKin also incorporates a two-term approximation Boltzmann solver, which updates the electron energy distribution function during the simulation, and calculates electron impact rate coefficients, using electron impact cross sections as an input. From the electron energy distribution function electron transport coefficients are also determined for the use in the continuity equation.

In this work we apply a temporally constant power deposition corresponding to the time averaged power measured in the experiment. For rf APPs the electron heating is strongly modulated in time, leading to a power and electron impact rate coefficients, that vary during the rf cycle. ${ }^{69,70}$ This effect is not captured in our model. However, Lazzaroni et al. ${ }^{70}$ investigated the differences between a conventional global model, using a time averaged power deposition, and one that takes into account time-varying power deposition within the rf period. For their case, using a $\mathrm{He} / \mathrm{O}_{2}$ reaction mechanism, the densities of neutral species calculated by the modified model $\left(\mathrm{O}, \mathrm{O}_{3}, \mathrm{O}^{*}\right.$, $\mathrm{O}_{2}{ }^{*}$ ) were typically within a factor of 2 of those from the conventional model. The trends in the results of the two 
models were similar. Therefore, we expect that neglecting the time-varying power deposition in our model will only lead to a quantitative difference in the results, while the trends should remain valid.

Gas temperatures are self-consistently calculated using the GlobalKin code using ${ }^{50}$

$$
\begin{aligned}
\frac{\mathrm{d}}{\mathrm{d} t}\left(\frac{3}{2} N_{\mathrm{g}} c_{\mathrm{p}} T_{\mathrm{g}}\right)= & \sum_{i} \frac{3}{2} n_{\mathrm{e}} \nu_{m i}\left(\frac{2 m_{\mathrm{e}}}{M_{i}}\right) k_{\mathrm{B}}\left(T_{\mathrm{e}}-T_{i}\right) \\
& -\sum_{i} \Delta H_{i} R_{i}-\frac{\kappa}{\Lambda^{2}}\left(T_{\mathrm{g}}-T_{\mathrm{s}}\right)
\end{aligned}
$$

Here, $N_{\mathrm{g}}$ is the gas density, $c_{\mathrm{p}}$ the specific heat of the gas, $T_{\mathrm{g}}$ the gas temperature, $\Delta H_{i}$ the change of enthalpy for reactions with rate $R_{i}, \kappa$ the thermal conductivity of the gas, and $T_{\mathrm{s}}$ the surface temperature of the reactor wall. Therefore, GlobalKin balances gas heating via electron collisions (first term on right hand side), chemical reactions (second term), and heat exchange with surrounding walls (third term). Here, we assume $T_{\mathrm{g}}^{0}=295 \mathrm{~K}$ (room temperature) as the initial temperature of the gas before entering the plasma channel. Coupled powers are typically small in this work, therefore it is assumed that the reactor wall is not significantly heated and $T_{\mathrm{s}}$ is set to $295 \mathrm{~K}$. This is in good agreement with previous observations, ${ }^{24}$ where the electrode temperature was measured using an infrared thermometer in a very similar plasma configuration under a variation of plasma power.

The model incorporates 43 species and 390 reactions. Table 1 contains the species in the mechanism. The plasma reaction mechanism is in Appendix A (Tables 5-8). At the surfaces, it is assumed that most neutral and negatively charged species (except electrons) do not react, while positive ions are neutralised with a probability of 1 . The species assumed to react differently are listed in Table 4 in the Appendix A. A detailed discussion of the role of surface interactions in a similar simulation system is given elsewhere. $^{71}$

In this work, the model is solved for a channel length of $2.4 \mathrm{~cm}$, with a gas flow rate of $5 \mathrm{slm}$, which corresponds to a gas velocity of about $11 \mathrm{~m} \mathrm{~s}^{-1}$. Using a pseudo-1D plug flow, temporally computed densities are converted into spatially dependent quantities. Where species densities are presented as a function of humidity content, densities are extracted from the simulation at the axial centre of the source (at $1.2 \mathrm{~cm}$ ), which is the position where measurements were made.
From the plasma dimensions, the diffusion length $\Lambda_{\mathrm{D}}$, a necessary parameter for determining diffusion losses of particles, is calculated as $^{72}$

$$
\frac{1}{\Lambda_{\mathrm{D}}{ }^{2}}=\left(\frac{\pi}{x}\right)^{2}+\left(\frac{\pi}{y}\right)^{2}+\left(\frac{\pi}{l}\right)^{2}
$$

for a plasma with rectangular cross section $(x \times y)$ and length $l$. For the plasma source used here, $\Lambda_{\mathrm{D}}=0.0316 \mathrm{~cm}$. (This is larger than the 'COST Reference Microplasma Jet' with $\Lambda_{\mathrm{D}}=0.0225 \mathrm{~cm}$.)

\subsection{Pathway analysis}

The PumpKin software ${ }^{73}$ is used to identify the production and destruction pathways for the selected neutral species. The reaction pathway of a species of interest results from (a) analysing the elementary reactions that contribute directly or in subsequence to the formation of this species and selecting the significant ones only, (b) algebraically summing up the formal notations of these reactions, and (c) eliminating shorterlived species, here the electrons and some ions, to end up with a simplified net reaction. The short-lived species are defined as those with a lifetime shorter than a lifetime set by the user, which we denote as $\tau_{\mathrm{p}}$. Note, that this so-called net reaction should not be mistaken as an elementary reaction, since it is specific to the choice of eliminated species. This approach is particularly useful for understanding the production and destruction of species which are formed via complex reaction pathways involving a chain of elementary reactions, as opposed to simply one or two.

Among the neutral species considered in this work $\mathrm{He}^{*}$ and $\mathrm{He}_{2}{ }^{*}$ metastables have the shortest effective lifetime. For the pathway analysis, we therefore choose $\tau_{\mathrm{p}}$ to be slightly shorter than the lifetime of these species, which is in accordance with previous work. ${ }^{52}$ Table 2 shows the strong dependence of the

Table 2 Lifetimes of the shortest-lived neutral species calculated by PumpKin for $5 \mathrm{slm}$ He flow and $14 \mathrm{~W} \mathrm{~cm}^{-3}$ plasma power, and varying humidity content. Conditions are the same as for the investigations of $\mathrm{OH}$ densities under a variation of the humidity content discussed later in Section 4.2. These lifetimes serve as timescale of interest for the pathway analysis

\begin{tabular}{|c|c|c|c|}
\hline & Neutral & Positive & Negative \\
\hline $\mathrm{He}$ & $\mathrm{He}, \mathrm{He}^{*}, \mathrm{He}_{2}^{*}$ & $\mathrm{He}^{+}, \mathrm{He}_{2}^{+}$ & \\
\hline $\mathrm{O}$ & $\mathrm{O}, \mathrm{O}\left({ }^{1} \mathrm{D}\right), \mathrm{O}\left({ }^{1} \mathrm{~S}\right), \mathrm{O}_{2}, \mathrm{O}_{2}\left(\mathrm{a}^{1} \Delta\right), \mathrm{O}_{2}\left(\mathrm{~b}^{1} \Sigma\right), \mathrm{O}_{3}$ & $\mathrm{O}^{+}, \mathrm{O}_{2}^{+}, \mathrm{O}_{4}^{+}$ & $\mathrm{O}^{-}, \mathrm{O}_{2}^{-}$ \\
\hline $\mathrm{H}$ & $\mathrm{H}, \mathrm{H}_{2}$ & & \\
\hline $\mathrm{OH}$ & $\mathrm{OH}, \mathrm{HO}_{2}, \mathrm{H}_{2} \mathrm{O}, \mathrm{H}_{2} \mathrm{O}_{2}$ & $\begin{array}{l}\mathrm{OH}^{+}, \mathrm{H}_{2} \mathrm{O}^{+}\left(\mathrm{H}_{2} \mathrm{O}\right)_{n=0,1} \\
\mathrm{H}^{+}\left(\mathrm{H}_{2} \mathrm{O}\right)_{n=1-9} \\
\mathrm{O}_{2}^{+}\left(\mathrm{H}_{2} \mathrm{O}\right)\end{array}$ & $\mathrm{OH}^{-}, \mathrm{H}_{2} \mathrm{O}_{2}^{-}, \mathrm{OH}^{-}\left(\mathrm{H}_{2} \mathrm{O}\right)_{n=1-3}$ \\
\hline Others & & & $\mathrm{e}$ \\
\hline
\end{tabular}

\begin{tabular}{lll}
\hline $\mathrm{H}_{2} \mathrm{O}$ content $(\mathrm{ppm})$ & $\mathrm{He}^{*}$ lifetime $(\mu \mathrm{s})$ & $\mathrm{He}_{2}{ }^{*}$ lifetime $(\mu \mathrm{s})$ \\
\hline 10 & 2.539 & 1.931 \\
100 & 0.350 & 0.188 \\
1000 & 0.036 & 0.021 \\
10000 & 0.004 & 0.013
\end{tabular}

Table 1 Species considered in the simulation 
simulated lifetime on the humidity admixture for specific plasma conditions. These findings support the conclusion of Niemi et al., ${ }^{46}$ that the metastable character of these helium species at high pressure is significantly reduced in the presence of small admixtures or even impurity levels of molecular gases through Penning ionization under atmospheric pressure conditions.

\section{Results}

\subsection{OH densities along plasma channel}

The density of $\mathrm{OH}$ along the plasma channel for an intermediate humidity content of $5400 \mathrm{ppm}$ and a plasma power density of $18 \mathrm{~W} \mathrm{~cm}^{-3}$ is shown in Fig. 7. Experimental results show a rapid increase of the $\mathrm{OH}$ density over the first $2 \mathrm{~mm}$ of the channel. With increasing distance from the gas inlet the density stays approximately constant between $3.5 \times 10^{14} \mathrm{~cm}^{3}$ and $4.0 \times 10^{14} \mathrm{~cm}^{3}$ up to the end of the channel. A similar trend is also observed in the simulation. Absolute simulated and experimental densities agree well within around $25 \%$, which is likely within the combined uncertainties of experimental data (as shown as error bars in Fig. 7) and simulations. Uncertainties in the simulation results would most likely occur due to uncertainties in used reaction rate coefficients, and considered reaction pathways, and were shown to be within a factor 10 for a $\mathrm{He} / \mathrm{O}_{2}$ reaction mechanism under similar plasma conditions. ${ }^{74}$

To gain insight into the dynamics of $\mathrm{OH}$ formation, a pathway analysis is performed for the three regions highlighted in Fig. 7, which correspond to the fast build-up of $\mathrm{OH}$ at the entrance of the plasma channel $(0-0.2 \mathrm{~cm})$, a steady-state region $(2-2.5 \mathrm{~cm})$ and the decay of $\mathrm{OH}$ in the plasma effluent

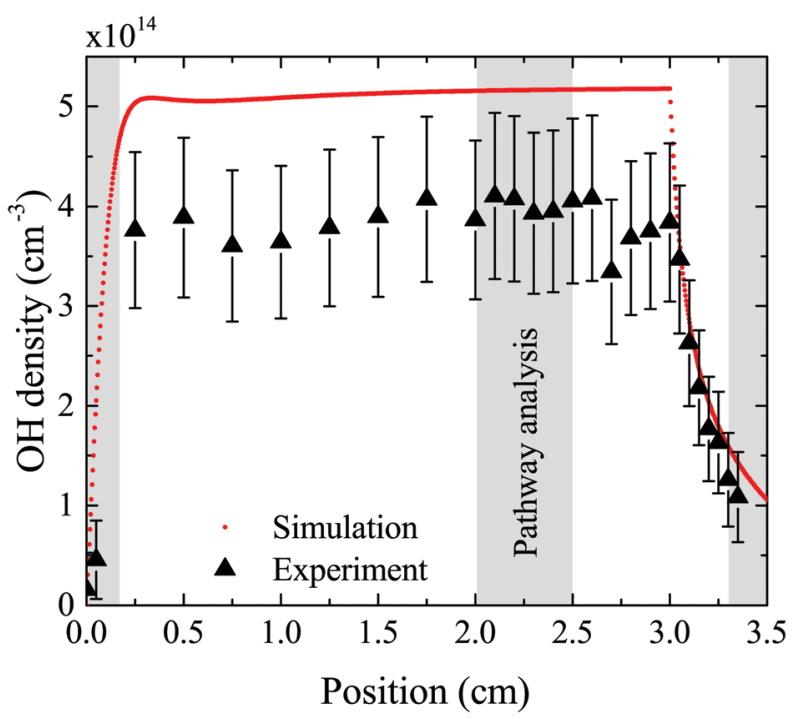

Fig. 7 Absolute density of $\mathrm{OH}$ as a function of position along the discharge channel, where $0 \mathrm{~cm}$ corresponds to the inlet and $3 \mathrm{~cm}$ to the outlet of the channel. Experimental results obtained using the UVBBAS II setup (black triangles) are taken at $18 \mathrm{~W} \mathrm{~cm}^{-3}$ plasma power density, $5 \mathrm{slm}$ total He flow, and 5400 ppm humidity. Corresponding simulation results are indicated by red dots. Shaded areas are used for the PumpKin pathway analysis.
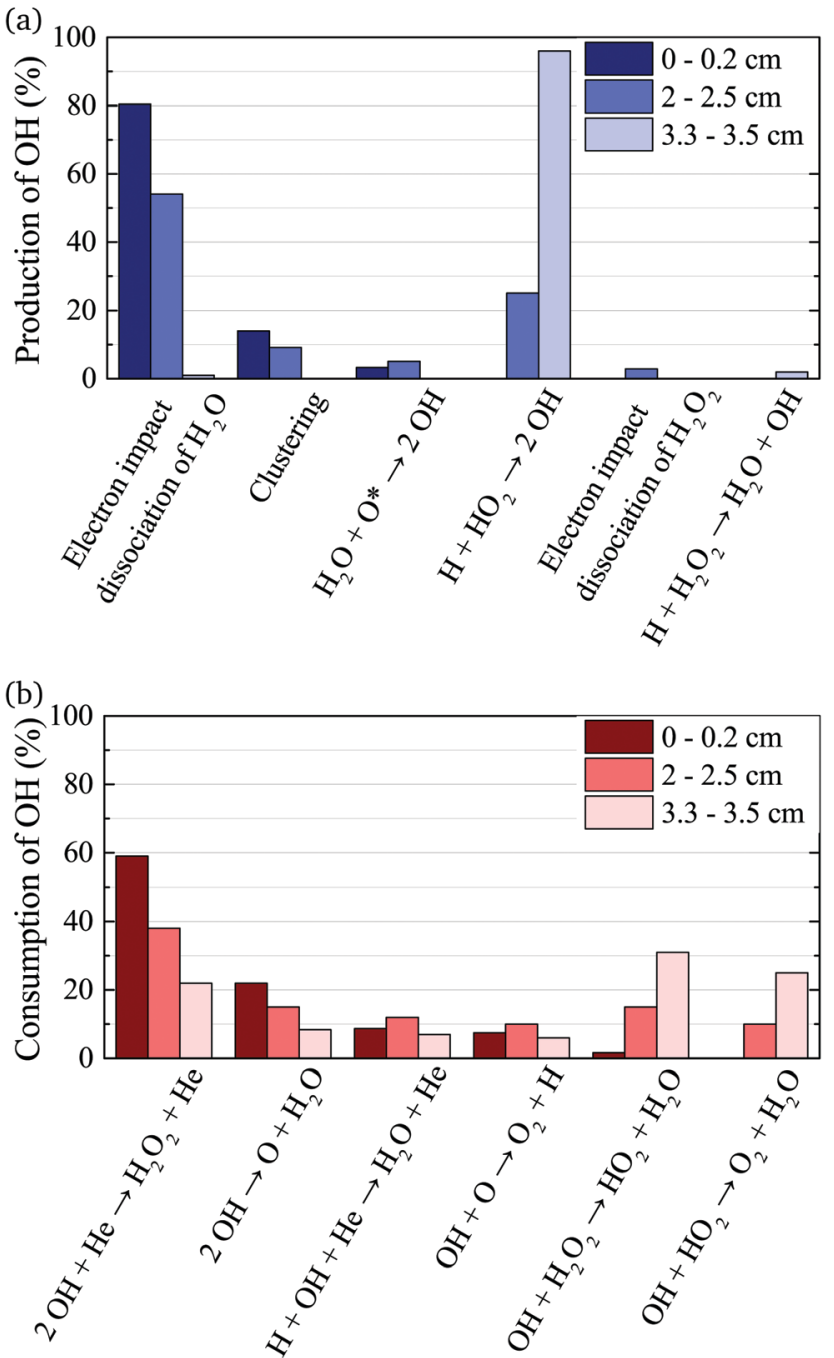

Fig. 8 Production (a) and consumption (b) pathways of $\mathrm{OH}$ at different positions in the plasma source, as indicated in Fig. 7

$(3.3-3.5 \mathrm{~cm})$. The dominant production and consumption pathways for $\mathrm{OH}$, averaged over each region, are shown in Fig. 8.

At the entrance of the discharge channel $(0-0.2 \mathrm{~cm})$, the gas consists mainly of the initial feed gas mixture plus some rapidly forming species such as ions and electrons. Therefore, the main production reaction for $\mathrm{OH}$ is through electron impact with water vapor, either via dissociation or dissociative attachment

$$
\begin{gathered}
\mathrm{e}+\mathrm{H}_{2} \mathrm{O} \rightarrow \mathbf{O H}+\mathrm{H}+\mathrm{e} \quad(60 \%) \\
\mathrm{e}+\mathrm{H}_{2} \mathrm{O} \rightarrow \mathbf{O H}+\mathrm{H}+\mathrm{e} \quad(9 \%) \\
\mathrm{e}+\mathrm{H}_{2} \mathrm{O} \rightarrow \mathbf{O H}+\mathrm{H}^{-} \quad(11 \%)
\end{gathered}
$$

The products of eqn (15) are ground state atomic hydrogen and $\mathrm{OH}$ in its excited $\mathrm{OH}(\mathrm{A})$ state, while the products of eqn (14) are both in their ground states. The percentage contribution for each reaction to the total production of $\mathrm{OH}$ is shown in brackets. 
Another production mechanism for $\mathrm{OH}$ is through the formation, and subsequent destruction, of charged water clusters, as was previously identified by Ding and Lieberman. ${ }^{52}$ The formation of these clusters is typically a multi-step process. For positive clusters, this process usually begins through ionisation of $\mathrm{H}_{2} \mathrm{O}$, either through electron impact or Penning ionisation with $\mathrm{He}^{*}$. These water ions then collide with water molecules to form the cluster ion $\mathrm{H}^{+}\left(\mathrm{H}_{2} \mathrm{O}\right)$, which accumulates additional water molecules through a series of reactions:

$$
\begin{aligned}
& \mathrm{H}_{2} \mathrm{O}^{+}+\mathrm{H}_{2} \mathrm{O} \rightarrow \mathbf{O H}+\mathrm{H}^{+}\left(\mathrm{H}_{2} \mathrm{O}\right) \\
& \mathrm{H}^{+}\left(\mathrm{H}_{2} \mathrm{O}\right)+n \times \mathrm{H}_{2} \mathrm{O}+\mathrm{He} \rightarrow \mathrm{H}^{+}\left(\mathrm{H}_{2} \mathrm{O}\right)_{n+1}+\mathrm{He}
\end{aligned}
$$

$$
\mathrm{H}_{2} \mathrm{O}^{+}+(n+1) \times \mathrm{H}_{2} \mathrm{O} \rightarrow \mathbf{O H}+\mathrm{H}^{+} \cdot\left(\mathrm{H}_{2} \mathrm{O}\right)_{n+1}
$$

Here, the reaction below the solid line represents the net reaction. Similar processes occur for negative ion clusters $\mathrm{OH}^{-}\left(\mathrm{H}_{2} \mathrm{O}\right)_{n}$, which are included in the reaction mechanism for $n \leq 3$.

The main consumption pathway for $\mathrm{OH}$ in the first $0.2 \mathrm{~cm}$ of the jet is the formation of $\mathrm{H}_{2} \mathrm{O}_{2}$, and recombination to water through

$$
\begin{gathered}
2 \mathrm{OH}+\mathrm{He} \rightarrow \mathrm{H}_{2} \mathrm{O}_{2}+\mathrm{He} \quad(59 \%) \\
2 \mathrm{OH} \rightarrow \mathrm{H}_{2} \mathrm{O}+\mathrm{O} \quad(22 \%) \\
\mathrm{H}+\mathbf{O H}+\mathrm{He} \rightarrow \mathrm{H}_{2} \mathrm{O}+\mathrm{He} \quad(9 \%)
\end{gathered}
$$

The rapid increase of $\mathrm{OH}$ density within the first two millimeters raises the question, if averaging the pathways over this region is a valid analysis. For both the production and consumption pathways, the contribution of each reaction does not change significantly, if evaluated for separate points within the first $0.2 \mathrm{~cm}$ instead of averaging over this region. However, the ratio of the total rate of production and consumption changes significantly, leading to the increase in $\mathrm{OH}$ density over this region. Further from the gas inlet, the rates of production and consumption equalise leading to an equilibrium $\mathrm{OH}$ density.

In the quasi steady state region $(2-2.5 \mathrm{~cm})$, the previous pathways still dominate. However, additional species with intermediate lifetimes build up along the channel and begin to play a role in the formation of $\mathrm{OH}$. For example, hydroperoxy radicals $\left(\mathrm{HO}_{2}\right)$ promote production of $\mathrm{OH}$ through reactions with $\mathrm{H}$

$$
\mathrm{H}+\mathrm{HO}_{2} \rightarrow 2 \mathrm{OH}(25 \%)
$$

while $\mathrm{H}_{2} \mathrm{O}_{2}$ and $\mathrm{HO}_{2}$ lead to the destruction of $\mathrm{OH}$ through

$$
\begin{gathered}
\mathrm{OH}+\mathrm{H}_{2} \mathrm{O}_{2} \rightarrow \mathrm{HO}_{2}+\mathrm{H}_{2} \mathrm{O} \quad(15 \%) \\
\mathbf{O H}+\mathrm{HO}_{2} \rightarrow \mathrm{O}_{2}+\mathrm{H}_{2} \mathrm{O} \quad(10 \%)
\end{gathered}
$$

In the afterglow region $(3.3-3.5 \mathrm{~cm})$, a rapid decay of $\mathrm{OH}$ occurs both in experiment and simulation, as shown in Fig. 7. Short lived species such as ions and electrons recombine rapidly, while metastable species like $\mathrm{He}^{*}$ and $\mathrm{He}_{2}{ }^{*}$ are consumed through Penning ionization with water before reaching this region. Therefore, the chemistry in the plasma effluent is dominated by intermediate and long lived neutral species, where $\mathrm{OH}$ is produced mainly through reactions between $\mathrm{H}$ and longer-lived neutral species:

$$
\begin{gathered}
\mathrm{H}+\mathrm{HO}_{2} \rightarrow 2 \mathrm{OH} \quad(96 \%) \\
\mathrm{H}+\mathrm{H}_{2} \mathrm{O}_{2} \rightarrow \mathbf{O H}+\mathrm{H}_{2} \mathrm{O} \quad(2 \%)
\end{gathered}
$$

In this region, consumption occurs at a higher rate than production, leading to a decrease in the $\mathrm{OH}$ density, with reactions (22) and (18) (collisions with $\mathrm{H}_{2} \mathrm{O}_{2}$ and $\mathrm{OH}$ ) dominating.

\subsection{OH densities under varying humidity content}

The density of $\mathrm{OH}$ measured by UV-BBAS in the centre of the plasma channel (at position $1.2 \mathrm{~cm}$ ) as a function of the $\mathrm{H}_{2} \mathrm{O}$ content in the feed gas is shown in Fig. 9(a). The $\mathrm{OH}$ density increases sub-linearly with increasing $\mathrm{H}_{2} \mathrm{O}$ content, as previously observed. ${ }^{34,43}$ Absolute densities obtained in this work also agree well with results obtained by others. ${ }^{34,43}$ Absolute $\mathrm{OH}$ densities measured with the two different experimental setups agree well within the uncertainties in each measurement.

The simulated $\mathrm{OH}$ densities at different feed gas humidity contents are shown in Fig. 9(a). In general, good agreement in the trends of experimental and simulation results is observed. Absolute $\mathrm{OH}$ densities agree particularly well at low $\mathrm{H}_{2} \mathrm{O}$ contents $<2000$ ppm. Towards higher $\mathrm{H}_{2} \mathrm{O}$ contents, simulated densities are higher than those measured experimentally. The largest difference is a factor 1.8 at the highest $\mathrm{H}_{2} \mathrm{O}$ content, which is reasonable agreement given the previously mentioned uncertainties.

$\mathrm{OH}(\mathrm{X})$ rotational temperatures and gas temperatures calculated using GlobalKin are shown in Fig. 9(b), and found to be in good quantitative agreement with each other. In both experiment and simulations, temperatures stay fairly constant with increasing water content. While in the simulation, a very small decrease of the gas temperature is observed, the experimental data is more scattered, and a clear trend cannot be observed taking into account the uncertainties of the measurement.

The main production and consumption pathways for $\mathrm{OH}$ at different $\mathrm{H}_{2} \mathrm{O}$ admixtures are shown in Fig. 10. Two production pathways dominate for all $\mathrm{H}_{2} \mathrm{O}$ admixtures. The dominant pathway for $\mathrm{OH}$ production at lower $\mathrm{H}_{2} \mathrm{O}$ contents is via Penning ionisation of $\mathrm{H}_{2} \mathrm{O}$, and subsequent cluster association reactions (eqn (17)). At any stage of the clustering process, the clusters can be destroyed by dissociative recombination with electrons

$$
\mathrm{e}+\mathrm{H}^{+}\left(\mathrm{H}_{2} \mathrm{O}\right)_{n} \rightarrow \mathrm{H}+n \times \mathrm{H}_{2} \mathrm{O}
$$

Towards higher $\mathrm{H}_{2} \mathrm{O}$ contents, this pathway is gradually replaced by direct electron impact dissociation or dissociative electron attachment with $\mathrm{H}_{2} \mathrm{O}$ (eqn (14) and (16)).

$\mathrm{OH}$ is mainly consumed by reactions with other $\mathrm{OH}$ radicals (eqn (18) and (19)) and $\mathrm{O}$

$$
\mathrm{OH}+\mathrm{O} \rightarrow \mathrm{O}_{2}+\mathrm{H}
$$

Towards higher water admixtures, the contributions of these reactions to the consumption of $\mathrm{OH}$ decrease slightly, and reactions of $\mathrm{OH}$ with $\mathrm{H}$, and more slowly forming species such as $\mathrm{H}_{2} \mathrm{O}_{2}$ and $\mathrm{HO}_{2}$ become more important. 

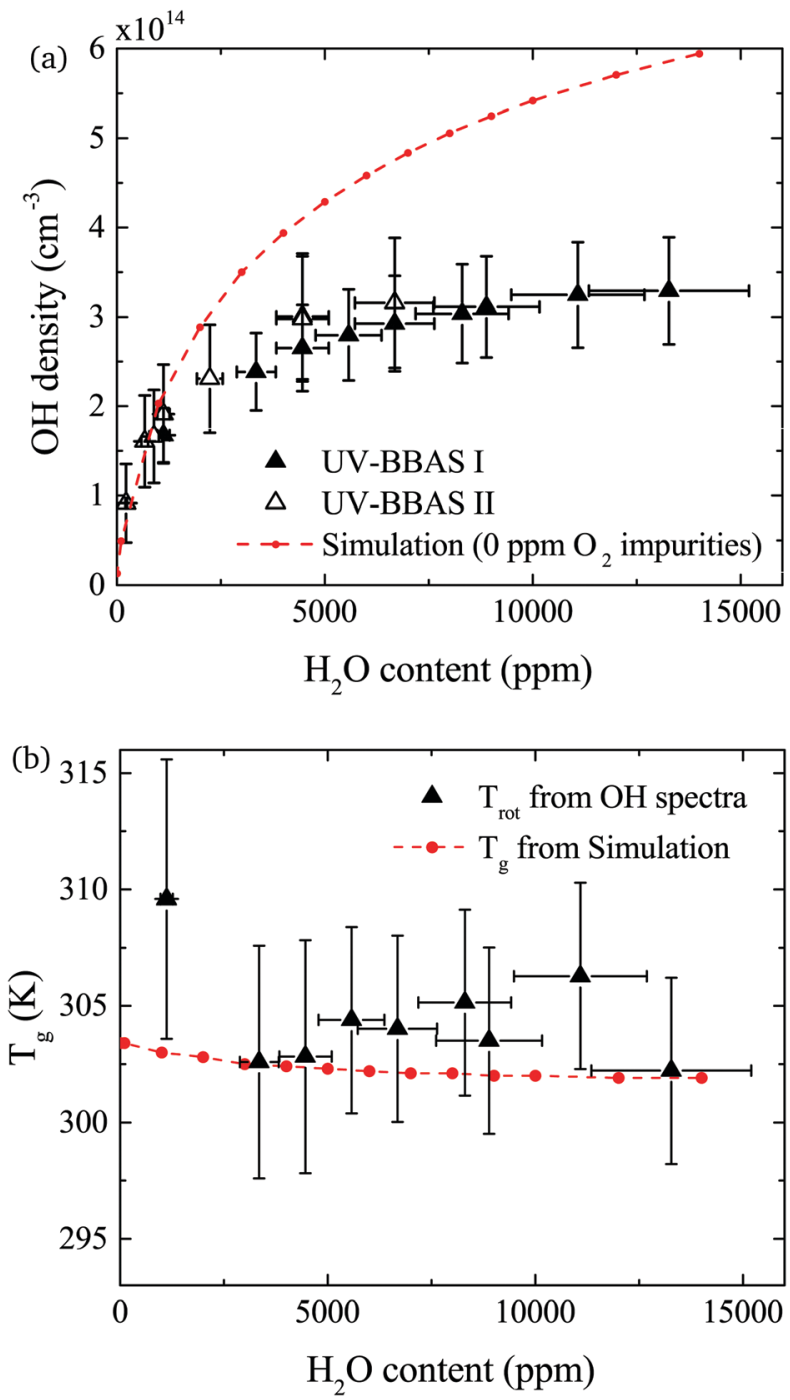

Fig. 9 (a) Absolute $\mathrm{OH}$ densities as a function of the water content of the He feed gas for a total He flow of $5 \mathrm{slm}$ and $14 \mathrm{~W} \mathrm{~cm}^{-3}$ plasma power. Triangles represent the experimental values (taken in the centre of the plasma channel at $x=1.2 \mathrm{~cm}$ ) and the dashed red line the simulation results. $\mathrm{OH}$ densities are measured using two different UV-BBAS setups, as described in the text. (b) Rotational temperatures obtained from the experimental $\mathrm{OH}(\mathrm{X})$ absorbance spectra measured with the UV-BBAS I setup (black triangles) and gas temperatures calculated using GlobalKin (red dashed line). Error bars for temperature measurements represent uncertainties resulting from the fitting procedure.

In both experiment and simulation, $\mathrm{OH}$ densities increase rapidly with increasing $\mathrm{H}_{2} \mathrm{O}$ at low $\mathrm{H}_{2} \mathrm{O}$ content, and less rapidly at high $\mathrm{H}_{2} \mathrm{O}$ content. The transition between these two regimes occurs at lower $\mathrm{H}_{2} \mathrm{O}$ content (around $2000 \mathrm{ppm}$ ) in the experiment compared to the simulation (around $3000 \mathrm{ppm}$ ). This leads to the increasing discrepancy between simulation and experiment at higher $\mathrm{H}_{2} \mathrm{O}$ contents where the experimental $\mathrm{OH}$ densities saturate and the simulated $\mathrm{OH}$ densities continue to slowly increase. The reason for this transition is investigated by looking at the most important formation pathways for $\mathrm{OH}$, which are production by electron impact dissociation and dissociative

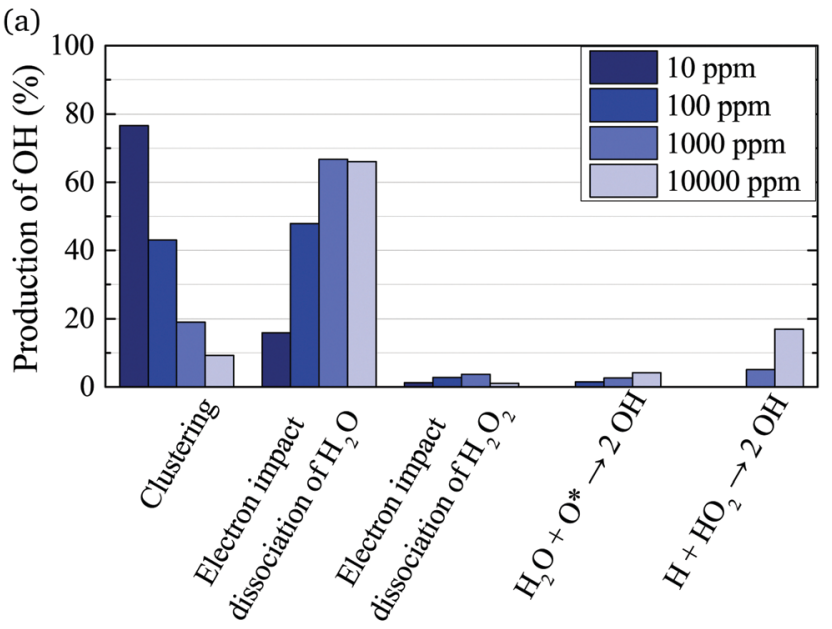

(b)

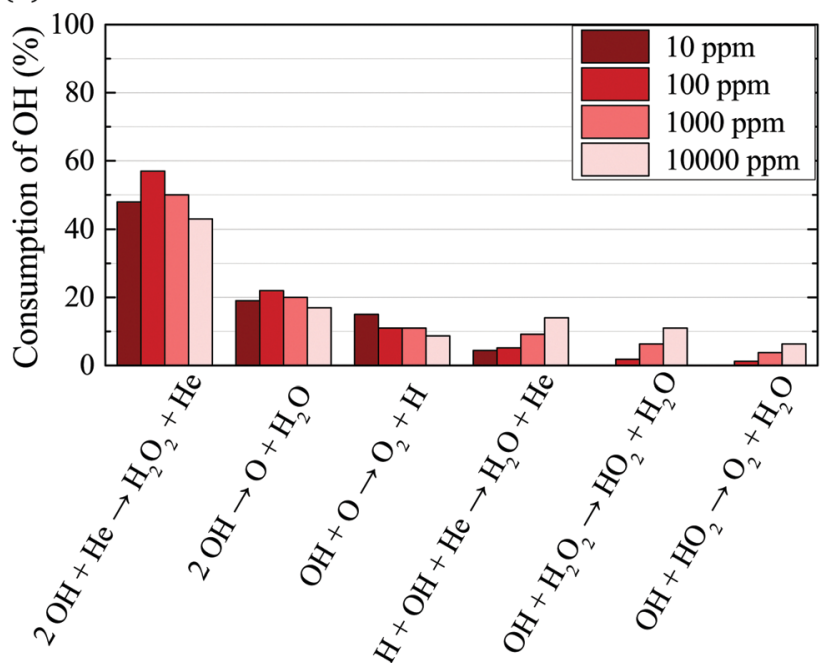

Fig. 10 Dominant production (a) and consumption (b) pathways of $\mathrm{OH}$ for different $\mathrm{H}_{2} \mathrm{O}$ feed gas contents. The rates from which percentages are calculated are averaged over the whole discharge channel $(0-2.4 \mathrm{~cm}$, without effluent region).

attachment of $\mathrm{H}_{2} \mathrm{O}$ (eqn (14)-(16)), and consumption via reactions with $\mathrm{OH}$ to form $\mathrm{H}_{2} \mathrm{O}_{2}$ and $\mathrm{H}_{2} \mathrm{O}$ (eqn (18) and (19)). As the gas temperature remains relatively constant with changing water content, rate coefficients for consumption of $\mathrm{OH}$ also stay approximately constant. The reaction rate coefficient for production of $\mathrm{OH}$ is dependent on the electron temperature $T_{\mathrm{e}}$, and the electron density $n_{\mathrm{e}}$. Fig. 11(a) shows the two quantities as a function of humidity content. $T_{\mathrm{e}}$ and $n_{\mathrm{e}}$ show opposite trends with increasing $\mathrm{H}_{2} \mathrm{O}$ admixture. $T_{\mathrm{e}}$, which is calculated from balancing the electron energy sources and losses (see eqn (11)), increases with increasing $\mathrm{H}_{2} \mathrm{O}$ content due to increasing electron energy losses in inelastic collisions with water molecules. For constant power input, the increased electron energy losses and $T_{\mathrm{e}}$ are balanced by a decrease in $n_{\mathrm{e}}$ with increasing $\mathrm{H}_{2} \mathrm{O}$ content.

The effect of these changes on the total rate coefficient for dissociation $k_{\text {diss }}=k_{14}+k_{15}+k_{16}$ and the dissociation frequency $R=k_{\text {diss }} n_{\mathrm{e}}$ is shown in Fig. 11(b). Due to the variation in $T_{\mathrm{e}}, k_{\mathrm{diss}}$ increases with increasing humidity content, exhibiting a 

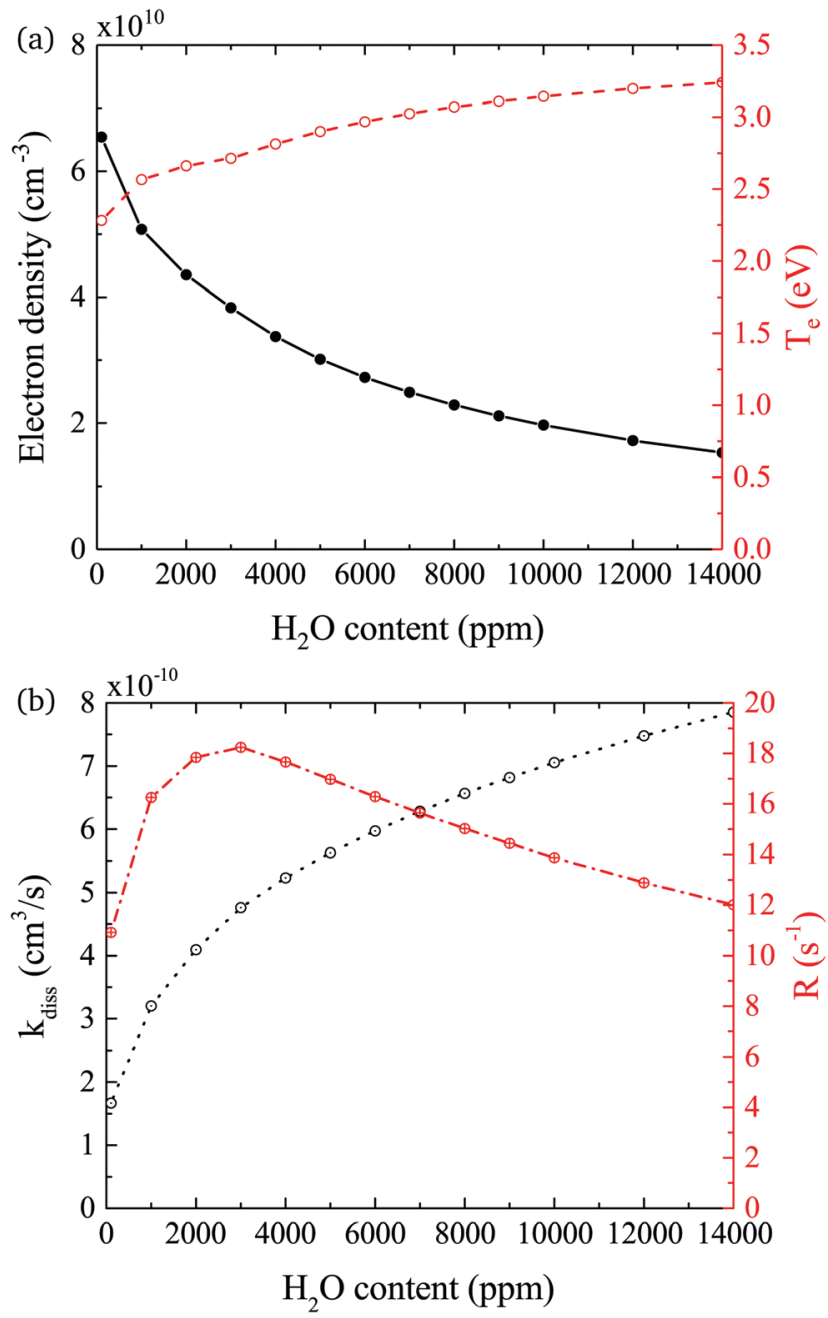

Fig. 11 (a) Electron density $n_{\mathrm{e}}$ and temperature $T_{\mathrm{e}}$, and (b) combined rate coefficient $k_{\text {diss }}$ for electron impact dissociation and dissociative attachment and dissociation frequency $R=k_{\text {diss }} n_{\mathrm{e}}$. Conditions are $5 \mathrm{slm}$ total He flow and $14 \mathrm{~W} \mathrm{~cm}^{-3}$ plasma power.

similar trend to the $\mathrm{OH}$ densities shown in Fig. 9. Here, the transition from a fast to a slow increase also occurs around $3000 \mathrm{ppm}$. The dissociation frequency $R$ exhibits a peak at this humidity content, which represents the optimum between the increasing $T_{\mathrm{e}}$ and decreasing $n_{\mathrm{e}}$. Thus, the origin of the transition between fast and slow increase in $\mathrm{OH}$ density with increasing humidity content is a result of the transition between an increasing dissociation frequency below $3000 \mathrm{ppm}_{2} \mathrm{O}$ to a decreasing dissociation frequency above $3000 \mathrm{ppm}_{2} \mathrm{O}$. Overall, the dissociation rate $R \times n_{\mathrm{H}_{2} \mathrm{O}}$, and therefore the $\mathrm{OH}$ density, increases over the whole range due to the increasing value of $n_{\mathrm{H}_{2} \mathrm{O}}$. Based on this discussion, the differing $\mathrm{H}_{2} \mathrm{O}$ contents at which the transition occurs in the experiment and simulation may indicate that the rate of electron energy loss with increasing $\mathrm{H}_{2} \mathrm{O}$ content is misrepresented in the simulation. Another reason for the discrepancy between the simulated and measured trend in $\mathrm{OH}$ densities at higher water contents might be due to an additional consumption mechanism for $\mathrm{OH}$, which is not taken into account in this work, such as the population of vibrationally excited states, which would also scale with $T_{\mathrm{e}}$.

\subsection{O densities as a function of humidity content}

The absolute $\mathrm{O}$ density measured by VUV-FTAS in the centre of the discharge (at $x=1.2 \mathrm{~cm}$, triangles) as a function of $\mathrm{H}_{2} \mathrm{O}$ content in the feed gas is shown in Fig. 12. The $\mathrm{O}$ density increases with increasing $\mathrm{H}_{2} \mathrm{O}$ content and approaches a steady-state value of around $3 \times 10^{13} \mathrm{~cm}^{-3}$. The simulated $\mathrm{O}$ density also shows an increase towards higher $\mathrm{H}_{2} \mathrm{O}$ admixtures, however, the $\mathrm{O}$ densities continue to increase more significantly at higher $\mathrm{H}_{2} \mathrm{O}$ content than the experimental results. This is similar to the case of the $\mathrm{OH}$ density discussed earlier. Simulated $\mathrm{O}$ densities are around a factor 2 lower than those obtained experimentally. The measured densities agree well with previous measurements in a similar source using twophoton absorption laser induced fluorescence. ${ }^{34}$

A possible explanation for the difference in absolute $\mathrm{O}$ densities and trends between the experiment and simulation may be limitations in the global model, particularly the accuracy of the rate coefficients used, as discussed earlier. $\mathrm{O}$ is not directly produced from $\mathrm{H}_{2} \mathrm{O}$ due to electron or heavy particle impact dissociation in significant amounts at the electron temperature of interest. As a result, $\mathrm{O}$ must be formed in a process taking at least two steps, meaning that the uncertainties in multiple rate coefficients will play a role in determining the uncertainty in the simulated $\mathrm{O}$ density. As a result, the simulated $\mathrm{O}$ density is likely to have a larger uncertainty than the simulated $\mathrm{OH}$ density, whose dominant formation occurs directly from electron collisions with $\mathrm{H}_{2} \mathrm{O}$. As shown in Fig. 13, the dominant production mechanism of $\mathrm{O}$ is via recombination of two $\mathrm{OH}$ molecules to form $\mathrm{H}_{2} \mathrm{O}$ and $\mathrm{O}$. At lower $\mathrm{H}_{2} \mathrm{O}$

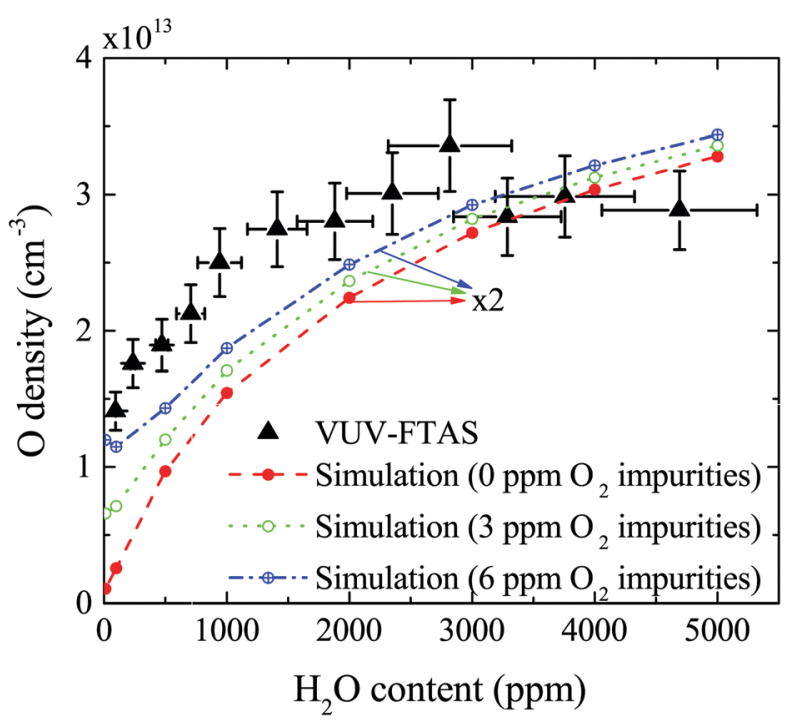

Fig. 12 Absolute $\mathrm{O}$ density as a function of the water content in the He feed gas, in the centre of the plasma channel (at position $x=1.2 \mathrm{~cm}$ ). Conditions are $5 \mathrm{slm}$ total He flow and $10 \mathrm{~W} \mathrm{~cm} \mathrm{~cm}^{-3}$ plasma power. Simulations are also shown for different impurity level concentrations of $\mathrm{O}_{2}$ which may be present in the feed gas. 

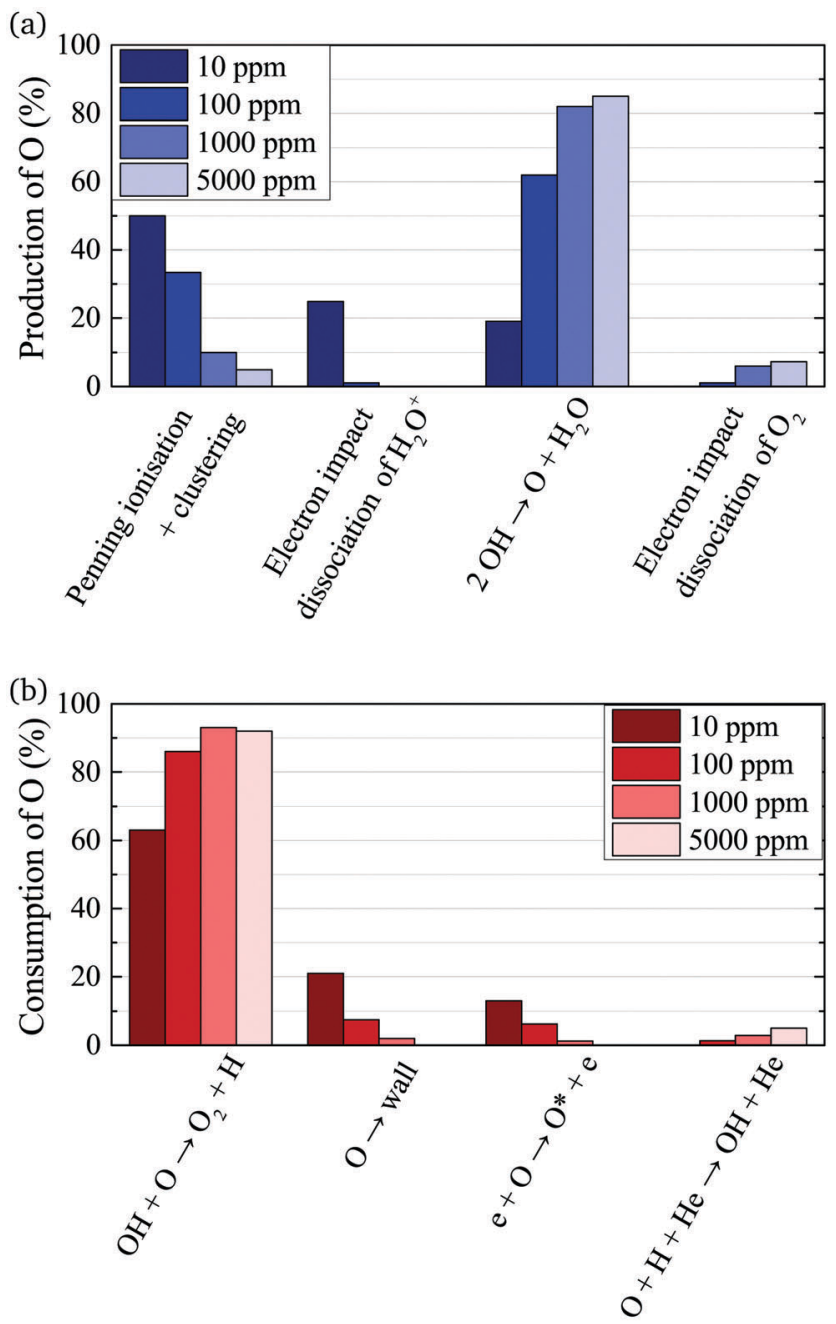

Fig. 13 Dominant production (a) and consumption (b) pathways of $\mathrm{O}$ for different admixtures of $\mathrm{H}_{2} \mathrm{O}$. The rates from which percentages are calculated are averaged over the whole discharge channel $(0-2.4 \mathrm{~cm}$, without effluent region).

contents, $\mathrm{O}$ is also formed through processes involving positive ion water clusters:

$$
\begin{aligned}
& \mathrm{OH}^{+}+\mathrm{H}_{2} \mathrm{O} \rightarrow \mathrm{H}^{+}\left(\mathrm{H}_{2} \mathrm{O}\right)+\mathbf{O} \\
& \mathrm{H}^{+}\left(\mathrm{H}_{2} \mathrm{O}\right)+n \cdot \mathrm{H}_{2} \mathrm{O}+\mathrm{He} \rightarrow \mathrm{H}^{+}\left(\mathrm{H}_{2} \mathrm{O}\right)_{n+1}+\mathrm{He}
\end{aligned}
$$

$$
\mathrm{OH}^{+}+(n+1) \times \mathrm{H}_{2} \mathrm{O} \rightarrow \mathbf{O}+\mathrm{H}^{+} \cdot\left(\mathrm{H}_{2} \mathrm{O}\right)_{n+1}
$$

With increasing $\mathrm{H}_{2} \mathrm{O}$ admixture the formation of $\mathrm{O}_{2}$ is also increased. As a result, electron impact dissociation of $\mathrm{O}_{2}$ becomes a more important production pathway for $\mathrm{O}$ :

$$
\begin{gathered}
\mathrm{e}+\mathrm{O}_{2} \rightarrow 2 \mathrm{O}+\mathrm{e}(6 \mathrm{eV}) \\
\mathrm{e}+\mathrm{O}_{2} \rightarrow \mathbf{O}+\mathrm{O}\left({ }^{1} \mathrm{D}\right)+\mathrm{e} \quad(8.4 \mathrm{eV})
\end{gathered}
$$

Where the numbers in brackets represent the electron energy thresholds for these reactions. $\mathrm{O}$ is mainly consumed by reactions involving $\mathrm{OH}$ forming $\mathrm{O}_{2}$ and $\mathrm{H}$ (eqn (27)).
The measured and simulated $\mathrm{O}$ densities show an increased discrepancy towards smaller $\mathrm{H}_{2} \mathrm{O}$ admixtures $<1000 \mathrm{ppm}$. A possible explanation for this might lie in the presence of unintentional air impurities in the experiment, which have been found previously to be able to influence the chemical kinetics in atmospheric pressure plasmas. ${ }^{75-77}$ For the measurement of $\mathrm{O}$, we use helium with a purity level of $99.999 \%$, whereas the main impurities are $\mathrm{H}_{2} \mathrm{O}(3 \mathrm{ppm})$ and $\mathrm{O}_{2}(2 \mathrm{ppm})$. Additional small impurities could arise from residual gases in the feed gas line. Simulations for two different non-zero $\mathrm{O}_{2}$ impurity concentrations in the order of typical $\mathrm{O}_{2}$ impurities originating from the feed gas supply are shown in Fig. 12. Particularly at low $\mathrm{H}_{2} \mathrm{O}$ content, these impurities lead to an increase of $\mathrm{O}$ compared to the simulation without $\mathrm{O}_{2}$ added as an impurity. Since the density of $\mathrm{O}$ produced from $\mathrm{H}_{2} \mathrm{O}$ is low, typically a few ppm, even small $\mathrm{O}_{2}$ containing impurities can significantly influence the $\mathrm{O}$ density produced in the plasma. At high $\mathrm{H}_{2} \mathrm{O}$ content, the influence of $\mathrm{O}_{2}$ impurities on the $\mathrm{O}$ density is smaller, and the plasma chemistry is dominated by hydrogen containing species.

\subsection{Numerical investigation of the production of longer-lived species}

The $\mathrm{OH}$ density reaches a steady-state value in the simulation well before the end of the plasma channel in both simulation and experiment. Particularly at higher $\mathrm{H}_{2} \mathrm{O}$ content, this is a result of $\mathrm{OH}$ being primarily produced by direct electron impact dissociation of $\mathrm{H}_{2} \mathrm{O}$ in a one step process (eqn (14)) and is consumed in interactions with other $\mathrm{OH}$ molecules. Atomic hydrogen behaves similarly, being produced mainly by electron impact dissociation and consumed via interactions with surfaces, ${ }^{71}$ both of which occur relatively quickly. However, other species do not reach a steady state within the length of the plasma channel, and instead continuously increase in density up to the outlet of the plasma source. This is particularly true for slowly forming, long-lived species such as $\mathrm{O}_{2}$, $\mathrm{H}_{2} \mathrm{O}_{2}$ and $\mathrm{H}_{2}$, as shown in Fig. 14. This finding suggests that the length of the plasma source, or the gas flow rate, and therefore the residence time of the gas, can be used to control the ratio of different species densities by taking advantage of the different timescales required for them to reach steady-state.

First, we will discuss the formation of $\mathrm{O}$ in more detail. The density of $\mathrm{O}$ does not reach a steady-state value in the simulation within the plasma channel for most investigated conditions using a $\mathrm{He}-\mathrm{H}_{2} \mathrm{O}$ gas mixture. Long timescales for simulations of atmospheric pressure $\mathrm{He}-\mathrm{H}_{2} \mathrm{O}$ plasmas to reach steady-state have also been found by others. ${ }^{78}$ This is in contrast to the case where similar sources are operated in He- $\mathrm{O}_{2}$ mixtures. ${ }^{79}$ In the work described in ref. 79, O densities approach steady-state towards the end of the plasma channel of the AAPPJ. In Fig. 14, O densities are increasing sharply within the first few millimetres of the channel, and then at a lower rate up to the end of the channel. Therefore, $\mathrm{O}$ densities follow a similar dependence as the $\mathrm{OH}$ densities also shown in Fig. 14. This is not surprising when considering that both the dominant production and consumption pathways are related to $\mathrm{OH}$, i.e. production by reactions of two $\mathrm{OH}$ molecules to form $\mathrm{H}_{2} \mathrm{O}$ and $\mathrm{O}$ 


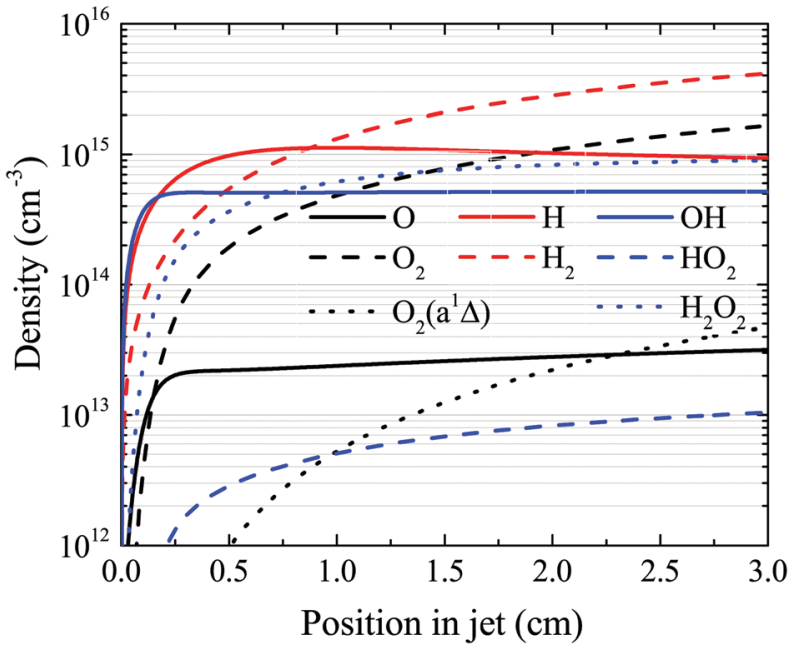

Fig. 14 Spatial development for several species of interest as a function of position in the plasma channel, under the same conditions shown in Fig. 7 (18 $\mathrm{W} \mathrm{cm}^{-3}$ plasma power, 5400 ppm humidity).

(eqn (19)), and consumption via collisions with $\mathrm{OH}$ to form $\mathrm{O}_{2}$ and $\mathrm{H}$ (eqn (27)). The fact that $\mathrm{O}$ is still building up within the channel, while $\mathrm{OH}$ approaches a steady-state value, is due to the continuous build-up of $\mathrm{O}_{2}$ in the channel, also shown in Fig. 14. Electron impact dissociation of $\mathrm{O}_{2}$ (eqn (29) and (30)) provides an additional formation mechanism for $\mathrm{O}$ further into the channel, although eqn (19) and (27) are still the dominant production and consumption pathways for $\mathrm{O}$. Overall, this leads to a slow increase of the $\mathrm{O}$ density while the $\mathrm{O}_{2}$ density continues to increase.

The formation of species that reach steady-state on timescales longer than the residence time in the discharge channel are usually comprised of a complex multi-step processes. As an example, we demonstrate the dominant pathways for formation of $\mathrm{O}_{2}$, which is an important precursor for the formation of excited states of $\mathrm{O}_{2}$, such as $\mathrm{O}_{2}\left(\mathrm{a}^{1} \Delta\right)$. Since $\mathrm{O}_{2}$ is a slowly forming species, we look at dominant production and consumption pathways for a longer timescale $\tau_{\mathrm{p}}$ than those previously given in Table 2 . The time scale of interest in the simulation is chosen so that only $\mathrm{He}, \mathrm{H}_{2} \mathrm{O}, \mathrm{O}_{2}$, $\mathrm{O}_{2}\left(\mathrm{a}^{1} \Delta\right), \mathrm{H}_{2}$, and $\mathrm{H}_{2} \mathrm{O}_{2}$ are treated as long-lived species, in accordance with previous studies. ${ }^{52}$ The computational lifetimes of the shortest-lived species of these six are listed in Table 3 for different $\mathrm{H}_{2} \mathrm{O}$ contents.

The two main net production reactions for the formation of molecular oxygen are found to be

$$
\begin{aligned}
2 \mathrm{H}_{2} \mathrm{O} & \rightarrow 2 \mathrm{H}_{2}+\mathbf{O}_{2} \\
\mathrm{H}_{2} \mathrm{O}_{2} & \rightarrow \mathrm{H}_{2}+\mathbf{O}_{2}
\end{aligned}
$$

Table 3 Lifetimes of the shortest-lived species out of $\mathrm{He}, \mathrm{H}_{2} \mathrm{O}, \mathrm{O}_{2}, \mathrm{O}_{2}(\mathrm{a}$ ${ }^{1} \Delta$ ), $\mathrm{H}_{2}$, and $\mathrm{H}_{2} \mathrm{O}_{2}$ for different humidity contents in the plasma

\begin{tabular}{lll}
\hline $\mathrm{H}_{2} \mathrm{O}$ content $(\mathrm{ppm})$ & $\mathrm{O}_{2}\left(\mathrm{a}^{1} \Delta\right)$ lifetime $(\mathrm{ms})$ & $\mathrm{H}_{2} \mathrm{O}_{2}$ lifetime $(\mathrm{ms})$ \\
\hline 100 & 2.78 & 4.38 \\
1000 & 2.74 & 2.74 \\
10000 & 4.55 & 1.35
\end{tabular}

Many different pathways are possible in order to obtain these net reactions. A few examples of these pathways are

$$
\begin{aligned}
& 3 \cdot\left(\mathrm{e}+\mathrm{H}_{2} \mathrm{O} \rightarrow \mathrm{H}+\mathrm{OH}+\mathrm{e}\right) \\
& 2 \mathrm{OH} \rightarrow \mathrm{O}+\mathrm{H}_{2} \mathrm{O} \\
& \mathrm{OH}+\mathrm{O} \rightarrow \mathrm{O}_{2}+\mathrm{H} \\
& 4 \cdot\left(\mathrm{H} \rightarrow \frac{1}{2} \mathrm{H}_{2}\right) \\
& 2 \mathrm{H}_{2} \mathrm{O} \rightarrow 2 \mathrm{H}_{2}+\mathrm{O}_{2} \\
& 3 \cdot\left(\mathrm{e}+\mathrm{He}^{-} \mathrm{He}^{*}+\mathrm{e}\right) \\
& 3 \cdot\left(\mathrm{He}^{*}+\mathrm{H}_{2} \mathrm{O} \rightarrow \mathrm{He}+\mathrm{H}_{2} \mathrm{O}^{+}\right) \\
& 3 \cdot\left(\mathrm{H}_{2} \mathrm{O}^{+}+\mathrm{H}_{2} \mathrm{O} \rightarrow \mathrm{OH}+\mathrm{H}^{+}\left(\mathrm{H}_{2} \mathrm{O}\right)\right) \\
& 3 \cdot\left(\mathrm{H}^{+}\left(\mathrm{H}_{2} \mathrm{O}\right)_{n}+\mathrm{H}_{2} \mathrm{O}+\mathrm{He}^{\prime} \mathrm{H}^{+}\left(\mathrm{H}_{2} \mathrm{O}\right)_{n+1}+\mathrm{He}\right) \\
& 3 \cdot\left(\mathrm{H}^{+}\left(\mathrm{H}_{2} \mathrm{O}\right)_{n}+\mathrm{e} \rightarrow \mathrm{H}+n \times \mathrm{H}_{2} \mathrm{O}\right) \\
& 2 \mathrm{OH} \rightarrow \mathrm{O}_{+} \mathrm{H}_{2} \mathrm{O} \\
& \mathrm{OH}+\mathrm{O} \rightarrow \mathrm{O}_{2}+\mathrm{H} \\
& 4 \cdot\left(\mathrm{H}^{2} \frac{1}{2} \mathrm{H}_{2}\right)
\end{aligned}
$$

$$
\begin{aligned}
& 2 \mathrm{H}_{2} \mathrm{O} \rightarrow 2 \mathrm{H}_{2}+\mathrm{O}_{2} \\
& 2 \cdot\left(\mathrm{e}+\mathrm{H}_{2} \mathrm{O} \rightarrow \mathrm{H}+\mathrm{OH}+\mathrm{e}\right) \\
& \mathrm{OH}+\mathrm{H}_{2} \mathrm{O}_{2} \rightarrow \mathrm{HO}_{2}+\mathrm{H}_{2} \mathrm{O} \\
& \mathrm{OH}+\mathrm{HO}_{2} \rightarrow \mathrm{O}_{2}+\mathrm{H}_{2} \mathrm{O} \\
& 2 \cdot\left(\mathrm{H} \rightarrow \frac{1}{2} \mathrm{H}_{2}\right)
\end{aligned}
$$$$
\mathrm{H}_{2} \mathrm{O}_{2} \rightarrow \mathrm{H}_{2}+\mathrm{O}_{2}
$$

Note that eqn (33) and (34) have the same net production reaction, although the intermediate steps towards the formation of $\mathrm{O}_{2}$ (i.e. the pathway) are different. Eqn (33) starts with the electron impact dissociation of $\mathrm{H}_{2} \mathrm{O}$ molecules. The reaction of $\mathrm{OH}$ with $\mathrm{OH}$ and $\mathrm{O}$ leads to the formation of $\mathrm{O}_{2}$. The $\mathrm{H}$ atoms formed recombine at surfaces to form $\mathrm{H}_{2}$.

Eqn (34) is the same net reaction, however, the step-by-step analysis reveals a different pathway. In this case, $\mathrm{H}_{2} \mathrm{O}$ molecules are first ionised via Penning ionisation with $\mathrm{He}^{*}$. $\mathrm{H}_{2} \mathrm{O}^{+}$ions then start accumulating more $\mathrm{H}_{2} \mathrm{O}$ molecules in a clustering process, where $\mathrm{OH}$ is produced. Similar to the previous pathways, the reaction of $\mathrm{OH}$ with $\mathrm{OH}$ and $\mathrm{O}$ lead to the formation of $\mathrm{O}_{2}$. The cluster ions produced are consumed by dissociative recombination with electrons, and $\mathrm{H}$, which is formed in that process, is lost by surface recombination. Other pathways exists that involve the formation of clusters, but are not explicitly discussed here. 
Eqn (35) has a different net production reaction than the others. In this case, $\mathrm{OH}$ produced from electron impact dissociation reacts with $\mathrm{H}_{2} \mathrm{O}_{2}$ to form reactive $\mathrm{HO}_{2}$, which then forms $\mathrm{O}_{2}$ during reactions with $\mathrm{OH}$.

\section{Conclusions}

In this work, the chemical kinetics in an rf atmospheric pressure plasma with humidity are investigated using experimental and numerical techniques. By using this combination, computed species densities are benchmarked against experimental densities. The simulations are then used to reveal the dominant formation pathways of species of interest, here $\mathrm{OH}$ and $\mathrm{O}$, and longer lived species such as $\mathrm{O}_{2}$, which is an important precursor for the formation of its excited states, such as $\mathrm{O}_{2}\left(\mathrm{a}^{1} \Delta\right)$. This work provides a detailed understanding of chemical kinetics in the active plasma. In many applications, reactive species will exit the plasma source and transit into an effluent region where they will mix with ambient air, where their chemical kinetics will differ. While this is not considered in this work, the results presented here provide a basis to be built on in future work to understand reactive species kinetics in this transition region.

Absolute number densities of $\mathrm{O}$ and $\mathrm{OH}$ are determined experimentally using VUV high-resolution Fourier-transform absorption spectroscopy, UV broad-band absorption spectroscopy, and numerically by using the 0-D plasma chemical kinetics code GlobalKin.

Absolute $\mathrm{OH}$ densities and formation pathways are investigated as a function of position in the discharge. Three different regions can be identified i.e. (a) a strong increase of $\mathrm{OH}$ density in the first few millimeters of the plasma channel, (b) a quasi steady-state region, and (c) a rapid drop of $\mathrm{OH}$ density in the plasma effluent region. During the fast increase and steady-state regions, $\mathrm{OH}$ is mainly produced via fast processes such as electron impact dissociation of $\mathrm{H}_{2} \mathrm{O}$, and consumed predominantly via reactions with other $\mathrm{OH}$ molecules to form $\mathrm{H}_{2} \mathrm{O}_{2}$ or $\mathrm{H}_{2} \mathrm{O}$. These relatively simple chemical kinetics make it possible for $\mathrm{OH}$ to reach an equilibrium value within the plasma channel.

Other species, whose densities have not been measured, are investigated numerically as a function of position in the plasma channel. Simulation results show that the $H$ density approaches a steady-state value within the plasma channel, similarly to $\mathrm{OH}$ as discussed previously, as it is mostly formed directly via electron impact dissociation of water, and consumed at surfaces to form stable $\mathrm{H}_{2}$. However, most other species generated in the $\mathrm{He}-\mathrm{H}_{2} \mathrm{O}$ plasma studied in this work do not reach a steady-state value within the length of the plasma channel due to more complex formation mechanisms. This has been shown using $\mathrm{O}_{2}$ as an example. Therefore, the length of the plasma source could be used as a control parameter to tune the chemical composition of the gas at the end of the plasma jet for applications.

Both $\mathrm{OH}$ and $\mathrm{O}$ densities are also investigated as a function of the humidity content in the He feed gas. It is found, both in experiments and simulations, that $\mathrm{O}$ and $\mathrm{OH}$ densities increase non-linearly with increasing feed gas humidity, offering the possibility of tailoring reactive species densities by changing the feed gas composition.

The maximum $\mathrm{OH}$ density is on the order of $3-4 \times 10^{14} \mathrm{~cm}^{-3}$ (13-17 ppm). It is found that at very low water content, $\mathrm{OH}$ is mainly produced via reactions between $\mathrm{H}_{2} \mathrm{O}^{+}$and water molecules to form $\mathrm{OH}$ and protonated water clusters of the form $\mathrm{H}^{+}$. $\left(\mathrm{H}_{2} \mathrm{O}\right)_{n}$, while electron impact dissociation of $\mathrm{H}_{2} \mathrm{O}$ becomes an increasingly important production pathway with increasing water content. The main loss channel for $\mathrm{OH}$ at all $\mathrm{H}_{2} \mathrm{O}$ contents is recombination to form $\mathrm{H}_{2} \mathrm{O}_{2}$.

The maximum $\mathrm{O}$ density on the other hand is found to be in the order of $3 \times 10^{13} \mathrm{~cm}^{-3}(1.3 \mathrm{ppm})$. Recombination of two $\mathrm{OH}$ molecules is the most important production process for $\mathrm{O}$ at all $\mathrm{H}_{2} \mathrm{O}$ contents, while at very low water content, $\mathrm{OH}$ is also strongly produced via reactions between $\mathrm{OH}^{+}$and water molecules to form $\mathrm{O}$ and protonated water clusters. Since the dominant destruction pathway of $\mathrm{O}$ is recombination with $\mathrm{OH}$ to form $\mathrm{O}_{2}$ and $\mathrm{H}$, the formation of $\mathrm{O}$ is strongly coupled to the $\mathrm{OH}$ density in the gas flow. At higher $\mathrm{H}_{2} \mathrm{O}$ concentrations, electron impact dissociation of accumulated $\mathrm{O}_{2}$ can also contribute to the production of $\mathrm{O}$. It is also found that towards low $\mathrm{H}_{2} \mathrm{O}$ content, production of $\mathrm{O}$ from air impurities in the ppm range originating from the feed gas can increase the $\mathrm{O}$ density via direct electron impact dissociation of $\mathrm{O}_{2}$. Towards higher $\mathrm{H}_{2} \mathrm{O}$ admixtures, this effect becomes less significant due to increased production via collisions involving $\mathrm{OH}$. Therefore, larger amounts of purposely admixed molecules lead to a better control of the plasma properties and reactive species than operating the source with small or no intentional admixtures.

\section{Conflicts of interest}

There are no conflicts to declare.

\section{Appendix}

\section{A. Reaction mechanism}

Table 4 shows wall recombination coefficients and return species for the simulations used in this work.

Table 4 Wall sticking coefficients and return fractions for various species considered in this work

\begin{tabular}{llll}
\hline Species & $\gamma$ & Return species & Ref. \\
\hline $\mathrm{He}_{2}{ }^{*}$ & 1.00 & $2 \mathrm{He}$ & est. \\
$\mathrm{O}$ & 0.02 & $0.5 \mathrm{O}_{2}$ & 48 and 80 \\
$\mathrm{O}_{2}\left(\mathrm{a}^{1} \Delta\right)$ & 0.0004 & $\mathrm{O}_{2}$ & 48 \\
$\mathrm{O}_{2}\left(\mathrm{~b}^{1} \Sigma\right)$ & 0.02 & $\mathrm{O}_{2}$ & 48 and 80 \\
$\mathrm{H}$ & 0.03 & $0.5 \mathrm{H}_{2}$ & 48 and 81 \\
$\mathrm{~N}$ & 1.00 & $0.5 \mathrm{~N}_{2}$ & est. \\
$\mathrm{He}_{2}{ }^{+}$ & 1.00 & $2 \mathrm{He}$ & est. \\
$\mathrm{O}_{4}^{+}$ & 1.00 & $2 \mathrm{O}_{2}$ & est. \\
$\mathrm{N}_{4}{ }^{+}$ & 1.00 & $2 \mathrm{~N}_{2}$ & est. \\
$\mathrm{O}_{2}{ }^{+}\left(\mathrm{H}_{2} \mathrm{O}\right)$ & 1.00 & $\mathrm{O}_{2}+\mathrm{H}_{2} \mathrm{O}$ & est. \\
$\mathrm{H}_{2} \mathrm{O}^{+}\left(\mathrm{H}_{2} \mathrm{O}\right)$ & 1.00 & $2 \mathrm{H}_{2} \mathrm{O}$ & est.
\end{tabular}


Table 5 shows electron impact reactions used in this work. Reaction rate coefficients are either taken from the literature, or calculated by the GlobalKin two-term Boltzmann equation solver.
For the latter, reaction rate coefficients are indicated as $f(E)$, and collisional cross sections are taken from the indicated literature. Electron impact cross-sections are taken from several databases, for

Table 5 Electron collisions

\begin{tabular}{|c|c|c|c|c|}
\hline No. & $E_{\mathrm{Thr}}(\mathrm{eV})$ & Reaction (rxn) & $\operatorname{Rate}^{a, b}$ & Ref. \\
\hline \multicolumn{5}{|c|}{ Elastic scattering and momentum transfer } \\
\hline 1 & 0.00 & $\mathrm{e}+\mathrm{He} \rightarrow \mathrm{He}+\mathrm{e}$ & $f(E)$ & 82 and 83 \\
\hline 2 & 0.00 & $\mathrm{e}+\mathrm{H}_{2} \mathrm{O} \rightarrow \mathrm{H}_{2} \mathrm{O}+\mathrm{e}$ & $f(E)$ & 84 and 89 \\
\hline 3 & 0.00 & $\mathrm{e}+\mathrm{O}_{2} \rightarrow \mathrm{O}_{2}+\mathrm{e}$ & $f(E)$ & 90 \\
\hline
\end{tabular}

Electron impact excitation and ionisation

\begin{tabular}{|c|c|c|c|c|}
\hline 4 & 19.80 & $\mathrm{e}+\mathrm{He} \rightarrow \mathrm{He}^{*}+\mathrm{e}$ & $f(E)$ & 82 and 83 \\
\hline 5 & 20.62 & $\mathrm{e}+\mathrm{He} \rightarrow \mathrm{He}^{*}+\mathrm{e}$ & $f(E)$ & 82 and 83 \\
\hline 6 & 24.58 & $\mathrm{e}+\mathrm{He} \rightarrow \mathrm{He}^{+}+\mathrm{e}$ & $f(E)$ & 82 and 83 \\
\hline 7 & 4.77 & $\mathrm{e}+\mathrm{He}^{*} \rightarrow \mathrm{He}^{+}+2 \mathrm{e}$ & $f(E)$ & $91^{c}$ \\
\hline 8 & 3.90 & $\mathrm{e}+\mathrm{He}_{2}^{*} \rightarrow \mathrm{He}_{2}^{+}+2 \mathrm{e}$ & $2.06 \times 10^{-13} \mathrm{e}^{-4.28 / T_{\mathrm{e}}}$ & $92^{d}$ \\
\hline 9 & 0.20 & $\mathrm{e}+\mathrm{H}_{2} \mathrm{O} \rightarrow \mathrm{H}_{2} \mathrm{O}+\mathrm{e}$ & $f(E)$ & $84^{e}$ \\
\hline 10 & 0.45 & $\mathrm{e}+\mathrm{H}_{2} \mathrm{O} \rightarrow \mathrm{H}_{2} \mathrm{O}+\mathrm{e}$ & $f(E)$ & $84^{e}$ \\
\hline 11 & 0.47 & $\mathrm{e}+\mathrm{H}_{2} \mathrm{O} \rightarrow \mathrm{H}_{2} \mathrm{O}+\mathrm{e}$ & $f(E)$ & $84^{e}$ \\
\hline 12 & 13.50 & $\mathrm{e}+\mathrm{H}_{2} \mathrm{O} \rightarrow \mathrm{H}_{2} \mathrm{O}^{+}+2 \mathrm{e}$ & $f(E)$ & 84 \\
\hline 13 & 13.50 & $\mathrm{e}+\mathrm{OH} \rightarrow \mathrm{OH}^{+}+2 \mathrm{e}$ & $f(E)$ & 93 \\
\hline 14 & 1.97 & $\mathrm{e}+\mathrm{O} \rightarrow \mathrm{O}\left({ }^{1} \mathrm{D}\right)+\mathrm{e}$ & $f(E)$ & 94 \\
\hline 15 & 4.19 & $\mathrm{e}+\mathrm{O} \rightarrow \mathrm{O}\left({ }^{1} \mathrm{~S}\right)+\mathrm{e}$ & $f(E)$ & 94 \\
\hline 16 & 13.62 & $\mathrm{e}+\mathrm{O} \rightarrow \mathrm{O}^{+}+2 \mathrm{e}$ & $f(E)$ & 94 \\
\hline 17 & 11.65 & $\mathrm{e}+\mathrm{O}\left({ }^{1} \mathrm{D}\right) \rightarrow \mathrm{O}^{+}+2 \mathrm{e}$ & $f(E)$ & $91^{c}$ \\
\hline 18 & 9.43 & $\mathrm{e}+\mathrm{O}\left({ }^{1} \mathrm{~S}\right) \rightarrow \mathrm{O}^{+}+2 \mathrm{e}$ & $f(E)$ & $95^{c}$ \\
\hline 19 & 0.02 & $\mathrm{e}+\mathrm{O}_{2} \rightarrow \mathrm{O}_{2}+\mathrm{e}$ & $f(E)$ & $90^{f}$ \\
\hline 20 & 0.19 & $\mathrm{e}+\mathrm{O}_{2} \rightarrow \mathrm{O}_{2}+\mathrm{e}$ & $f(E)$ & $90^{e}$ \\
\hline 21 & 0.19 & $\mathrm{e}+\mathrm{O}_{2} \rightarrow \mathrm{O}_{2}+\mathrm{e}$ & $f(E)$ & $90^{e}$ \\
\hline 22 & 0.38 & $\mathrm{e}+\mathrm{O}_{2} \rightarrow \mathrm{O}_{2}+\mathrm{e}$ & $f(E)$ & $90^{e}$ \\
\hline 23 & 0.38 & $\mathrm{e}+\mathrm{O}_{2} \rightarrow \mathrm{O}_{2}+\mathrm{e}$ & $f(E)$ & $90^{e}$ \\
\hline 24 & 0.57 & $\mathrm{e}+\mathrm{O}_{2} \rightarrow \mathrm{O}_{2}+\mathrm{e}$ & $f(E)$ & $90^{e}$ \\
\hline 25 & 0.75 & $\mathrm{e}+\mathrm{O}_{2} \rightarrow \mathrm{O}_{2}+\mathrm{e}$ & $f(E)$ & $90^{e}$ \\
\hline 26 & 0.98 & $\mathrm{e}+\mathrm{O}_{2} \rightarrow \mathrm{O}_{2}\left(\mathrm{a}^{1} \Delta\right)+\mathrm{e}$ & $f(E)$ & 90 \\
\hline 27 & 1.63 & $\mathrm{e}+\mathrm{O}_{2} \rightarrow \mathrm{O}_{2}\left(\mathrm{~b}^{1} \Sigma\right)+\mathrm{e}$ & $f(E)$ & 90 \\
\hline 28 & 4.50 & $\mathrm{e}+\mathrm{O}_{2} \rightarrow \mathrm{O}_{2}+\mathrm{e}$ & $f(E)$ & $90^{g}$ \\
\hline 29 & 12.06 & $\mathrm{e}+\mathrm{O}_{2} \rightarrow \mathrm{O}_{2}^{+}+\mathrm{e}$ & $f(E)$ & 90 \\
\hline 30 & 0.02 & $\mathrm{e}+\mathrm{O}_{2}\left(\mathrm{a}^{1} \Delta\right) \rightarrow \mathrm{O}_{2}\left(\mathrm{a}^{1} \Delta\right)+\mathrm{e}$ & $f(E)$ & As $\operatorname{rxn} 19^{h}$ \\
\hline 31 & 0.19 & $\mathrm{e}+\mathrm{O}_{2}\left(\mathrm{a}^{1} \Delta\right) \rightarrow \mathrm{O}_{2}\left(\mathrm{a}^{1} \Delta\right)+\mathrm{e}$ & $f(E)$ & As $\operatorname{rxn} 20^{h}$ \\
\hline 32 & 0.19 & $\mathrm{e}+\mathrm{O}_{2}\left(\mathrm{a}^{1} \Delta\right) \rightarrow \mathrm{O}_{2}\left(\mathrm{a}^{1} \Delta\right)+\mathrm{e}$ & $f(E)$ & As rxn $21^{h}$ \\
\hline 33 & 0.38 & $\mathrm{e}+\mathrm{O}_{2}\left(\mathrm{a}^{1} \Delta\right) \rightarrow \mathrm{O}_{2}\left(\mathrm{a}^{1} \Delta\right)+\mathrm{e}$ & $f(E)$ & As $\operatorname{rxn} 22^{h}$ \\
\hline 34 & 0.38 & $\mathrm{e}+\mathrm{O}_{2}\left(\mathrm{a}^{1} \Delta\right) \rightarrow \mathrm{O}_{2}\left(\mathrm{a}^{1} \Delta\right)+\mathrm{e}$ & $f(E)$ & As rxn $23^{h}$ \\
\hline 35 & 0.57 & $\mathrm{e}+\mathrm{O}_{2}\left(\mathrm{a}^{1} \Delta\right) \rightarrow \mathrm{O}_{2}\left(\mathrm{a}^{1} \Delta\right)+\mathrm{e}$ & $f(E)$ & As $\operatorname{rxn} 24^{h}$ \\
\hline 36 & 0.75 & $\mathrm{e}+\mathrm{O}_{2}\left(\mathrm{a}^{1} \Delta\right) \rightarrow \mathrm{O}_{2}\left(\mathrm{a}^{1} \Delta\right)+\mathrm{e}$ & $f(E)$ & As $\operatorname{rxn} 25^{h}$ \\
\hline 37 & 0.65 & $\mathrm{e}+\mathrm{O}_{2}\left(\mathrm{a}^{1} \Delta\right) \rightarrow \mathrm{O}_{2}\left(\mathrm{~b}^{1} \Sigma\right)+\mathrm{e}$ & $f(E)$ & $96^{i}$ \\
\hline 38 & 3.52 & $\mathrm{e}+\mathrm{O}_{2}\left(\mathrm{a}^{1} \Delta\right) \rightarrow \mathrm{O}_{2}+2 \mathrm{e}$ & $f(E)$ & As rxn $28^{h}$ \\
\hline 39 & 11.08 & $\mathrm{e}+\mathrm{O}_{2}\left(\mathrm{a}^{1} \Delta\right) \rightarrow \mathrm{O}_{2}^{+}+\mathrm{e}$ & $f(E)$ & As $\operatorname{rxn} 29^{h}$ \\
\hline 40 & 0.02 & $\mathrm{e}+\mathrm{O}_{2}\left(\mathrm{~b}^{1} \Sigma\right) \rightarrow \mathrm{O}_{2}\left(\mathrm{~b}^{1} \Sigma\right)+\mathrm{e}$ & $f(E)$ & As $\operatorname{rxn} 19^{h}$ \\
\hline 41 & 0.19 & $\mathrm{e}+\mathrm{O}_{2}\left(\mathrm{~b}^{1} \Sigma\right) \rightarrow \mathrm{O}_{2}\left(\mathrm{~b}^{1} \Sigma\right)+\mathrm{e}$ & $f(E)$ & As $\operatorname{rxn} 20^{h}$ \\
\hline 42 & 0.19 & $\mathrm{e}+\mathrm{O}_{2}\left(\mathrm{~b}^{1} \Sigma\right) \rightarrow \mathrm{O}_{2}\left(\mathrm{~b}^{1} \Sigma\right)+\mathrm{e}$ & $f(E)$ & As $\operatorname{rxn} 21^{h}$ \\
\hline 43 & 0.38 & $\mathrm{e}+\mathrm{O}_{2}\left(\mathrm{~b}^{1} \Sigma\right) \rightarrow \mathrm{O}_{2}\left(\mathrm{~b}^{1} \Sigma\right)+\mathrm{e}$ & $f(E)$ & As $\operatorname{rxn} 22^{h}$ \\
\hline 44 & 0.38 & $\mathrm{e}+\mathrm{O}_{2}\left(\mathrm{~b}^{1} \Sigma\right) \rightarrow \mathrm{O}_{2}\left(\mathrm{~b}^{1} \Sigma\right)+\mathrm{e}$ & $f(E)$ & As $\operatorname{rxn} 23^{h}$ \\
\hline 45 & 0.57 & $\mathrm{e}+\mathrm{O}_{2}\left(\mathrm{~b}^{1} \Sigma\right) \rightarrow \mathrm{O}_{2}\left(\mathrm{~b}^{1} \Sigma\right)+\mathrm{e}$ & $f(E)$ & As $\operatorname{rxn} 24^{h}$ \\
\hline 46 & 0.75 & $\mathrm{e}+\mathrm{O}_{2}\left(\mathrm{~b}^{1} \Sigma\right) \rightarrow \mathrm{O}_{2}\left(\mathrm{~b}^{1} \Sigma\right)+\mathrm{e}$ & $f(E)$ & As rxn $25^{h}$ \\
\hline 47 & 2.87 & $\mathrm{e}+\mathrm{O}_{2}\left(\mathrm{~b}^{1} \Sigma\right) \rightarrow \mathrm{O}_{2}+\mathrm{e}$ & $f(E)$ & As rxn $28^{h}$ \\
\hline 48 & 10.43 & $\mathrm{e}+\mathrm{O}_{2}\left(\mathrm{~b}^{1} \Sigma\right) \rightarrow \mathrm{O}_{2}^{+}+2 \mathrm{e}$ & $f(E)$ & As rxn $29^{h}$ \\
\hline \multicolumn{5}{|c|}{ Super-elastic collisions } \\
\hline 49 & -19.80 & $\mathrm{e}+\mathrm{He}^{*} \rightarrow \mathrm{He}+\mathrm{e}$ & $f(E)$ & 82 and $83^{j}$ \\
\hline 50 & -1.97 & $\mathrm{e}+\mathrm{O}\left({ }^{1} \mathrm{D}\right) \rightarrow \mathrm{O}+\mathrm{e}$ & $f(E)$ & $94^{j}$ \\
\hline 51 & -4.19 & $\mathrm{e}+\mathrm{O}\left({ }^{1} \mathrm{~S}\right) \rightarrow \mathrm{O}+\mathrm{e}$ & $f(E)$ & $94^{j}$ \\
\hline 52 & -0.98 & $\mathrm{e}+\mathrm{O}_{2}\left(\mathrm{a}^{1} \Delta\right) \rightarrow \mathrm{O}_{2}+\mathrm{e}$ & $f(E)$ & $90^{j}$ \\
\hline 53 & -1.63 & $\mathrm{e}+\mathrm{O}_{2}\left(\mathrm{~b}^{1} \Sigma\right) \rightarrow \mathrm{O}_{2}+\mathrm{e}$ & $f(E)$ & $90^{j}$ \\
\hline 54 & -0.65 & $\mathrm{e}+\mathrm{O}_{2}\left(\mathrm{~b}^{1} \Sigma\right) \rightarrow \mathrm{O}_{2}\left(\mathrm{a}^{1} \Delta\right)+\mathrm{e}$ & $f(E)$ & As $\operatorname{rxn} 37^{j}$ \\
\hline \multicolumn{5}{|c|}{ Electron impact dissociation } \\
\hline 55 & 0.00 & $\mathrm{e}+\mathrm{He}_{2}^{*} \rightarrow 2 \mathrm{He}+\mathrm{e}$ & $3.8 \times 10^{-15}$ & 97 \\
\hline 56 & 13.50 & $\mathrm{e}+\mathrm{H}_{2} \mathrm{O} \rightarrow \mathrm{O}\left({ }^{1} \mathrm{~S}\right)+2 \mathrm{H}+\mathrm{e}$ & $f(E)$ & 84 and 98 \\
\hline 57 & 7.62 & $\mathrm{e}+\mathrm{H}_{2} \mathrm{O} \rightarrow \mathrm{H}+\mathrm{OH}+\mathrm{e}$ & $f(E)$ & 84 and 99 \\
\hline 58 & 9.00 & $\mathrm{e}+\mathrm{H}_{2} \mathrm{O} \rightarrow \mathrm{H}+\mathrm{OH}+\mathrm{e}$ & $f(E)$ & 84 \\
\hline
\end{tabular}


Table 5 (continued)

\begin{tabular}{|c|c|c|c|c|}
\hline No. & $E_{\mathrm{Thr}}(\mathrm{eV})$ & Reaction (rxn) & Rate $^{a, b}$ & Ref. \\
\hline 60 & 8.80 & $\mathrm{e}+\mathrm{H}_{2} \rightarrow 2 \mathrm{H}+\mathrm{e}$ & $f(E)$ & 100 \\
\hline 63 & & $\mathrm{e}+\mathrm{H}_{2} \mathrm{O}_{2} \rightarrow 2 \mathrm{OH}+\mathrm{e}$ & $2.36 \times 10^{-15}$ & $103^{m}$ \\
\hline 64 & 6.00 & $\mathrm{e}+\mathrm{O}_{2} \rightarrow \mathrm{O}+\mathrm{O}+\mathrm{e}$ & $f(E)$ & 90 \\
\hline 65 & 8.40 & $\mathrm{e}+\mathrm{O}_{2} \rightarrow \mathrm{O}\left({ }^{1} \mathrm{D}\right)+\mathrm{O}+\mathrm{e}$ & $f(E)$ & 90 \\
\hline 68 & 7.42 & $\mathrm{e}+\mathrm{O}_{2}\left(\mathrm{a}^{1} \Delta\right) \rightarrow \mathrm{O}\left({ }^{1} \mathrm{D}\right)+\mathrm{O}+\mathrm{e}$ & $f(E)$ & As $\operatorname{rxn} 65^{h}$ \\
\hline 69 & 9.02 & $\mathrm{e}+\mathrm{O}_{2}\left(\mathrm{a}^{1} \Delta\right) \rightarrow \mathrm{O}\left({ }^{1} \mathrm{D}\right)+\mathrm{O}+\mathrm{e}$ & $f(E)$ & As $\operatorname{rxn} 66^{h}$ \\
\hline 70 & 4.37 & $\mathrm{e}+\mathrm{O}_{2}\left(\mathrm{~b}^{1} \Sigma\right) \rightarrow \mathrm{O}+\mathrm{O}+\mathrm{e}$ & $f(E)$ & As $\operatorname{rxn} 64^{h}$ \\
\hline 71 & 6.77 & $\mathrm{e}+\mathrm{O}_{2}\left(\mathrm{~b}{ }^{1} \Sigma\right) \rightarrow \mathrm{O}\left({ }^{1} \mathrm{D}\right)+\mathrm{O}+\mathrm{e}$ & $f(E)$ & As $\operatorname{rxn} 65^{h}$ \\
\hline 72 & 8.37 & $\mathrm{e}+\mathrm{O}_{2}\left(\mathrm{~b}{ }^{1} \Sigma\right) \rightarrow \mathrm{O}\left({ }^{1} \mathrm{D}\right)+\mathrm{O}+\mathrm{e}$ & $f(E)$ & As rxn $66^{h}$ \\
\hline 73 & 2.60 & $\mathrm{e}+\mathrm{O}_{3} \rightarrow \mathrm{O}+\mathrm{O}_{2}+\mathrm{e}$ & $1.7 \times 10^{-14} T_{\mathrm{e}}^{-0.57} \mathrm{e}^{-2.48 / T_{\mathrm{e}}}$ & 74 and 104 \\
\hline 74 & 5.72 & $\mathrm{e}+\mathrm{O}_{3} \rightarrow \mathrm{O}\left({ }^{1} \mathrm{D}\right)+\mathrm{O}_{2}\left(\mathrm{a}^{1} \Delta\right)+\mathrm{e}$ & $3.22 \times 10^{-13} T_{\mathrm{e}}^{-1.18} \mathrm{e}^{-9.17 / T_{\mathrm{e}}}$ & 74 and 104 \\
\hline \multicolumn{5}{|c|}{ (Dissociative) electron attachment } \\
\hline 77 & 5.30 & $\mathrm{e}+\mathrm{H}_{2} \mathrm{O} \rightarrow \mathrm{OH}+\mathrm{H}^{-}$ & $f(E)$ & 84 and 105 \\
\hline 78 & 4.43 & $\mathrm{e}+\mathrm{H}_{2} \mathrm{O} \rightarrow \mathrm{H}_{2}+\mathrm{O}^{-}$ & $f(E)$ & 84 and 105 \\
\hline 79 & 4.30 & $\mathrm{e}+\mathrm{H}_{2} \mathrm{O} \rightarrow \mathrm{H}+\mathrm{OH}^{-}$ & $f(E)$ & 84 and 105 \\
\hline 80 & 0.00 & $\mathrm{e}+\mathrm{H}_{2} \mathrm{O}_{2} \rightarrow \mathrm{H}_{2} \mathrm{O}+\mathrm{O}^{-}$ & $f(E)$ & 106 \\
\hline 81 & 0.00 & $\mathrm{e}+\mathrm{H}_{2} \mathrm{O}_{2} \rightarrow \mathrm{OH}+\mathrm{OH}^{-}$ & $f(E)$ & 106 \\
\hline 82 & 5.38 & $\mathrm{e}+\mathrm{O}_{2} \rightarrow \mathrm{O}+\mathrm{O}^{-}$ & $f(E)$ & 90 \\
\hline 83 & 3.50 & $\mathrm{e}+\mathrm{O}_{2}\left(\mathrm{a}^{1} \Delta\right) \rightarrow \mathrm{O}+\mathrm{O}^{-}$ & $f(E)$ & 107 \\
\hline 84 & 2.85 & $\mathrm{e}+\mathrm{O}_{2}\left(\mathrm{~b}^{1} \Sigma\right) \rightarrow \mathrm{O}+\mathrm{O}^{-}$ & $f(E)$ & As $\operatorname{rxn} 83^{h}$ \\
\hline 85 & 0.00 & $\mathrm{e}+\mathrm{O}_{3} \rightarrow \mathrm{O}_{2}+\mathrm{O}^{-}$ & $f(E)$ & 108 \\
\hline 86 & 0.25 & $\mathrm{e}+\mathrm{O}_{3} \rightarrow \mathrm{O}_{2}^{-}+\mathrm{O}$ & $f(E)$ & 108 \\
\hline \multicolumn{5}{|c|}{ Electron detachment } \\
\hline 95 & 0.00 & $\mathrm{e}+\mathrm{H}^{+} \cdot\left(\mathrm{H}_{2} \mathrm{O}\right) \rightarrow \mathrm{OH}+\mathrm{H}_{2}$ & $5.37 \times 10^{-14} T_{\mathrm{e}}^{-0.5}$ & 112,114 and 115 \\
\hline 96 & 0.00 & $\mathrm{e}+\mathrm{H}^{+} \cdot\left(\mathrm{H}_{2} \mathrm{O}\right) \rightarrow \mathrm{OH}+2 \mathrm{H}$ & $3.05 \times 10^{-13} T_{\mathrm{e}}^{-0.5}$ & 112,114 and 115 \\
\hline 97 & 0.00 & $\mathrm{e}+\mathrm{H}^{+} \cdot\left(\mathrm{H}_{2} \mathrm{O}\right)_{2} \rightarrow \mathrm{H}+2 \mathrm{H}_{2} \mathrm{O}$ & $1.84 \times 10^{-12} T_{\mathrm{e}}^{-0.08}$ & 116 \\
\hline 98 & 0.00 & $\mathrm{e}+\mathrm{H}^{+} \cdot\left(\mathrm{H}_{2} \mathrm{O}\right)_{3} \rightarrow 3 \mathrm{H}_{2} \mathrm{O}+\mathrm{H}$ & $2.24 \times 10^{-12} T_{\mathrm{e}}^{-0.08}$ & 116 \\
\hline 99 & 0.00 & $\mathrm{e}+\mathrm{H}^{+} \cdot\left(\mathrm{H}_{2} \mathrm{O}\right)_{4} \rightarrow 4 \mathrm{H}_{2} \mathrm{O}+\mathrm{H}$ & $3.6 \times 10^{-12}$ & 116 \\
\hline 100 & 0.00 & $\mathrm{e}+\mathrm{H}^{+} \cdot\left(\mathrm{H}_{2} \mathrm{O}\right)_{5} \rightarrow 5 \mathrm{H}_{2} \mathrm{O}+\mathrm{H}$ & $4.1 \times 10^{-12}$ & 117 \\
\hline 101 & 0.00 & $\mathrm{e}+\mathrm{H}^{+} \cdot\left(\mathrm{H}_{2} \mathrm{O}\right)_{6} \rightarrow 6 \mathrm{H}_{2} \mathrm{O}+\mathrm{H}$ & $5.13 \times 10^{-12}$ & 117 \\
\hline 102 & 0.00 & $\mathrm{e}+\mathrm{H}^{+} \cdot\left(\mathrm{H}_{2} \mathrm{O}\right)_{7} \rightarrow 7 \mathrm{H}_{2} \mathrm{O}+\mathrm{H}$ & $1.0 \times 10^{-12}$ & 117 \\
\hline 103 & 0.00 & $\mathrm{e}+\mathrm{H}^{+} \cdot\left(\mathrm{H}_{2} \mathrm{O}\right)_{8} \rightarrow 8 \mathrm{H}_{2} \mathrm{O}+\mathrm{H}$ & $4.1 \times 10^{-12}$ & As rxn 100 \\
\hline 104 & 0.00 & $\mathrm{e}+\mathrm{H}^{+} \cdot\left(\mathrm{H}_{2} \mathrm{O}\right)_{9} \rightarrow 9 \mathrm{H}_{2} \mathrm{O}+\mathrm{H}$ & $4.1 \times 10^{-12}$ & As rxn 100 \\
\hline 105 & 0.00 & $\mathrm{e}+\mathrm{H}_{2} \mathrm{O}^{+} \cdot\left(\mathrm{H}_{2} \mathrm{O}\right) \rightarrow \mathrm{H}+\mathrm{OH}+\mathrm{H}_{2} \mathrm{O}$ & $9.63 \times 10^{-13} T_{\mathrm{e}}^{-0.2}$ & $118^{n}$ \\
\hline 106 & 0.00 & $\mathrm{e}+\mathrm{O}_{2}^{+} \rightarrow 2 \mathrm{O}$ & $3.72 \times 10^{-15} T_{\mathrm{e}}^{-0.7}$ & 119 \\
\hline 107 & 0.00 & $\mathrm{e}+\mathrm{O}_{2}^{+} \rightarrow \mathrm{O}+\mathrm{O}\left({ }^{1} \mathrm{D}\right)$ & $7.44 \times 10^{-15} T_{\mathrm{e}}^{-0.7}$ & 119 and 120 \\
\hline 108 & 0.00 & $\mathrm{e}+\mathrm{O}_{2}^{+} \rightarrow 2 \mathrm{O}\left({ }^{1} \mathrm{D}\right)$ & $7.44 \times 10^{-15} T_{\mathrm{e}}^{-0.7}$ & 119 and 120 \\
\hline 109 & 0.00 & $\mathrm{e}+\mathrm{O}_{2}^{+} \cdot\left(\mathrm{H}_{2} \mathrm{O}\right) \rightarrow \mathrm{O}_{2}+\mathrm{H}_{2} \mathrm{O}$ & $7.22 \times 10^{-13} T_{\mathrm{e}}^{-0.2}$ & 118 \\
\hline 110 & 0.00 & $\mathrm{e}+\mathrm{O}_{4}^{+} \rightarrow 2 \mathrm{O}+\mathrm{O}_{2}$ & $5.17 \times 10^{-14} T_{\mathrm{e}}^{-1.0}$ & 118 \\
\hline 111 & 0.00 & $\mathrm{e}+\mathrm{O}_{4}^{+} \rightarrow 2 \mathrm{O}_{2}$ & $2.76 \times 10^{-13} T_{\mathrm{e}}^{-0.5}$ & 86 \\
\hline
\end{tabular}

${ }^{a} \mathrm{In} \mathrm{m}^{3} \mathrm{~s}^{-1}$ and $\mathrm{m}^{6} \mathrm{~s}^{-1}$ for two- and three-body processes, respectively. ${ }^{b} f(E)$ denotes rate coefficients are calculated by the internal GlobalKin two-term Boltzmann equation solver using cross sections obtained from the indicated literature. ${ }^{c}$ Cross sections are calculated from an expression in cited reference. ${ }^{d}$ Calculated assuming a Maxwell distribution function and cross sections from the given reference. ${ }^{e}$ Vibrational excitation cross section included in cross section set for two-term Boltzmann solver. Vibrational states not simulated self-consistently in reaction kinetics. ${ }^{f}$ Rotational excitation cross section included in cross section set for two-term Boltzmann solver. Rotations states not simulated self-consistently in reaction kinetics. ${ }^{g}$ Electronic excitation cross section included in cross section set for two-term Boltzmann solver. This electronic state is not simulated self-consistently in reaction kinetics. ${ }^{h}$ Cross section estimated by shifting and scaling the corresponding cross section for the ground state by the excitation threshold of the excited state. ${ }^{i}$ Born-Bethe fit to data in the cited reference. ${ }^{j}$ Obtained from reverse process by detailed balance. ${ }^{k}$ In the reference reaction rates were calculated using Bolsig $+{ }^{121}$ and cross sections obtained from the Morgan database ${ }^{122}$ for a $\mathrm{He} / \mathrm{H}_{2} \mathrm{O}$ plasma. ${ }^{l}$ Cross section assumed to be the same as that for CO. ${ }^{m}$ Value is approximated in reference based on cross section for electron impact dissociation of $\mathrm{O}_{2} \cdot{ }^{n}$ Value is estimated in reference. 
Table 6 Ion-ion chemistry

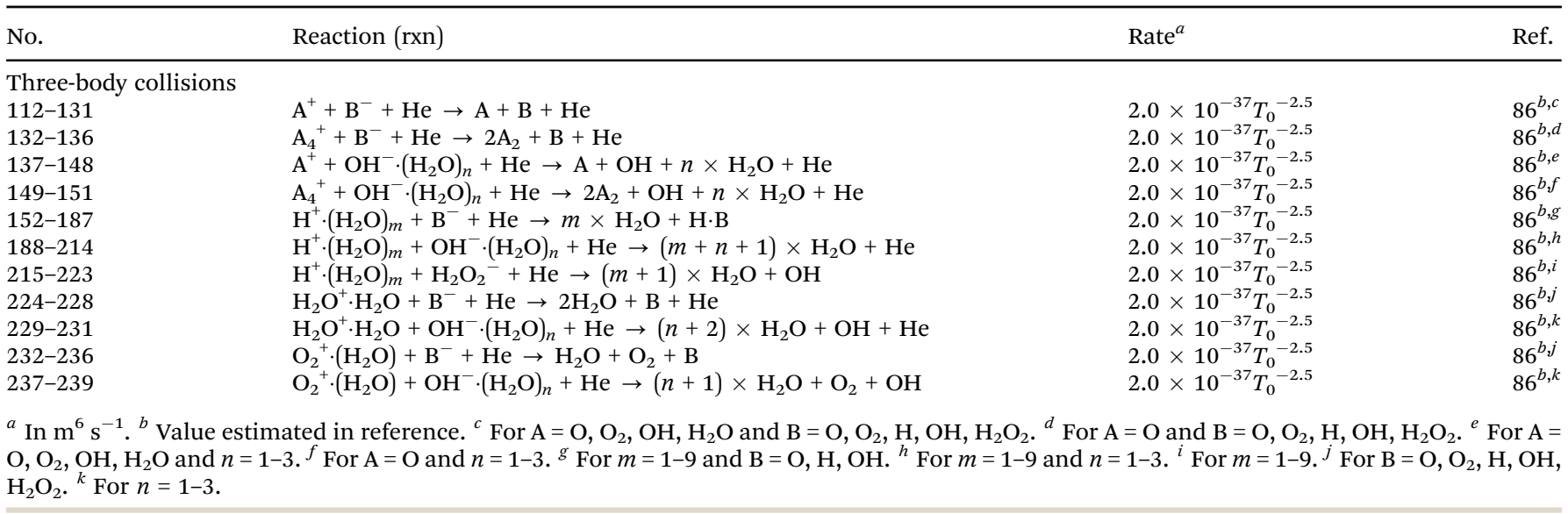

example $\mathrm{He},{ }^{82,83}$ or $\mathrm{H}_{2} \mathrm{O} .^{84}$ Although not all of the reactions from these databases are included in the plasma-chemical reaction mechanism shown here, they are still accounted for in the Boltzmann solver calculation for the electron energy distribution function and electron transport coefficients. Any other approach to obtain reaction rate coefficients is denoted by footnotes.

Table 6 shows reaction rate coefficients for ion-ion recombination processes. It is generally known that ion-ion recombination processes can occur both as two- or three-body processes, depending on the gas pressure. Two-body reaction rate coefficients for several different gases have been obtained in ref. 85 at low pressure, and found to be in the order of $10^{-13} \mathrm{~m}^{3} \mathrm{~s}^{-1}$ or lower. Taking into account the He density at atmospheric pressure and at $315 \mathrm{~K}$, and the rate coefficient for three-body ion-ion recombination proposed by Kossyi, ${ }^{86}$ the effective two-body reaction rate amounts to a value in the order of $10^{-12} \mathrm{~m}^{3} \mathrm{~s}^{-1}$. Due to this higher effective rate coefficient under our conditions, we only include three-body ion-ion recombination rate coefficients in this work. These reactions are found to be particularly important for the destruction of the higher-mass water clusters, which are abundant at higher $\mathrm{H}_{2} \mathrm{O}$ admixtures. Similar observations have been made by Liu et al., ${ }^{48}$ who, after an analysis of the robustness of their chemistry model, only included a few ion-ion recombination reactions in their simplified models, a large fraction of which were three-body recombination processes for the collisions of higher mass cluster ions. We also found that under our conditions, ion-ion recombination between positive He ions and negative ions are negligible due to the rapidly decreasing He ion density with increasing water content, which again is in accordance with the findings of Liu et al., ${ }^{48}$ and the fact that He ions undergo charge exchange reactions with most neutral species due to their high ionisation potential.

Table 7 shows reaction rate coefficients for collisions between ions and neutrals. In this table a number of three-body processes are included. Three-body processes are typically characterised by a pressure dependence. The nature of these reactions mean that this pressure dependence normally takes the form of a curve exhibiting low- and high-pressure limits. In the low-pressure limit the effective rate coefficient (i.e. the three-body rate coefficient multiplied by the

Table 7 lon-neutral chemistry

\begin{tabular}{|c|c|c|c|}
\hline No. & Reaction (rxn) & Rate $^{a}$ & Ref. \\
\hline 240 & $\mathrm{He}^{+}+\mathrm{OH} \rightarrow \mathrm{O}^{+}+\mathrm{H}+\mathrm{He}$ & $1.1 \times 10^{-15} T_{0}^{-0.5}$ & 112 and 123 \\
\hline 241 & $\mathrm{He}^{+}+\mathrm{H}_{2} \mathrm{O} \rightarrow \mathrm{H}_{2} \mathrm{O}^{+}+\mathrm{He}$ & $6.05 \times 10^{-17} T_{0}^{-0.5}$ & 112 and 124 \\
\hline 243 & $\mathrm{He}^{+}+\mathrm{O} \rightarrow \mathrm{O}^{+}+\mathrm{He}$ & $5.00 \times 10^{-17}$ & 125 \\
\hline 244 & $\mathrm{He}^{+}+\mathrm{O}_{2} \rightarrow \mathrm{O}^{+}+\mathrm{O}+\mathrm{He}$ & $1.1 \times 10^{-15}$ & 112 and 126 \\
\hline 245 & $\mathrm{He}^{+}+\mathrm{O}_{2} \rightarrow \mathrm{O}_{2}^{+}+\mathrm{He}$ & $3.3 \times 10^{-17}$ & 112 and 126 \\
\hline 248 & $\mathrm{He}_{2}{ }^{+}+\mathrm{H}_{2} \mathrm{O} \rightarrow \mathrm{H}^{+} \cdot\left(\mathrm{H}_{2} \mathrm{O}\right)+2 \mathrm{He}$ & $2.86 \times 10^{-16} T_{0}^{-0.5}$ & As rxn 242 \\
\hline 249 & $\mathrm{He}_{2}^{+}+\mathrm{O}_{2} \rightarrow \mathrm{O}^{+}+\mathrm{O}+2 \mathrm{He}$ & $1.1 \times 10^{-15}$ & As rxn 244 \\
\hline 250 & $\mathrm{He}_{2}^{+}+\mathrm{O}_{2} \rightarrow \mathrm{O}_{2}^{+}+2 \mathrm{He}$ & $3.3 \times 10^{-17}$ & As rxn 245 \\
\hline 251 & $\mathrm{H}^{+} \cdot\left(\mathrm{H}_{2} \mathrm{O}\right)_{2}(+\mathrm{He}) \rightarrow \mathrm{H}^{+} \cdot\left(\mathrm{H}_{2} \mathrm{O}\right)+\mathrm{H}_{2} \mathrm{O}(+\mathrm{He})$ & Effective & $87^{c, d}$ \\
\hline 252 & $\mathrm{H}^{+} \cdot\left(\mathrm{H}_{2} \mathrm{O}\right)_{3}(+\mathrm{He}) \rightarrow \mathrm{H}^{+} \cdot\left(\mathrm{H}_{2} \mathrm{O}\right)_{2}+\mathrm{H}_{2} \mathrm{O}(+\mathrm{He})$ & Effective & $87^{c, d}$ \\
\hline 253 & $\mathrm{H}^{+} \cdot\left(\mathrm{H}_{2} \mathrm{O}\right)_{4}(+\mathrm{He}) \rightarrow \mathrm{H}^{+} \cdot\left(\mathrm{H}_{2} \mathrm{O}\right)_{3}+\mathrm{H}_{2} \mathrm{O}(+\mathrm{He})$ & Effective & $87^{c, d}$ \\
\hline 254 & $\mathrm{H}^{+} \cdot\left(\mathrm{H}_{2} \mathrm{O}\right)_{5}(+\mathrm{He}) \rightarrow \mathrm{H}^{+} \cdot\left(\mathrm{H}_{2} \mathrm{O}\right)_{4}+\mathrm{H}_{2} \mathrm{O}(+\mathrm{He})$ & Effective & $87^{c, d}$ \\
\hline 260 & $\mathrm{OH}^{+}+\mathrm{OH} \rightarrow \mathrm{H}_{2} \mathrm{O}^{+}+\mathrm{O}$ & $7.0 \times 10^{-16} T_{0}^{-0.5}$ & 112 and 123 \\
\hline 261 & $\mathrm{OH}^{+}+\mathrm{H}_{2} \mathrm{O} \rightarrow \mathrm{H}_{2} \mathrm{O}^{+}+\mathrm{OH}$ & $1.56 \times 10^{-15}$ & 128 \\
\hline
\end{tabular}


Table 7 (continued)

\begin{tabular}{|c|c|c|c|}
\hline No. & Reaction (rxn) & Rate $^{a}$ & Ref. \\
\hline 262 & $\mathrm{OH}^{+}+\mathrm{H}_{2} \mathrm{O} \rightarrow \mathrm{H}^{+} \cdot\left(\mathrm{H}_{2} \mathrm{O}\right)+\mathrm{O}$ & $1.27 \times 10^{-15}$ & 128 \\
\hline 263 & $\mathrm{OH}^{+}+\mathrm{O} \rightarrow \mathrm{O}_{2}^{+}+\mathrm{H}$ & $7.1 \times 10^{-16}$ & 112 and 123 \\
\hline 264 & $\mathrm{OH}^{+}+\mathrm{O}_{2} \rightarrow \mathrm{O}_{2}^{+}+\mathrm{OH}$ & $5.9 \times 10^{-16}$ & 112 and 127 \\
\hline 265 & $\mathrm{H}_{2} \mathrm{O}^{+}+\mathrm{H}_{2} \rightarrow \mathrm{H}^{+} \cdot\left(\mathrm{H}_{2} \mathrm{O}\right)+\mathrm{H}$ & $6.4 \times 10^{-16}$ & 112 and 129 \\
\hline 266 & $\mathrm{H}_{2} \mathrm{O}^{+}+\mathrm{OH} \rightarrow \mathrm{H}^{+} \cdot\left(\mathrm{H}_{2} \mathrm{O}\right)+\mathrm{O}$ & $6.9 \times 10^{-16} T_{0}^{-0.5}$ & 112 and 123 \\
\hline 267 & $\mathrm{H}_{2} \mathrm{O}^{+}+\mathrm{H}_{2} \mathrm{O} \rightarrow \mathrm{H}^{+} \cdot\left(\mathrm{H}_{2} \mathrm{O}\right)+\mathrm{OH}$ & $2.05 \times 10^{-15}$ & 128 \\
\hline 268 & $\mathrm{H}_{2} \mathrm{O}^{+}+\mathrm{O} \rightarrow \mathrm{O}_{2}^{+}+\mathrm{H}_{2}$ & $4.0 \times 10^{-17}$ & 112 and 130 \\
\hline 269 & $\mathrm{H}_{2} \mathrm{O}^{+}+\mathrm{O}_{2} \rightarrow \mathrm{O}_{2}^{+}+\mathrm{H}_{2} \mathrm{O}$ & $3.3 \times 10^{-16}$ & 131 \\
\hline 270 & $\mathrm{H}_{2} \mathrm{O}^{+} \cdot \mathrm{H}_{2} \mathrm{O}+\mathrm{H}_{2} \mathrm{O} \rightarrow \mathrm{H}^{+} \cdot\left(\mathrm{H}_{2} \mathrm{O}\right)_{2}+\mathrm{OH}$ & $1.4 \times 10^{-15}$ & 118 \\
\hline 271 & $\mathrm{O}^{+}+\mathrm{H}_{2} \rightarrow \mathrm{OH}^{+}+\mathrm{H}$ & $1.7 \times 10^{-15}$ & 112 and 132 \\
\hline 272 & $\mathrm{O}^{+}+\mathrm{OH} \rightarrow \mathrm{OH}^{+}+\mathrm{O}$ & $3.6 \times 10^{-15} T_{0}^{-0.5}$ & 112 and 123 \\
\hline 273 & $\mathrm{O}^{+}+\mathrm{OH} \rightarrow \mathrm{O}_{2}^{+}+\mathrm{H}$ & $3.6 \times 10^{-15} T_{0}^{-0.5}$ & 112 and 123 \\
\hline 274 & $\mathrm{O}^{+}+\mathrm{H}_{2} \mathrm{O} \rightarrow \mathrm{H}_{2} \mathrm{O}^{+}+\mathrm{O}$ & $3.2 \times 10^{-15}$ & 132 \\
\hline 275 & $\mathrm{O}^{+}+\mathrm{O}_{2} \rightarrow \mathrm{O}_{2}^{+}+\mathrm{O}$ & $2.0 \times 10^{-17} T_{0}^{-0.4}$ & 133 \\
\hline 276 & $\mathrm{O}_{2}^{+} \cdot \mathrm{H}_{2} \mathrm{O}(+\mathrm{He}) \rightarrow \mathrm{O}_{2}^{+}+\mathrm{H}_{2} \mathrm{O}(+\mathrm{He})$ & Effective & $87^{c, d}$ \\
\hline 277 & $\mathrm{O}_{2}^{+} \cdot \mathrm{H}_{2} \mathrm{O}+\mathrm{H}_{2} \mathrm{O} \rightarrow \mathrm{H}_{2} \mathrm{O}^{+} \cdot \mathrm{H}_{2} \mathrm{O}+\mathrm{O}_{2}$ & $1.0 \times 10^{-15}$ & $118^{b}$ \\
\hline 278 & $\mathrm{O}_{4}^{+}+\mathrm{He} \rightarrow \mathrm{O}_{2}^{+}+\mathrm{O}_{2}+\mathrm{He}$ & $3.4 \times 10^{-20}$ & 74 and 134 \\
\hline 279 & $\mathrm{O}_{4}^{+}+\mathrm{H}_{2} \mathrm{O} \rightarrow \mathrm{O}_{2}^{+} \cdot \mathrm{H}_{2} \mathrm{O}+\mathrm{O}_{2}$ & $1.7 \times 10^{-15}$ & 135 \\
\hline 280 & $\mathrm{O}_{4}^{+}+\mathrm{O} \rightarrow \mathrm{O}_{2}^{+}+\mathrm{O}_{3}$ & $3.0 \times 10^{-16}$ & 118 \\
\hline 281 & $\mathrm{O}_{4}^{+}+\mathrm{O}_{2} \rightarrow \mathrm{O}_{2}^{+}+2 \mathrm{O}_{2}$ & $1.0 \times 10^{-11} T_{0}{ }^{-4.2} \mathrm{e}^{-5400 / T_{g}}$ & 74 and 134 \\
\hline 282 & $\mathrm{O}_{4}^{+}+\mathrm{O}_{2}\left(\mathrm{a}^{1} \Delta\right) \rightarrow \mathrm{O}_{2}^{+}+2 \mathrm{O}_{2}$ & $1.0 \times 10^{-16}$ & $118^{b}$ \\
\hline 283 & $\mathrm{O}_{4}^{+}+\mathrm{O}_{2}\left(\mathrm{~b}^{1} \Sigma\right) \rightarrow \mathrm{O}_{2}^{+}+2 \mathrm{O}_{2}$ & $1.0 \times 10^{-16}$ & As $\operatorname{rxn} 282$ \\
\hline \multicolumn{4}{|c|}{ Two-body collisions - negative ions } \\
\hline 284 & $\mathrm{H}^{-}+\mathrm{He} \rightarrow \mathrm{H}+\mathrm{He}+\mathrm{e}$ & $4.43 \times 10^{-17} \mathrm{e}^{-5829 / T_{g}}$ & 136 \\
\hline 285 & $\mathrm{H}^{-}+\mathrm{H}_{2} \mathrm{O} \rightarrow \mathrm{OH}^{-}+\mathrm{H}_{2}$ & $4.8 \times 10^{-15}$ & 112 and 137 \\
\hline 286 & $\mathrm{OH}^{-}+\mathrm{H} \rightarrow \mathrm{H}_{2} \mathrm{O}+\mathrm{e}^{-2}$ & $1.4 \times 10^{-15}$ & 112 and 138 \\
\hline 287 & $\mathrm{H}_{2} \mathrm{O}_{2}^{-}+\mathrm{H}_{2} \mathrm{O} \rightarrow \mathrm{OH}^{-} \cdot\left(\mathrm{H}_{2} \mathrm{O}\right)+\mathrm{OH}$ & $1.0 \times 10^{-17}$ & $139^{f}$ \\
\hline 288 & $\mathrm{O}^{-}+\mathrm{H}_{2} \mathrm{O} \rightarrow \mathrm{OH}^{-}+\mathrm{OH}$ & $1.4 \times 10^{-15}$ & 105 \\
\hline 289 & $\mathrm{O}^{-}+\mathrm{O}_{2} \rightarrow \mathrm{O}_{2}^{-}+\mathrm{O}$ & $1.0 \times 10^{-18}$ & 74 and 134 \\
\hline 290 & $\mathrm{O}^{-}+\mathrm{O}_{2}\left(\mathrm{a}^{1} \Delta\right) \rightarrow \mathrm{O}_{2}^{-}+\mathrm{O}$ & $7.9 \times 10^{-16} \mathrm{e}^{-890 / T_{g}}$ & 74 and 140 \\
\hline 291 & $\mathrm{O}^{-}+\mathrm{O}_{2}\left(\mathrm{a}^{1} \Delta\right) \rightarrow \mathrm{O}_{3}+\mathrm{e}$ & $6.1 \times 10^{-16}$ & 74 and 140 \\
\hline 292 & $\mathrm{O}^{-}+\mathrm{O}_{2}\left(\mathrm{~b}^{1} \Sigma\right) \rightarrow \mathrm{O}_{2}^{-}+\mathrm{O}$ & $7.9 \times 10^{-16} \mathrm{e}^{-890 / T_{g}}$ & As rxn 290 \\
\hline 293 & $\mathrm{O}^{-}+\mathrm{O}_{2}\left(\mathrm{~b}^{1} \Sigma\right) \rightarrow \mathrm{O}_{3}+\mathrm{e}$ & $6.1 \times 10^{-16}$ & 74 and 140 \\
\hline 294 & $\mathrm{O}^{-}+\mathrm{O}_{3} \rightarrow \mathrm{O}_{2}^{-}+\mathrm{O}_{2}$ & $1.0 \times 10^{-17}$ & 74 and 134 \\
\hline 295 & $\mathrm{O}_{2}^{-}+\mathrm{O} \rightarrow \mathrm{O}^{-}+\mathrm{O}_{2}$ & $8.5 \times 10^{-17} T_{0}{ }^{-1.7}$ & $141^{g}$ \\
\hline 296 & $\mathrm{O}_{2}^{-}+\mathrm{O} \rightarrow \mathrm{O}_{3}+\mathrm{e}^{-}$ & $8.5 \times 10^{-17} T_{0}^{-1.7}$ & $141^{g}$ \\
\hline \multicolumn{4}{|c|}{ Three-body collisions - positive ions } \\
\hline 297 & $\mathrm{He}^{+}+2 \mathrm{He} \rightarrow \mathrm{He}_{2}^{+}+\mathrm{He}$ & $1.4 \times 10^{-43} T_{0}^{-0.6}$ & 142 \\
\hline 298 & $\mathrm{H}^{+} \cdot\left(\mathrm{H}_{2} \mathrm{O}\right)+\mathrm{H}_{2} \mathrm{O}(+\mathrm{He}) \rightarrow \mathrm{H}^{+} \cdot\left(\mathrm{H}_{2} \mathrm{O}\right)_{2}(+\mathrm{He})$ & Effective & 87 and $143^{c, d}$ \\
\hline 299 & $\mathrm{H}^{+} \cdot\left(\mathrm{H}_{2} \mathrm{O}\right)_{2}+\mathrm{H}_{2} \mathrm{O}(+\mathrm{He}) \rightarrow \mathrm{H}^{+} \cdot\left(\mathrm{H}_{2} \mathrm{O}\right)_{3}(+\mathrm{He})$ & Effective & 87 and $143^{c, d}$ \\
\hline 300 & $\mathrm{H}^{+} \cdot\left(\mathrm{H}_{2} \mathrm{O}\right)_{3}+\mathrm{H}_{2} \mathrm{O}(+\mathrm{He}) \rightarrow \mathrm{H}^{+} \cdot\left(\mathrm{H}_{2} \mathrm{O}\right)_{4}(+\mathrm{He})$ & Effective & 87 and $143^{c, d}$ \\
\hline 301 & $\mathrm{H}^{+} \cdot\left(\mathrm{H}_{2} \mathrm{O}\right)_{4}+\mathrm{H}_{2} \mathrm{O}(+\mathrm{He}) \rightarrow \mathrm{H}^{+} \cdot\left(\mathrm{H}_{2} \mathrm{O}\right)_{5}(+\mathrm{He})$ & Effective & 87 and $143^{c, d}$ \\
\hline 302 & $\mathrm{H}^{+} \cdot\left(\mathrm{H}_{2} \mathrm{O}\right)_{5}+\mathrm{H}_{2} \mathrm{O}(+\mathrm{He}) \rightarrow \mathrm{H}^{+} \cdot\left(\mathrm{H}_{2} \mathrm{O}\right)_{6}(+\mathrm{He})$ & Effective & 87 and $143^{c, d}$ \\
\hline 303 & $\mathrm{H}^{+} \cdot\left(\mathrm{H}_{2} \mathrm{O}\right)_{6}+\mathrm{H}_{2} \mathrm{O}(+\mathrm{He}) \rightarrow \mathrm{H}^{+} \cdot\left(\mathrm{H}_{2} \mathrm{O}\right)_{7}(+\mathrm{He})$ & Effective & 87 and $143^{b, c, d}$ \\
\hline 304 & $\mathrm{H}^{+} \cdot\left(\mathrm{H}_{2} \mathrm{O}\right)_{7}+\mathrm{H}_{2} \mathrm{O}(+\mathrm{He}) \rightarrow \mathrm{H}^{+} \cdot\left(\mathrm{H}_{2} \mathrm{O}\right)_{8}(+\mathrm{He})$ & Effective & est. $^{e}$ \\
\hline 305 & $\mathrm{H}^{+} \cdot\left(\mathrm{H}_{2} \mathrm{O}\right)_{8}+\mathrm{H}_{2} \mathrm{O}(+\mathrm{He}) \rightarrow \mathrm{H}^{+} \cdot\left(\mathrm{H}_{2} \mathrm{O}\right)_{9}(+\mathrm{He})$ & Effective & est. $^{e}$ \\
\hline 306 & $\mathrm{O}_{2}^{+}+\mathrm{H}_{2} \mathrm{O}(+\mathrm{He}) \rightarrow \mathrm{O}_{2}^{+} \cdot \mathrm{H}_{2} \mathrm{O}(+\mathrm{He})$ & Effective & $87^{c, d}$ \\
\hline 307 & $\mathrm{O}_{2}^{+}+\mathrm{O}_{2}(+\mathrm{He}) \rightarrow \mathrm{O}_{4}^{+}(+\mathrm{He})$ & Effective & $87^{c, d}$ \\
\hline \multicolumn{4}{|c|}{ Three-body collisions - negative ions } \\
\hline 308 & $\mathrm{OH}^{-}+\mathrm{H}_{2} \mathrm{O}+\mathrm{He} \rightarrow \mathrm{OH}^{-} \cdot\left(\mathrm{H}_{2} \mathrm{O}\right)+\mathrm{He}$ & $8.0 \times 10^{-42}$ & $144^{h}$ \\
\hline 309 & $\mathrm{OH}^{-} \cdot\left(\mathrm{H}_{2} \mathrm{O}\right)+\mathrm{H}_{2} \mathrm{O}+\mathrm{He} \rightarrow \mathrm{OH}^{-} \cdot\left(\mathrm{H}_{2} \mathrm{O}\right)_{2}+\mathrm{He}$ & $2.5 \times 10^{-43}$ & $144^{h}$ \\
\hline 310 & $\mathrm{OH}^{-} \cdot\left(\mathrm{H}_{2} \mathrm{O}\right)_{2}+\mathrm{H}_{2} \mathrm{O}+\mathrm{He} \rightarrow \mathrm{OH}^{-} \cdot\left(\mathrm{H}_{2} \mathrm{O}\right)_{3}+\mathrm{He}$ & $1.5 \times 10^{-43}$ & $144^{h}$ \\
\hline 311 & $\mathrm{O}^{-}+\mathrm{H}_{2} \mathrm{O}+\mathrm{He} \rightarrow \mathrm{H}_{2} \mathrm{O}_{2}^{-}+\mathrm{He}$ & $1.3 \times 10^{-40}$ & 139 \\
\hline
\end{tabular}

${ }^{a} \mathrm{In} \mathrm{s}^{-1}, \mathrm{~m}^{3} \mathrm{~s}^{-1}$ and $\mathrm{m}^{6} \mathrm{~s}^{-1}$ for one-, two- and three-body reactions, respectively. ${ }^{b}$ Value is estimated in reference. ${ }^{c}$ Effective rate coefficients calculated from pressure dependent rates as described by Sieck ${ }^{87}$ for $1 \mathrm{~atm}$ and a temperature range $280-350 \mathrm{~K}$. ${ }^{d}$ Background gas is (humid) air in given reference. Gas efficiency factors for He background gas are not known for these reactions, but could potentially change calculated reaction rate coefficients if taken into account. ${ }^{e}$ Rate coefficients are estimated by extrapolating the coefficients $k_{0}^{300}$ and $A$ given by Sieck et al. ${ }^{87}$ using an exponential fit, and using constant values $n=16, B=5000$, and $k_{\mathrm{L}}=10^{-24} .{ }^{f}$ Value is listed as a lower limit in reference. ${ }^{g}$ Estimated branching ratio. ${ }^{h}$ Third body is $\mathrm{H}_{2} \mathrm{O}$ in reference.

third body density) is linear with the third body density. In the high pressure limit the effective rate coefficient is independent of the density of the third body. In the region between the two limits the effective rate coefficient is non-linear with the third body density.
For a number of reactions, this transition region occurs around atmospheric pressure, therefore effective rate coefficients must be calculated using available knowledge of the high and low pressure limits. The coefficients which have been explicitly calculated for 
atmospheric pressure are marked as "effective" in Tables 7 and 8. Among these reactions is the formation and destruction of protonated water clusters $\mathrm{H}^{+} \cdot\left(\mathrm{H}_{2} \mathrm{O}\right)_{n}$, where the rate coefficients are given by Sieck et $a .^{87}$ Here, the expressions given in ref. 87 are used to calculate the effective rate coefficients for these reactions under our plasma operating conditions (atmospheric pressure, $T_{\mathrm{g}}=280-350 \mathrm{~K}$ ). Results are fitted with an Arrhenius expression, where possible, in order to keep the temperature dependence for these reactions, since the formation of cluster ions is highly temperature dependent. ${ }^{87}$ The rate coefficients for the formation of the two highest order clusters taken into account in this work are estimated by extrapolating the coefficients $k_{0}^{300}$ and $A$ given by Sieck et al. using an exponential fit, and using constant values $n=16$,
$B=5000$, and $k_{\mathrm{L}}=10^{-24}$ (see Sieck et al. ${ }^{87}$ for further description of these coefficients).

Table 8 shows reaction rate coefficients for collisions between ions and neutrals. Similar to the description of ion-neutral reactions in Table 7, a number reactions rates in Table 8, including neutral reactions of several $\mathrm{O}$ and $\mathrm{H}$ containing species, are specified as "effective". Data to calculate rate coefficients for these reactions has generally been taken from the IUPAC chemical kinetics database. ${ }^{88}$

For the calculation of "effective" decay rates, and generally for three-body processes, we have multiplied the three-body rate coefficient from the respective sources by a background gas dependent efficiency factor, if available, where the collider gas is different from $\mathrm{He}$ in the reference. This accounts for the fact that $\mathrm{He}$ is a less effective quencher compared to other

Table 8 Neutral chemistry

\begin{tabular}{|c|c|c|c|}
\hline No. & Reaction (rxn) & Rate $^{a}$ & Ref. \\
\hline \multicolumn{4}{|c|}{ Two-body collisions } \\
\hline 312 & $\mathrm{He}+\mathrm{O}\left({ }^{1} \mathrm{D}\right) \rightarrow \mathrm{O}+\mathrm{He}$ & $7.0 \times 10^{-22}$ & $145^{b}$ \\
\hline 313 & $\mathrm{He}+\mathrm{O}\left({ }^{1} \mathrm{~S}\right) \rightarrow \mathrm{O}+\mathrm{He}$ & $7.0 \times 10^{-22}$ & As rxn 312 \\
\hline 314 & $\mathrm{He}+\mathrm{O}_{2}\left(\mathrm{a}^{1} \Delta\right) \rightarrow \mathrm{O}_{2}+\mathrm{He}$ & $8.0 \times 10^{-27}$ & $146^{b}$ \\
\hline 315 & $\mathrm{He}+\mathrm{O}_{2}\left(\mathrm{~b}^{1} \Sigma\right) \rightarrow \mathrm{O}_{2}\left(\mathrm{a}^{1} \Delta\right)+\mathrm{He}$ & $1.0 \times 10^{-23} T_{0}^{0.5}$ & $125^{c}$ \\
\hline 316 & $2 \mathrm{He}^{*} \rightarrow \mathrm{He}+\mathrm{He}^{+}+\mathrm{e}$ & $4.5 \times 10^{-16}$ & 46 and 97 \\
\hline 317 & $2 \mathrm{He}^{*} \rightarrow \mathrm{He}_{2}^{+}+\mathrm{e}$ & $1.05 \times 10^{-15}$ & 46 and 97 \\
\hline 318 & $\mathrm{He}^{*}+\mathrm{He}_{2}^{*} \rightarrow 2 \mathrm{He}+\mathrm{He}^{+}+\mathrm{e}$ & $5.0 \times 10^{-16}$ & $97^{d}$ \\
\hline 319 & $\mathrm{He}^{*}+\mathrm{He}_{2}^{*} \rightarrow \mathrm{He}+\mathrm{He}_{2}^{+}+\mathrm{e}$ & $2.0 \times 10^{-15}$ & $97^{d}$ \\
\hline 320 & $\mathrm{He}^{*}+\mathrm{OH} \rightarrow \mathrm{OH}^{+}+\mathrm{He}+\mathrm{e}$ & $6.08 \times 10^{-16}$ & As rxn 321 \\
\hline 321 & $\mathrm{He}^{*}+\mathrm{H}_{2} \mathrm{O} \rightarrow \mathrm{He}+\mathrm{H}_{2} \mathrm{O}^{+}+\mathrm{e}$ & $6.08 \times 10^{-16}$ & $147^{e}$ \\
\hline 322 & $\mathrm{He}^{*}+\mathrm{H}_{2} \mathrm{O} \rightarrow \mathrm{He}+\mathrm{OH}^{+}+\mathrm{H}+\mathrm{e}$ & $1.39 \times 10^{-16}$ & $147^{e}$ \\
\hline 323 & $\mathrm{He}^{*}+\mathrm{H}_{2} \mathrm{O}_{2} \rightarrow \mathrm{He}+\mathrm{OH}^{+}+\mathrm{OH}+\mathrm{e}$ & $6.08 \times 10^{-16}$ & As rxn 321 \\
\hline 324 & $\mathrm{He}^{*}+\mathrm{O} \rightarrow \mathrm{O}^{+}+\mathrm{He}+\mathrm{e}$ & $2.54 \times 10^{-16}$ & As rxn 327 \\
\hline 325 & $\mathrm{He}^{*}+\mathrm{O}\left({ }^{1} \mathrm{D}\right) \rightarrow \mathrm{O}^{+}+\mathrm{He}+\mathrm{e}$ & $2.54 \times 10^{-16}$ & As rxn 327 \\
\hline 326 & $\mathrm{He}^{*}+\mathrm{O}\left({ }^{1} \mathrm{~S}\right) \rightarrow \mathrm{O}^{+}+\mathrm{He}+\mathrm{e}$ & $2.54 \times 10^{-16}$ & As rxn 327 \\
\hline 327 & $\mathrm{He}^{*}+\mathrm{O}_{2} \rightarrow \mathrm{O}_{2}^{+}+\mathrm{He}+\mathrm{e}$ & $2.54 \times 10^{-16}$ & 148 \\
\hline 328 & $\mathrm{He}^{*}+\mathrm{O}_{2}\left(\mathrm{a}^{1} \Delta\right) \rightarrow \mathrm{O}_{2}^{+}+\mathrm{He}+\mathrm{e}$ & $2.54 \times 10^{-16}$ & As rxn 327 \\
\hline 329 & $\mathrm{He}^{*}+\mathrm{O}_{2}\left(\mathrm{~b}^{1} \Sigma\right) \rightarrow \mathrm{O}_{2}^{+}+\mathrm{He}+\mathrm{e}$ & $2.54 \times 10^{-16}$ & As rxn 327 \\
\hline 330 & $\mathrm{He}^{*}+\mathrm{O}_{3} \rightarrow \mathrm{O}_{2}^{+}+\mathrm{O}+\mathrm{He}+\mathrm{e}$ & $2.6 \times 10^{-16}$ & $74^{c}$ \\
\hline 331 & $\mathrm{He}_{2}^{*}+\mathrm{H}_{2} \mathrm{O} \rightarrow 2 \mathrm{He}+\mathrm{H}_{2} \mathrm{O}^{+}+\mathrm{e}$ & $2.2 \times 10^{-15}$ & 149 \\
\hline 332 & $\mathrm{He}_{2}^{*}+\mathrm{O} \rightarrow \mathrm{O}^{+}+2 \mathrm{He}+\mathrm{e}$ & $3.6 \times 10^{-16}$ & As rxn 335 \\
\hline 333 & $\mathrm{He}_{2}^{*}+\mathrm{O}\left({ }^{1} \mathrm{D}\right) \rightarrow \mathrm{O}^{+}+2 \mathrm{He}+\mathrm{e}$ & $3.6 \times 10^{-16}$ & As rxn 335 \\
\hline 334 & $\mathrm{He}_{2}^{*}+\mathrm{O}\left({ }^{1} \mathrm{~S}\right) \rightarrow \mathrm{O}^{+}+2 \mathrm{He}+\mathrm{e}$ & $3.6 \times 10^{-16}$ & As rxn 335 \\
\hline 335 & $\mathrm{He}_{2}^{*}+\mathrm{O}_{2} \rightarrow \mathrm{O}_{2}^{+}+2 \mathrm{He}+\mathrm{e}$ & $3.6 \times 10^{-16}$ & 149 \\
\hline 336 & $\mathrm{He}_{2}^{*}+\mathrm{O}_{2}\left(\mathrm{a}^{1} \Delta\right) \rightarrow \mathrm{O}_{2}^{+}+2 \mathrm{He}+\mathrm{e}$ & $3.6 \times 10^{-16}$ & As rxn 335 \\
\hline 337 & $\mathrm{He}_{2}{ }^{*}+\mathrm{O}_{2}\left(\mathrm{~b}^{1} \Sigma\right) \rightarrow \mathrm{O}_{2}^{+}+2 \mathrm{He}+\mathrm{e}$ & $3.6 \times 10^{-16}$ & As rxn 335 \\
\hline 338 & $\mathrm{He}_{2}^{*}+\mathrm{O}_{3} \rightarrow \mathrm{O}_{2}^{+}+\mathrm{O}+2 \mathrm{He}+\mathrm{e}$ & $3.6 \times 10^{-16}$ & $74^{c}$ \\
\hline 339 & $\mathrm{H}+\mathrm{HO}_{2} \rightarrow \mathrm{H}_{2}+\mathrm{O}_{2}$ & $5.6 \times 10^{-18}$ & 88 \\
\hline 340 & $\mathrm{H}+\mathrm{HO}_{2} \rightarrow 2 \mathrm{OH}$ & $7.2 \times 10^{-17}$ & 88 \\
\hline 341 & $\mathrm{H}+\mathrm{HO}_{2} \rightarrow \mathrm{H}_{2} \mathrm{O}+\mathrm{O}$ & $2.4 \times 10^{-18}$ & 88 \\
\hline 342 & $\mathrm{H}+\mathrm{H}_{2} \mathrm{O}_{2} \rightarrow \mathrm{H}_{2} \mathrm{O}+\mathrm{OH}$ & $1.7 \times 10^{-17} \mathrm{e}^{-1800 / T_{g}}$ & 150 \\
\hline 343 & $\mathrm{H}+\mathrm{H}_{2} \mathrm{O}_{2} \rightarrow \mathrm{H}_{2}+\mathrm{HO}_{2}$ & $2.8 \times 10^{-18} \mathrm{e}^{-1890 / T_{g}}$ & 150 \\
\hline 344 & $\mathrm{H}+\mathrm{O}_{3} \rightarrow \mathrm{OH}+\mathrm{O}_{2}$ & $1.4 \times 10^{-16} \mathrm{e}^{-470 / T_{g}}$ & 151 and 152 \\
\hline 345 & $\mathrm{H}_{2}+\mathrm{OH} \rightarrow \mathrm{H}_{2} \mathrm{O}+\mathrm{H}$ & $4.27 \times 10^{-19} T_{0}^{2.41} \mathrm{e}^{-1240 / T_{g}}$ & 153 \\
\hline 346 & $\mathrm{H}_{2}+\mathrm{O}\left({ }^{1} \mathrm{D}\right) \rightarrow \mathrm{OH}+\mathrm{H}$ & $1.2 \times 10^{-16}$ & 88 \\
\hline 347 & $\mathrm{H}_{2}+\mathrm{O}\left({ }^{1} \mathrm{~S}\right) \rightarrow \mathrm{OH}+\mathrm{H}$ & $1.2 \times 10^{-16}$ & As rxn 346 \\
\hline 348 & $2 \mathrm{OH} \rightarrow \mathrm{H}_{2} \mathrm{O}+\mathrm{O}$ & $6.2 \times 10^{-20} T_{0}^{2.6} \mathrm{e}^{945 / T_{\mathrm{g}}}$ & 88 \\
\hline 349 & $\mathrm{OH}+\mathrm{HO}_{2} \rightarrow \mathrm{O}_{2}+\mathrm{H}_{2} \mathrm{O}$ & $4.8 \times 10^{-17} \mathrm{e}^{250 / T_{g}}$ & 88, 154 and 155 \\
\hline 350 & $\mathrm{OH}+\mathrm{H}_{2} \mathrm{O}_{2} \rightarrow \mathrm{HO}_{2}+\mathrm{H}_{2} \mathrm{O}$ & $2.9 \times 10^{-18} \mathrm{e}^{-160 / T_{g}}$ & 88 \\
\hline 351 & $\mathrm{OH}+\mathrm{O} \rightarrow \mathrm{H}+\mathrm{O}_{2}$ & $2.4 \times 10^{-17} \mathrm{e}^{110 / T_{\mathrm{g}}}$ & 88,156 and 157 \\
\hline 352 & $\mathrm{OH}+\mathrm{O}\left({ }^{1} \mathrm{D}\right) \rightarrow \mathrm{O}_{2}+\mathrm{H}$ & $2.4 \times 10^{-17} \mathrm{e}^{110 / T_{\mathrm{g}}}$ & As rxn 351 \\
\hline 353 & $\mathrm{OH}+\mathrm{O}\left({ }^{1} \mathrm{~S}\right) \rightarrow \mathrm{O}_{2}+\mathrm{H}$ & $2.4 \times 10^{-17} \mathrm{e}^{110 / T_{g}}$ & As rxn 351 \\
\hline 354 & $\mathrm{OH}+\mathrm{O}_{3} \rightarrow \mathrm{O}_{2}+\mathrm{HO}_{2}$ & $1.7 \times 10^{-18} \mathrm{e}^{-940 / T_{g}}$ & 88 \\
\hline 355 & $\mathrm{H}_{2} \mathrm{O}+\mathrm{O}\left({ }^{1} \mathrm{D}\right) \rightarrow 2 \mathrm{OH}$ & $1.63 \times 10^{-16} \mathrm{e}^{60 / T_{\mathrm{g}}}$ & 151 \\
\hline 356 & $\mathrm{H}_{2} \mathrm{O}+\mathrm{O}\left({ }^{1} \mathrm{~S}\right) \rightarrow \mathrm{O}+\mathrm{H}_{2} \mathrm{O}$ & $4.5 \times 10^{-17}$ & 158 \\
\hline 357 & $\mathrm{H}_{2} \mathrm{O}+\mathrm{O}\left({ }^{1} \mathrm{~S}\right) \rightarrow \mathrm{O}\left({ }^{1} \mathrm{D}\right)+\mathrm{H}_{2} \mathrm{O}$ & $1.5 \times 10^{-16}$ & 158 \\
\hline 358 & $\mathrm{H}_{2} \mathrm{O}+\mathrm{O}\left({ }^{1} \mathrm{~S}\right) \rightarrow 2 \mathrm{OH}$ & $3.05 \times 10^{-16}$ & 158 \\
\hline 359 & $\mathrm{H}_{2} \mathrm{O}+\mathrm{O}_{2}\left(\mathrm{a}^{1} \Delta\right) \rightarrow \mathrm{O}_{2}+\mathrm{H}_{2} \mathrm{O}$ & $4.8 \times 10^{-24}$ & 151 \\
\hline 360 & $\mathrm{H}_{2} \mathrm{O}+\mathrm{O}_{2}\left(\mathrm{~b}^{1} \Sigma\right) \rightarrow \mathrm{O}_{2}+\mathrm{H}_{2} \mathrm{O}$ & $3.9 \times 10^{-18} \mathrm{e}^{125 / T_{g}}$ & 151 \\
\hline 361 & $\mathrm{HO}_{2}+\mathrm{O} \rightarrow \mathrm{OH}+\mathrm{O}_{2}$ & $2.7 \times 10^{-17} \mathrm{e}^{224 / T_{\mathrm{g}}}$ & 88 and 155 \\
\hline
\end{tabular}


Table 8 (continued)

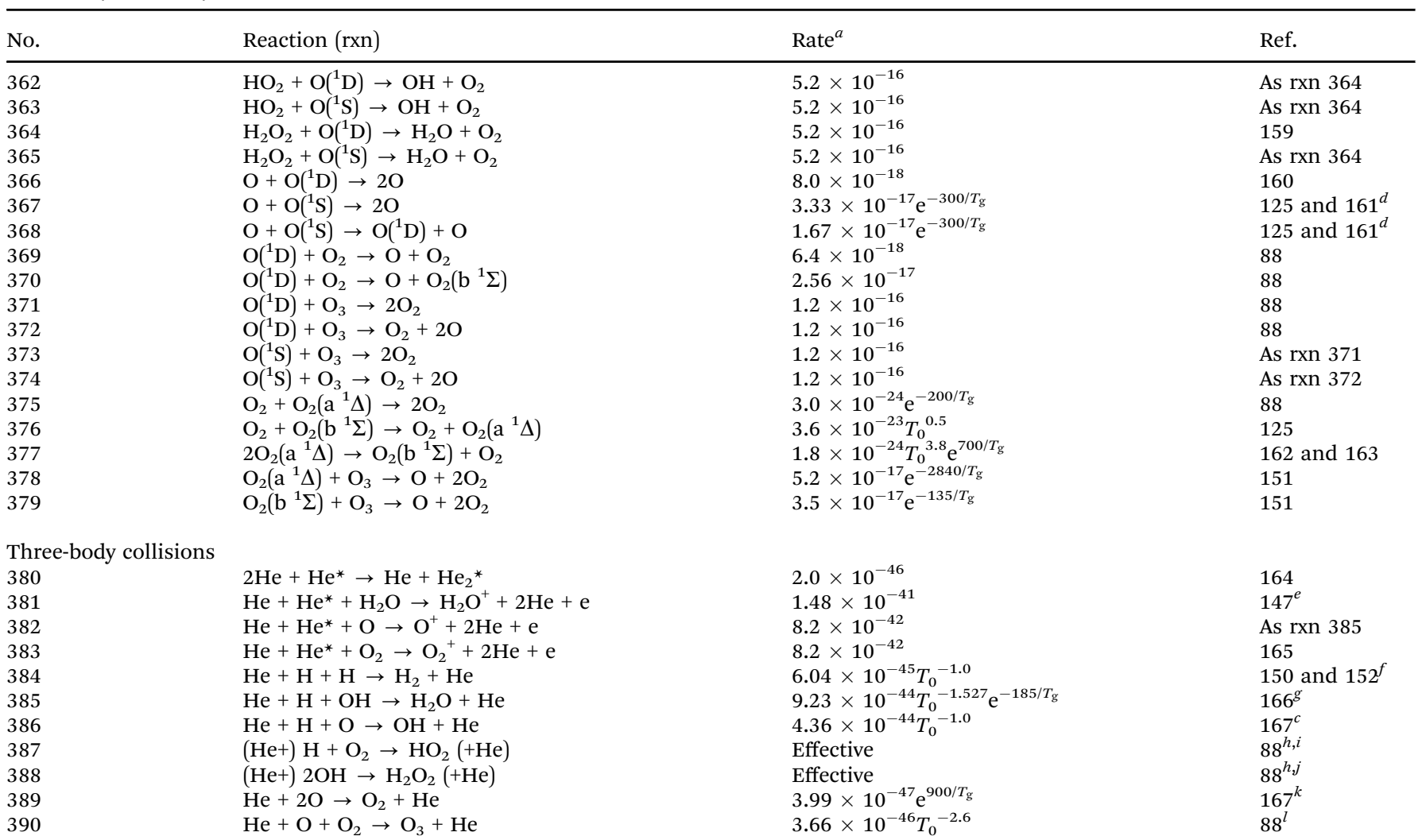

${ }^{a} \mathrm{In} \mathrm{m}^{3} \mathrm{~s}^{-1}$ and $\mathrm{m}^{6} \mathrm{~s}^{-1}$ for two- and three-body collisions, respectively. ${ }^{b}$ Value in an upper limit in reference. ${ }^{c}$ Estimated value in reference. ${ }^{d}$ Estimated branching ratio. ${ }^{e}$ Branching ratios taken from Sanders. ${ }^{168}{ }^{f}$ Third body is Ar instead of He in reference. The gas efficiency factor is assumed to be $1 .^{g}$ Third body is Ar instead of He in reference. The gas efficiency factor is assumed to be 0.65 . This factor is calculated by dividing reaction rate coefficients for $\mathrm{He}$ and $\mathrm{Ar}$ as background gases for the same reaction measured by Zellner et al. ${ }^{169} \mathrm{~h}$ Effective rate coefficients calculated from pressure dependent rates for $1 \mathrm{~atm}$ and fitted by an Arrhenius expression in the temperature range $280-350 \mathrm{~K} .{ }^{i}$ Third body is $\mathrm{N}_{2}$ instead of $\mathrm{He}$ in reference. The gas efficiency factor is assumed to be 0.43 . This factor is calculated by dividing reaction rate coefficients for He and $\mathrm{N}_{2}$ as background gases for the same reaction measured by Hsu et al. ${ }^{170 j}$ Recommended rate coefficient in reference is for $\mathrm{N}_{2}$ background gas instead of He. We apply a gas efficiency factor of 0.41 to the low-pressure limit reaction rate coefficient to account for this. This factor is calculated by dividing the room temperature rate coefficient from the given reference for He background gas (measured by Forster et al. ${ }^{171}$ ) by the recommended value (measured by Fulle et al. ${ }^{172}$ ). ${ }^{k}$ Third body is Ar instead of He in reference. The gas efficiency factor is assumed to be 0.77 . This factor is calculated by dividing reaction rate coefficients for He and $\mathrm{Ar}$ as background gases for the same reaction measured by Campbell and Thrush. ${ }^{169}{ }^{l}$ Third body is $\mathrm{N}_{2}$ instead of He in reference. The gas efficiency factor is assumed to be 0.61 . This factor is calculated by dividing reaction rate coefficients for $\mathrm{He}$ and $\mathrm{N}_{2}$ as background gases for the same reaction measured by Lin and Leu. ${ }^{173}$

background gases. More details for specific reactions are denoted in footnotes.

In addition to the $\mathrm{He}-\mathrm{H}_{2} \mathrm{O}$ chemistry, we also include oxygen neutrals and ions. This makes it possible to investigate the influence of $\mathrm{O}_{2}$ impurities at low $\mathrm{H}_{2} \mathrm{O}$ contents on the plasma chemistry. In contrast to Liu et al., we do not include the ions $\mathrm{HeH}^{+}, \mathrm{H}^{+}$, and $\mathrm{H}_{2}{ }^{+}$due to their generally low densities compared to the more abundant protonated water clusters under all investigated conditions, and the fact that in this work, the focus lies on the investigation of the neutral particle dynamics.

\section{B. List of equipment}

The equipment used for the investigations in this work is listed in Table 9.

Table 9 Equipment used in different experimental setups for power coupling into the plasma and acquiring absorption spectra

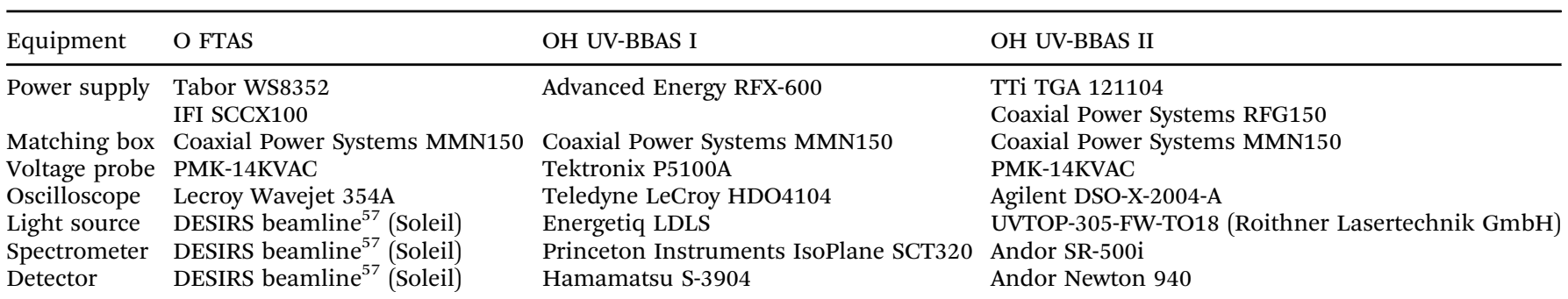




\section{Acknowledgements}

The authors would like to thank Dr Daniel Schröder, Dr Mickaël Foucher and Richard Armitage for helping with experimental setups and taking measurements. We are grateful to Denis Joyeux for the development of the FTS and for his help during the synchrotron campaign. This work was financially supported by the UK EPSRC (EP/K018388/1 \& EP/H003797/2), and the York-Paris Low Temperature Plasma Collaborative Research Centre. Additionally, this work was performed within the LABEX Plas@par project and received financial state aid, managed by the Agence National de la Recherche as part of the programme "Investissements d'avenir" (ANR-11-IDEX-0004-02). Apiwat Wijaikhum acknowledges financial support from the Development and Promotion of Science and Technology Talents Project (DPST), Royal Government of Thailand scholarship, and ThEP Center through project 'Cold atmospheric pressure plasma against drug resistant microorganisms for wound healing' (ThEP-60-PHM-CMU1). Andrew R. Gibson acknowledges funding from the Wellcome Trust [ref. 204829] through the Centre for Future Health (CFH) at the University of York. Helen Davies acknowledges financial support from the Wellcome Trust 4 year PhD programme [WT095024MA]: "Combating Infectious Disease: Computation Approaches in Translational Science”. James Dedrick acknowledges financial support from an Australian Government Endeavour Research Fellowship. The participation of Mark J. Kushner was supported by the US Department of Energy (DE-SC0001319 and DE-SC0014132) and US National Science Foundation (PHY-1519117).

\section{Notes and references}

1 G. Fridman, G. Friedman, A. Gutsol, A. B. Shekhter, V. N. Vasilets and A. Fridman, Plasma Processes Polym., 2008, 5, 503-533.

2 M. G. Kong, G. Kroesen, G. Morfill, T. Nosenko, T. Shimizu, J. van Dijk and J. L. Zimmermann, New J. Phys., 2009, 11, 115012.

3 T. von Woedtke, S. Reuter, K. Masur and K.-D. Weltmann, Phys. Rep., 2013, 530, 291-320.

4 X. Lu, G. V. Naidis, M. Laroussi, S. Reuter, D. B. Graves and K. Ostrikov, Phys. Rep., 2016, 630, 1-84.

5 M. Laroussi, IEEE Trans. Plasma Sci., 2002, 30, 1409-1415. 6 M. Laroussi, Plasma Processes Polym., 2005, 2, 391-400.

7 R. E. J. Sladek and E. Stoffels, J. Phys. D: Appl. Phys., 2005, 38, 1716-1721.

8 A. M. Hirst, M. S. Simms, V. M. Mann, N. J. Maitland, D. O'Connell and F. M. Frame, Br. J. Cancer, 2015, 112, 1536-1545.

9 E. A. Ratovitski, X. Cheng, D. Yan, J. H. Sherman, J. Canady, B. Trink and M. Keidar, Plasma Processes Polym., 2014, 11, 1128-1137.

10 M. Vandamme, E. Robert, S. Lerondel, V. Sarron, D. Ries, S. Dozias, J. Sobilo, D. Gosset, C. Kieda, B. Legrain, J. M. Pouvesle and A. Le Pape, Int. J. Cancer, 2011, 130, 2185-2194.
11 A. R. Gibson, H. O. McCarthy, A. A. Ali, D. O'Connell and W. G. Graham, Plasma Processes Polym., 2014, 11, 1142-1149.

12 D. O'Connell, L. J. Cox, W. B. Hyland, S. J. McMahon, S. Reuter, W. G. Graham, T. Gans and F. J. Currell, Appl. Phys. Lett., 2011, 98, 043701.

13 G. Isbary, J. Heinlin, T. Shimizu, J. L. Zimmermann, G. Morfill, H.-U. Schmidt, R. Monetti, B. Steffes, W. Bunk, Y. Li, T. Klaempfl, S. Karrer, M. Landthaler and W. Stolz, Br. J. Dermatol., 2012, 167, 404-410.

14 A. V. Nastuta, I. Topala, C. Grigoras, V. Pohoata and G. Popa, J. Phys. D: Appl. Phys., 2011, 44, 105204.

15 R. S. Tipa and G. M. W. Kroesen, IEEE Trans. Plasma Sci., 2011, 39, 2978-2979.

16 K. Mizuno, K. Yonetamari, Y. Shirakawa, T. Akiyama and R. Ono, J. Phys. D: Appl. Phys., 2017, 50, 12 LT01.

17 G. Isbary, G. Morfill, H. U. Schmidt, M. Georgi, K. Ramrath, J. Heinlin, S. Karrer, M. Landthaler, T. Shimizu, B. Steffes, W. Bunk, R. Monetti, J. L. Zimmermann, R. Pompl and W. Stolz, Br. J. Dermatol., 2010, 163, 78-82.

18 M. Schuster, C. Seebauer, R. Rutkowski, A. Hauschild, F. Podmelle, C. Metelmann, B. Metelmann, T. von Woedtke, S. Hasse, K.-D. Weltmann and H.-R. Metelmann, J. Craniomaxillofac. Surg., 2016, 44, 1445-1452.

19 D. B. Graves, J. Phys. D: Appl. Phys., 2012, 45, 263001.

20 B. Halliwell and J. M. C. Gutteridge. Free radicals in biology \& medicine. Oxford University Press, 4th edn, 2007.

21 H. Sies, Exp. Physiol., 1997, 82, 291-295.

22 K. Niemi, D. O’Connell, N. de Oliveira, D. Joyeux, L. Nahon, J. P. Booth and T. Gans, Appl. Phys. Lett., 2013, 103, 034102.

23 J. Dedrick, S. Schröter, K. Niemi, A. Wijaikhum, E. Wagenaars, N. de Oliveira, L. Nahon, J. P. Booth, D. O'Connell and T. Gans, J. Phys. D: Appl. Phys., 2017, 50, 455204.

24 A. Wijaikhum, D. Schroeder, S. Schröter, A. R. Gibson, K. Niemi, J. Friderich, A. Greb, V. Schulz-vonder Gathen, D. O'Connell and T. Gans, Plasma Sources Sci. Technol., 2017, 26, 115004.

25 C. Douat, S. Hübner, R. Engeln and J. Benedikt, Plasma Sources Sci. Technol., 2016, 25, 025027.

26 W. Van Gaens, S. Iseni, A. Schmidt-Bleker, K. D. Weltmann, S. Reuter and A. Bogaerts, New J. Phys., 2015, 17, 033003.

27 J. S. Sousa, K. Niemi, L. J. Cox, Q. Th. Algwari, T. Gans and D. O'Connell, J. Appl. Phys., 2011, 109, 123302.

28 J. Waskoenig, K. Niemi, N. Knake, L. M. Graham, S. Reuter, V. Schulz-vonder Gathen and T. Gans, Plasma Sources Sci. Technol., 2010, 19, 045018.

29 S. Große-Kreul, S. Hübner, S. Schneider, A. von Keudell and J. Benedikt, EPJ Techn. Instrum., 2016, 3, 1-16.

30 H. J. Forman, J. M. Fukuto, T. Miller, H. Zhang, A. Rinna and S. Levy, Arch. Biochem. Biophys., 2008, 477, 183-195.

31 T. Verreycken, N. Sadeghi and P. J. Bruggeman, Plasma Sources Sci. Technol., 2014, 23, 045005.

32 A. Nikiforov, L. Li, N. Britun, R. Snyders, P. Vanraes and C. Leys, Plasma Sources Sci. Technol., 2014, 23, 015015.

33 I. Yagi, R. Ono, T. Oda and K. Takaki, Plasma Sources Sci. Technol., 2014, 24, 015002. 
34 J. Benedikt, D. Schröder, S. Schneider, G. Willems, A. Pajdarová, J. Vlček and V. Schulz-vonder Gathen, Plasma Sources Sci. Technol., 2016, 25, 045013.

35 W. D. Kulatilaka, J. R. Gord, V. R. Katta and S. Roy, Opt. Lett., 2012, 37, 3051.

36 J. B. Schmidt, B. L. Sands, W. D. Kulatilaka, S. Roy, J. Scofield and J. R. Gord, Plasma Sources Sci. Technol., 2015, 24, 032004.

37 J. B. Schmidt, B. Sands, J. Scofield, J. R. Gord and S. Roy, Plasma Sources Sci. Technol., 2017, 26, 055004.

38 G. Willems, J. Benedikt and A. von Keudell, J. Phys. D: Appl. Phys., 2017, 50, 335204.

39 Z. Abd-Allah, D. A. G. Sawtell, K. McKay, G. T. West, P. J. Kelly and J. W. Bradley, J. Phys. D: Appl. Phys., 2015, 48, 085202.

40 P. Bruggeman, F. Iza, D. Lauwers and Y. A. Gonzalvo, J. Phys. D: Appl. Phys., 2009, 43, 012003.

41 Y. Gorbanev, C. C. W. Verlackt, S. Tinck, E. Tuenter, K. Foubert, P. Cos and A. Bogaerts, Phys. Chem. Chem. Phys., 2018, 20, 2797-2808.

42 J. Winter, H. Tresp, M. U. Hammer, S. Iseni, S. Kupsch, A. Schmidt-Bleker, K. Wende, M. Dünnbier, K. Masur and K.-D. Weltmann, et al., J. Phys. D: Appl. Phys., 2014, 47, 285401.

43 P. Bruggeman, G. Cunge and N. Sadeghi, Plasma Sources Sci. Technol., 2012, 21, 035019.

44 C. Hibert, I. Gaurand, O. Motret and J. M. Pouvesle, J. Appl. Phys., 1999, 85, 7070-7075.

45 G. Dilecce, P. F. Ambrico, M. Simek and S. De Benedictis, J. Phys. D: Appl. Phys., 2012, 45, 125203.

46 K. Niemi, J. Waskoenig, N. Sadeghi, T. Gans and D. O’Connell, Plasma Sources Sci. Technol., 2011, 20, 055005.

47 C. Lazzaroni, P. Chabert, M. A. Lieberman, A. J. Lichtenberg and A. Leblanc, Plasma Sources Sci. Technol., 2012, 21, 035013.

48 D. X. Liu, P. Bruggeman, F. Iza, M. Z. Rong and M. G. Kong, Plasma Sources Sci. Technol., 2010, 19, 025018.

49 W. Van Gaens and A. Bogaerts, J. Phys. D: Appl. Phys., 2014, 47, 079502.

50 A. M. Lietz and M. J. Kushner, J. Phys. D: Appl. Phys., 2016, 49, 425204.

51 A. Hurlbatt, A. R. Gibson, S. Schröter, J. Bredin, A. P. S. Foote, P. Grondein, D. O'Connell and T. Gans, Plasma Processes Polym., 2016, 14, 1600138.

52 K. Ding and M. A. Lieberman, J. Phys. D: Appl. Phys., 2014, 48, 035401.

53 K. McKay, D. X. Liu, M. Z. Rong, F. Iza and M. G. Kong, J. Phys. D: Appl. Phys., 2012, 45, 172001.

54 D. X. Liu, F. Iza, X. H. Wang, M. G. Kong and M. Z. Rong, Appl. Phys. Lett., 2011, 98, 221501.

55 J. Golda, J. Held, B. Redeker, M. Konkowski, P. Beijer, A. Sobota, G. Kroesen, N. St. J. Braithwaite, S. Reuter, M. M. Turner, T. Gans, D. O'Connell and V. Schulz-von der Gathen, J. Phys. D: Appl. Phys., 2016, 49, 084003.

56 O. A. Alduchov and R. E. Eskridge, J. Appl. Meteorol., 1996, 35, 601-609.

57 L. Nahon, N. de Oliveira, G. A. Garcia, J.-F. Gil, B. Pilette, O. Marcouillé, B. Lagarde and F. Polack, J. Synchrotron Radiat., 2012, 19, 508-520.
58 N. de Oliveira, M. Roudjane, D. Joyeux, D. Phalippou, J.-C. Rodier and L. Nahon, Nat. Photonics, 2011, 5, 149-153.

59 D. Marinov, C. Drag, C. Blondel, O. Guaitella, J. Golda, B. Klarenaar, R. Engeln, V. Schulz-vonder Gathen and J.-P. Booth, Plasma Sources Sci. Technol., 2016, 25, 06LT03.

60 A. Kramida, Yu. Ralchenko and J. Reader, Available: http:// physics.nist.gov/asd, 2016, December 15, [Online], National Institute of Standards and NIST ASD Team, NIST Atomic Spectra Database (ver. 5.3), and MD. Technology, Gaithersburg.

61 M. Foucher, D. Marinov, E. Carbone, P. Chabert and J.-P. Booth, Plasma Sources Sci. Technol., 2015, 24, 042001.

62 G. H. Dieke and H. M. Crosswhite, J. Quant. Spectrosc. Radiat. Transfer, 1962, 2, 97-199.

63 L. Earls, Phys. Rev., 1935, 48, 423-424.

64 K. R. German, J. Chem. Phys., 1975, 62, 2584-2587.

65 A. Goldman and J. R. Gillis, J. Quant. Spectrosc. Radiat. Transfer, 1981, 25, 111-135.

66 V. L. Kasyutich, Eur. Phys. J. D, 2005, 33, 29-33.

67 S. Hofmann, A. F. H. van Gessel, T. Verreycken and P. Bruggeman, Plasma Sources Sci. Technol., 2011, 20, 065010.

68 D. Marinov and N. St. J. Braithwaite, Plasma Sources Sci. Technol., 2014, 23, 062005.

69 K. Niemi, T. Gans and D. O'Connell, Plasma Sources Sci. Technol., 2013, 22, 032001.

70 C. Lazzaroni, M. A. Lieberman, A. J. Lichtenberg and P. Chabert, J. Phys. D: Appl. Phys., 2012, 45, 495204.

71 S. Schröter, A. R. Gibson, M. J. Kushner, T. Gans and D. O'Connell, Plasma Phys. Controlled Fusion, 2018, 60, 014035.

72 J. R. Roth. Industrial Plasma Processing. IOP Publishing, Bristol and Philadelphia, 1995.

73 A. H. Markosyan, A. Luque, F. J. Gordillo-Vázquez and U. Ebert, Comput. Phys. Commun., 2014, 185, 2697-2702.

74 M. M. Turner, Plasma Sources Sci. Technol., 2015, 24, 035027.

75 T. Murakami, K. Niemi, T. Gans, D. O’Connell and W. G. Graham, Plasma Sources Sci. Technol., 2013, 22, 015003.

76 T. Murakami, K. Niemi, T. Gans, D. O'Connell and W. G. Graham, Plasma Sources Sci. Technol., 2013, 22, 045010.

77 T. Murakami, K. Niemi, T. Gans, D. O'Connell and W. G. Graham, Plasma Sources Sci. Technol., 2014, 23, 025005.

78 K. Ding, M. A. Lieberman and A. J. Lichtenberg, J. Phys. D: Appl. Phys., 2014, 47, 305203.

79 N. Knake and V. Schulz-vonder Gathen, Eur. Phys. J. D, 2010, 60, 645-652.

80 B. F. Gordiets, C. M. Ferreira, V. L. Guerra, J. M. A. H. Loureiro, J. Nahorny, D. Pagnon, M. Touzeau and M. Vialle, IEEE Trans. Plasma Sci., 1995, 23, 750-768.

81 I. Méndez, F. J. Gordillo-Vazquez, V. J. Herrero and I. Tanarro, J. Phys. Chem. A, 2006, 110, 6060-6066.

82 Biagi v8.9 database, www.lxcat.net, retrieved July 2012.

83 S. F. Biagi, Fortran program, MAGBOLTZ, versions 8.9 and after.

84 Y. Itikawa and N. Mason, J. Phys. Chem. Ref. Data, 2005, 34, 1-22. 
85 T. M. Miller, N. S. Shuman and A. A. Viggiano, J. Chem. Phys., 2012, 136, 204306.

86 I. A. Kossyi, A. Y. Kostinsky, A. A. Matveyev and V. P. Silakov, Plasma Sources Sci. Technol., 1992, 1, 207-220.

87 L. Wayne Sieck, J. T. Heron and D. S. Green, Plasma Chem. Plasma Process, 2000, 20, 235-258.

88 R. Atkinson, D. L. Baulch, R. A. Cox, J. N. Crowley, R. F. Hampson, R. G. Hynes, M. E. Jenkin, M. J. Rossi and J. Troe, Atmos. Chem. Phys., 2004, 4, 1461-1738.

89 M. Yousfi and M. D. Benabdessadok, J. Appl. Phys., 1996, 80, 6619-6630.

90 S. A. Lawton and A. V. Phelps, J. Chem. Phys., 1978, 69, 1055-1068.

91 L. Vriens, Phys. Lett., 1964, 5, 260-261.

92 M. R. Flannery, K. J. McCann and N. W. Winter, J. Phys. B: At. Mol. Phys., 1981, 14, 3789-3796.

93 R. Riahi, P. Teulet, Z. Ben Lakhdar and A. Gleizes, Eur. Phys. J. D, 2006, 40, 223-230.

94 R. R. Laher and F. R. Gilmore, J. Phys. Chem. Ref. Data, 1990, 19, 277-305.

95 M. Gryziński, Phys. Rev., 1965, 138, A336-A358.

96 R. I. Hall and S. Trajmar, J. Phys. B: At. Mol. Phys., 1975, 8, L293-L296.

97 R. Deloche, P. Monchicourt, M. Cheret and F. Lambert, Phys. Rev. A: At., Mol., Opt. Phys., 1976, 13, 1140-1176.

98 W. Kedzierski, J. Derbyshire, C. Malone and J. W. McConkey, J. Phys. B: At., Mol. Opt. Phys., 1998, 31, 5361-5368.

99 T. Harb, W. Kedzierski and J. W. McConkey, J. Chem. Phys., 2001, 115, 5507-5512.

100 S. J. B. Corrigan, J. Chem. Phys., 1965, 43, 4381-4386.

101 M. Hayashi, J. Phys., Colloq., 1979, 40, C7/45-C7/46.

102 W. Liu and G. A. Victor, Astrophys. J., 1994, 435, 909-919.

103 I. A. Soloshenko, V. V. Tsiolko, S. S. Pogulay, A. G. Terent'yeva, V. Y. Bazhenov, A. I. Shchedrin, A. V. Ryabtsev and A. I. Kuzmichev, Plasma Sources Sci. Technol., 2007, 16, 56-66.

104 M. Gupta and K. L. Baluja, J. Phys. B: At., Mol. Opt. Phys., 2005, 38, 4057-4073.

105 C. E. Melton and G. A. Neece, J. Am. Chem. Soc., 1971, 93, 6757-6759.

106 D. Nandi, E. Krishnakumar, A. Rosa, W.-F. Schmidt and E. Illenberger, Chem. Phys. Lett., 2003, 373, 454-459.

107 P. D. Burrow., J. Chem. Phys., 1973, 59, 4922-4931.

108 S. Matejcik, A. Kiendler, P. Cicman, J. Skalny, P. Stampfli, E. Illenberger, Y. Chu, A. Stamatovic and T. D. Märk, Plasma Sources Sci. Technol., 1997, 6, 140-146.

109 R. K. Janev, W. D. Langer, K. Evans Jr. and D. E. Post Jr., Elementary Processes in Hydrogen-Helium Plasmas: Cross Sections and Reaction Rate Coefficients, Springer-Verlag, Berlin, 1987, ch. 7.

110 H. B. Pedersen, N. Djurić, M. J. Jensen, D. Kella, C. P. Safvan, H. T. Schmidt, L. Vejby-Christensen and L. H. Andersen, Phys. Rev. A: At., Mol., Opt. Phys., 1999, 60, 2882-2899.

111 H. Deutsch, P. Scheier, K. Becker and T. D. Märk, Chem. Phys. Lett., 2003, 382, 26-31.
112 D. McElroy, C. Walsh, A. J. Markwick, M. A. Cordiner, K. Smith and T. J. Millar, Astron. Astrophys., 2013, 550, A36.

113 S. Rosén, A. Derkatch, J. Semaniak, A. Neau, A. Al-Khalili, A. Le Padellec, L. Vikor, R. Thomas, H. Danared, M. af Ugglas and M. Larsson, Faraday Discuss., 2000, 115, 295-302.

114 M. J. Jensen, R. C. Bilodeau, C. P. Safvan, K. Seiersen, L. H. Andersen, H. B. Pedersen and O. Heber, Astrophys. J., 2000, 543, 764-774.

115 O. Novotný, H. Buhr, J. Stuützel, M. B. Mendes, M. H. Berg, D. Bing, M. Froese, M. Grieser, O. Heber, B. JordonThaden, C. Krantz, M. Lange, M. Lestinsky, S. Novotny, S. Menk, D. A. Orlov, A. Petrignani, M. L. Rappaport, A. Shornikov, D. Schwalm, D. Zajfman and A. Wolf, J. Phys. Chem. A, 2010, 114, 4870-4874.

116 C.-M. Huang, M. Whitaker, M. A. Biondi and R. Johnsen, Phys. Rev. A: At., Mol., Opt. Phys., 1978, 18, 64-67.

117 M. T. Leu, M. A. Biondi and R. Johnsen, Phys. Rev. A: At., Mol., Opt. Phys., 1973, 7, 292-298.

118 M. H. Bortner and T. Baurer. Defense Nuclear Agency reaction rate handbook, revision no. 7 , DaD Nuclear Information and Analysis Center, 7th edn, 1979.

119 R. Peverall, S. Rosén, J. R. Peterson, M. Larsson, A. AlKhalili, L. Vikor, J. Semaniak, R. Bobbenkamp, A. Le Padellec and A. N. Maurellis, et al., J. Chem. Phys., 2001, 114, 6679-6689.

120 A. I. Florescu Mitchell and J. B. A. Mitchell, Phys. Rep., 2006, 430, 277-374.

121 G. J. M. Hagelaar and L. C. Pitchford, Plasma Sources Sci. Technol., 2005, 14, 722-733.

122 Morgan (Kinema Research \& Software) database, www. lxcat.net, retrieved on.

123 S. S. Prasad and W. T. Huntress Jr., Astrophys. J., Suppl. Ser., 1980, 43, 1-35.

124 G. Mauclaire, R. Derai and R. Marx, Int. J. Mass Spectrom. Ion Phys., 1978, 26, 289-301.

125 D. S. Stafford and M. J. Kushner, J. Appl. Phys., 2004, 96, 2451-2465.

126 N. G. Adams and D. Smith, J. Phys. B: At. Mol. Phys., 1976, 9, 1439-1451.

127 J. D. C. Jones, K. Birkinshaw and N. D. Twiddy, Chem. Phys. Lett., 1981, 77, 484-488.

128 W. T. Huntress, J. Chem. Phys., 1973, 59, 4742-4756.

129 A. B. Rakshit and P. Warneck, J. Chem. Soc., Faraday Trans. 2, 1980, 76, 1084-1094.

130 A. A. Viggiano, D. L. Albritton, F. C. Fehsenfeld, N. G. Adams, D. Smith and F. Howorka, Astrophys. J., 1980, 236, 492-497.

131 V. G. Anicich, J. Phys. Chem. Ref. Data, 1993, 22, 1469-1569. 132 D. Smith, N. G. Adams and T. M. Miller, J. Chem. Phys., 1978, 69, 308-318.

133 M. McFarland, J. Chem. Phys., 1973, 59, 6620-6628.

134 Y. Ikezoe, S. Matsuoka, M. Takebe and A. Viggiano, Gas Phase Ion-Molecule Reaction Rate Constants Through 1986, Maruzen Company Ltd., 1987.

135 A. B. Rakshit and P. Warneck, J. Chem. Phys., 1980, 73, 5074-5080. 
136 R. L. Champion, L. D. Doverspike and S. K. Lam, Phys. Rev. A: At., Mol., Opt. Phys., 1976, 13, 617-621.

137 O. Martinez, Z. Yang, N. J. Demarais, T. P. Snow and V. M. Bierbaum, Astrophys. J., 2010, 720, 173-177.

138 E. E. Ferguson, At. Data Nucl. Data Tables, 1973, 12, 159-178.

139 F. C. Fehsenfeld and E. E. Ferguson, J. Chem. Phys., 1974, 61, 3181-3191.

140 A. Midey, I. Dotan and A. A. Viggiano, J. Phys. Chem. A, 2008, 112, 3040-3045.

141 S. G. Ard, J. J. Melko, B. Jiang, Y. Li, N. S. Shuman, H. Guo and A. A. Viggiano, J. Chem. Phys., 2013, 139, 144302.

142 H. Böhringer, W. Glebe and F. Arnold, J. Phys. B: At. Mol. Phys., 1983, 16, 2619-2626.

143 Y. K. Lau, S. Ikuta and P. Kebarle, J. Am. Chem. Soc., 1982, 104, 1462-1469.

144 J. de Urquijo, A. Bekstein, G. Ruiz-Vargas and F. J. GordilloVáquez, J. Phys. D: Appl. Phys., 2012, 46, 035201.

145 R. F. Heidner III and D. Husain, Int. J. Chem. Kinet., 1974, 6, 77-87.

146 F. D. Findlay, J. Chem. Phys., 1971, 55, 545-551.

147 C. B. Collins and F. W. Lee, J. Chem. Phys., 1979, 70, 1275-1285.

148 J. M. Pouvesle, A. Khacef, J. Stevefelt, H. Jahani, V. V. Gylys and C. B. Collins, J. Chem. Phys., 1988, 88, 3061-3071.

149 J. M. Pouvesle, J. Stevefelt., W. Lee, H. R. Jahani, V. T. Gylys and C. B. Collins, J. Chem. Phys., 1985, 83, 2836-2839.

150 D. L. Baulch, C. J. Cobos, R. A. Cox, C. Esser, P. Frank, Th. Just, J. A. Kerr, M. J. Pilling, J. Troe and R. W. Walker, et al., J. Phys. Chem. Ref. Data, 1992, 21, 411-734.

151 J. B. Burkholder, S. P. Sander, J. Abbatt, J. R. Barker, R. E. Huie, C. E. Kolb, M. J. Kurylo, V. L. Orkin, D. M. Wilmouth and P. H. Wine. JPL Publication 15-10, Jet Propulsion Laboratory, Pasadena, 2015, http://jpldatae val.jpl.nasa.gov/.

152 J. A. Manion, R. E. Huie, R. D. Levin, D. R. Burgess Jr., V. L. Orkin, W. Tsang, W. S. McGivern, J. W. Hudgens, V. D. Knyazev, D. B. Atkinson, E. Chai, A. M. Tereza, C.-Y. Lin, T. C. Allison, W. G. Mallard, F. Westley, J. T. Herron, R. F. Hampson and D. H. Frizzell, NIST Chemical KineticsDatabase, NIST Standard ReferenceDatabase 17, Version 7.0 (Web Version), Release 1.6.8, Data version2015.12. National Institute of Standards and Technology, Gaithersburg, Maryland, 20899-8320. Web address: http://kinetics.nist.gov/.
153 V. L. Orkin, S. N. Kozlov, G. A. Poskrebyshev and M. J. Kurylo, J. Phys. Chem. A, 2006, 110, 6978-6985.

154 L. F. Keyser, J. Phys. Chem., 1988, 92, 1193-1200.

155 D. L. Baulch, C. T. Bowman, C. J. Cobos, R. A. Cox, Th. Just, J. A. Kerr, M. J. Pilling, D. Stocker, J. Troe, W. Tsang and R. W. Walker, J. Phys. Chem. Ref. Data, 2005, 34, 757-1397.

156 R. S. Lewis and R. T. Watson, J. Phys. Chem., 1980, 84, 3495-3503.

157 M. J. Howard and I. W. M. Smith, J. Chem. Soc., Faraday Trans. 2, 1981, 77, 997-1008.

158 T. G. Slanger and G. Black, J. Chem. Phys., 1978, 68, 989-997.

159 I. S. Fletcher and D. Husain, Rev. Can. Chim., 1976, 54, 1765-1770.

160 V. J. Abreu, J. H. Yee, S. C. Solomon and A. Dalgarno, Planet. Space Sci., 1986, 34, 1143-1145.

161 K. Schofield, J. Photochem., 1978, 9, 55-68.

162 R. G. Derwent and B. A. Thrush, Trans. Faraday Soc., 1971, 67, 2036-2043.

163 R. F. Heidner III, C. E. Gardner, T. M. El-Sayed, G. I. Segal and J. V. V. Kasper, J. Chem. Phys., 1981, 74, 5618-5626.

164 G. Myers and A. J. Cunningham, J. Chem. Phys., 1977, 67, 247-253.

165 G. Myers and A. J. Cunningham, J. Chem. Phys., 1977, 67, 3352-3359.

166 S. R. Sellevåg, Y. Georgievskii and J. A. Miller, J. Phys. Chem. A, 2008, 112, 5085-5095.

167 W. Tsang and R. F. Hampson, J. Phys. Chem. Ref. Data, 1986, 15, 1087-1222.

168 R. A. Sanders and E. E. Muschlitz, Int. J. Mass Spectrom. Ion Phys., 1977, 23, 99-108.

169 R. Zellner, K. Erler and D. Field, Symp. (Int.) Combust., [Proc.], 1977, 16, 939-948.

170 K. J. Hsu, J. L. Durant and F. Kaufman, J. Phys. Chem., 1987, 91, 1895-1899.

171 R. Forster, M. Frost, D. Fulle, H. F. Hamann, H. Hippler, A. Schlepegrell and J. Troe, J. Chem. Phys., 1995, 103, 2949-2958.

172 D. Fulle, H. F. Hamann, H. Hippler and J. Troe, J. Chem. Phys., 1996, 105, 1001-1006.

173 C. L. Lin and M. T. Leu, Int. J. Chem. Kinet., 1982, 14, 417-434.

174 H. Deutsch, K. Becker, M. Probst, W. Zhu and T. D. Märk, Int. J. Mass. Spectrom., 2008, 277, 151-154. 